$$
9 /
$$

MASTER

A MEASUREMENT OF ANISOTROPY IN THE COSMIC BACKGROUND RADIATION ON A LARGE ANGULAR SCALE AT $33 \mathrm{GHz}$

Marc Victor Gorenstein (Ph. D. thesis)

November 1978

Prepared for the U. S. Department of Energy under Contract W-740S-ENG-48

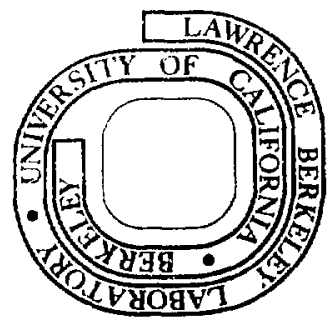




\title{
A Measurement of Anisotropy in the Cosmic Background Radiation on a Large Angular Scale at $33 \mathrm{GHz}$
}

\author{
Marc Victor Gorenstein \\ The Physics Division of the Lawrence Berkeley Laboratory, \\ and the Space Sciences Laboratory of the University of California \\ at Berkeley, Berkeley California, 94720
}

\begin{abstract}
This thesis presents the results of a measurement of anisotropy in the $3 \mathrm{~K}$ cosmic background radiation on a large-angular-scale. Observations were carried out with a dual-antenna microwave radiometer operating at $33 \mathrm{GHz}(0.89 \mathrm{~cm}$ wavelength) flown on board a U-2 aircraft to $20-\mathrm{km}$ altitude. In eleven flights, between December 1976 and May 1978, the radiometer measured differential intensity between pairs of directions distributed over most of the northern celestial hemisphere with an rms sensitivity of $\pm 46 \mathrm{~m} / \sqrt{\mathrm{Hz}}$. The measurements show clear evidence of anisotropy that is readily interpreted as due to the motion of the earth relative to the sources of the radiation; the anisotropy is well fit by a cosine distribution of amplitude $3.61 \pm 0.54$ milli-degrees Kelvin $\left(\mathrm{m}{ }^{\circ} \mathrm{K}\right)$, one part in 800 of $3 \%$, implying a velocity of $361 \pm 54 \mathrm{~km} / \mathrm{sec}$ toward the direction $11.23 \pm 0.46$ hours right ascension, and $19.0 \pm 7.5^{\circ}$ declination. A simultaneous fit to a combined hypothesis of dipole $(\cos \theta)$ and quadrupole $\left(\cos ^{2} \theta\right)$ angular distributions places a $1 \mathrm{~m} \%$ limit on the amplitude of most components of quadrupole anisotropy with $90 \%$ confidence. Additional analysis places a $0.5 \mathrm{~m} \%$ limit on uncorrelated fluctuations (sky-roughness) in the $3 \%$ background on an angular scale of the antenna beam width, about $7^{\circ}$. This thesis describes the equipment development through three engineering flights and the data acquisition in eleven additional flights. The astrophysical results are then presented from the statistical analysis of the reduced data.
\end{abstract}




\section{Table of Contents}

page

Chapter I - The $3^{\circ} \mathrm{K}$ Background Radiation in an Expanding Universe

I.1 Introduction

1.2 Cosmology in the Early 20th Century

I.3 Prediction and Discovery of the $3^{\circ} \mathrm{K}$ Radiation

I.4 The Last Scattering of the $3^{\circ} \mathrm{K}$ Radiation From Matter

1.5 Anisotrepy in the $3^{\circ} \mathrm{K}$ Radiation

on a Large-Angular-Scale

I.6 Previous Measurements of Anisotropy in the $3^{\circ} \mathrm{K}$ Radiation

I.7 Thesis Organization

Chapter II - Experimental Design and Equipment Description

\section{Chapter III - Equipment Development and Data Taking}

III.I Introduction

III.2 Engineering Flights (Flights 1-3)

III.3 The Initial Data Flights (Flights 4-7)

III.4 Fingl Data Flights (Flights 8-14)

III.5 Flight Plan and ` ky Coverage

Chapter IV - Data Reduction

IV.1 Introduction 
IV.2 Editing and Averaging the 33-GHz Anisotropy Data

IV.3 Calibrations and Corrections to the Leg-measurements

IV.3a The Calibration Constant $C$ for the 33-GHz Radiometer

IV.3b The Galactic and Atmospheric Corrections, $\Delta T_{\text {rar }}$

IV.3c The Rotation Offset Carrection, $\Delta \boldsymbol{q}_{r m}$

IV.3d Conversion of Antenna Temperature to

Thermodynamic Temperature, $\frac{d T_{A}}{d T_{P}}$

IV.4 Radiometer Sensitivity

IV.5 Spurious Leg-measurements

IV.6 A nisotropy Data from Flight 4-14

IV.7 Systematic Errors due to Earth-Shine

\section{Chapter V - Astrophysical Analysis}

V.1 Introduction $4 d$

V.2 The Cosine (Dipole) Anisotropy Measured in Flights 8-14

V.3 Measurement of Cosine Anisotropy with Alternute Selections of Data

V.4 Comparison with Other Measurements

V.6 Limit on Sky-roughness on a $7^{\circ}$ Angular Scale

V.7 The Motion of the Sun and Groups of Galaxies Relative to the $3^{\circ} \mathrm{K}$ Background 60 


\section{Appendix E - Radiometer Gain and Calibration}

E.1 Introduction

E.2 Stability of the 33-GHz Radiometer Gain and Noise Temperature

\section{Appendix F - Astrophysical and Atmospheric Corrections to the Leg-measurements}


Appendix H - Fitting Procedures

H.1 Linear Least-squares-fit to $\cos \theta$ Hypothesis 


\section{List of Figures}

Page

I.1 Spectral Measurements of the Cosmic Background Radiation 2

$\begin{array}{ll}\text { II.1 Radiometers in Flight Configuration } & 16\end{array}$

II.2 Radiometers Installed in Upper Hatch of U-2 Aircraft 17

II.3 Schematic Diagram of Radiometer Components 18

III.1 Mean 33-GHz Radiometer-arm-offset, 26 Flight 7 - 14

II1.2 Geographical Flight Plan, Ninth Flight 28

$\begin{array}{ll}\text { III.3 Sky Coverage, Flights 4-14 } & 29\end{array}$

IV.1 Data Processing Flow Chart $\quad 32$

IV.2 Mean Radioneter Signals by Leg, Ninth Flight 35

IV.3 Mean 33-GHz Signal (Rotation Offet), Flights 4-14 38

V.1 Comparison of Data to Cosine Anisotropy, Flights 8-14 49

V.2 Cosine Anisotropy and Galactic Emission at $33 \mathrm{GHz}_{2}$

F.1 Galactic Synchrotron and HII Emission Extrapolated to $33 \mathrm{GHz}$ 


\section{List of Tables}

Page

I. Measurements of Cosine (24 hour) Anisotropy in the $3^{\circ} \mathrm{K}$ Radiation

III.1 Flight Circumstances

III.2 Engineering Flights 
Dipole $(\cos \theta)$ and Quadrupole $\left(\cos ^{2} \theta\right)$

V.7 Limits on Sky Roughness on a $7^{\circ}$ Angular Scale

V.8 The Motion of the Sun with Respect to the $3^{\circ} \mathrm{K}$ Radiation

V.9 Motions of the Sun Relative to Groups of Galaxies 


\section{Chapter I - The $3^{\circ} \mathrm{K}$ Background Radiation in an Expanding Universe}

\section{I.1 Introduction}

The discovery of "excess antenna temperature" from the sky at a frequency of $4.08 \mathrm{GHz}$, $7.4 \mathrm{~cm}$ (Penzias \& Wilson, 1965), and its immediate interpretation as a thermal remnant of an early hot phase of the expanding Universe (Dicke, Peebles, Roll \& Wilkinson, 1965), heralded a new era in the study of cosmology. The existence of this radiation is strong evidence of the finite age and evolutionary character of the Universe, and it provides a unique view of an epoch that presumably predates the formation of galaxies. Considerable experimental work, stimulated by the 1965 discovery, has yiclded spectral measurements that largely confirm the initial conjecture of a thermal (Planckian) radjation spectrum. Figure [.1* shows the results of measurements from wavelengths of $7 \mathrm{~cm} 100.1 \mathrm{~mm}$ and the comparison with a blackbody spectrum of 2.9 Kelvin. The discovery of the radiation has also had considcrable theorelical impact. if has focused the attention of most cosmologists on devcloping and extending the model of the hot big bang, which thus far is the only satisfactory account of this weak, ipparently thermal, background radiation.

The angular properties of the radiation - its high degrec ol isotropy - identifics it ats having cosmological origins. Isotropy, the lack of variation in intensity (1emperature) between different directions in the sky, provides a critical test of the Cosmological Principle, the conjecture that, in the large, matter and energy are distributed homogencously in space and isolropically in direction. A search for anisotropy is the most sensitive prohe of deviations from what appears to be a highly summetric Universe. Anisotropy can arise in two ways, through cosmological deviations from isotropy or from the local motion of the earth relative to the sources of $3 \%$ background. In the first case, the distribution of the sources that last scaltered the radiation or the space-time through which the radiation traversed may be anisotropic. The investigation of this "intrinsic" anisolropy tests the Cosmological Principle, and deviations from isotropy in the cosmic background can provide important information about the detailed nature of the carly

"ihroughoul this thesis we will refer to the radiation as the $3 \%$ background, and generally employ the value

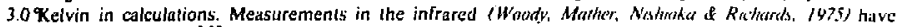
found a value of $2.99+8.07 \%$. Since this spectral measurement in the infrured enconipasses the greatcr fraktion of the energy in the $3 \mathrm{~K}$ peak we will adopt this value However it . the thermal nature of ihe radiation ralher than its precise Iemperalure that is most relevant. 
FIgure I.1 - Spectral Measurements of the Cosmlc Background Radlation (Woody, Mather, Nishioka \& Richaris, 1975)

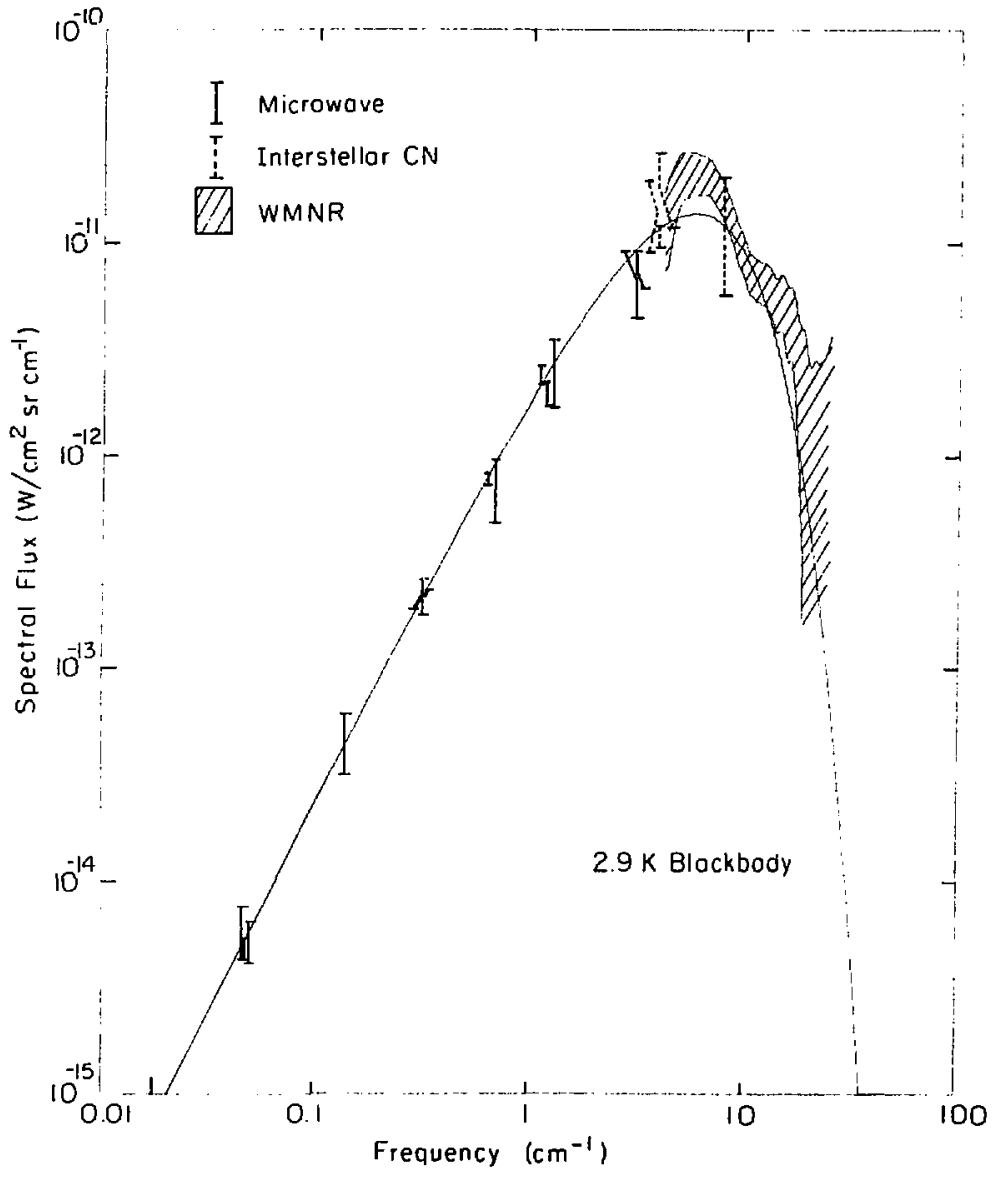


Universe. In 'he second case, in an otherwise isotropic Universe, an observer moving relative to the distant sources of the radiation would see a modulation of its temperature with direction. This latter effect has the form of a first order Doppler shift in the radiation temperature (Peeoles Wilkinson, 1968), which is, for low velocities $(\beta<<1)$,

$$
T(\theta)=T_{0}(1+\beta \cos \theta)
$$

where

$\boldsymbol{\beta}$ is the velocity divided by the velocity of light.

$T_{0}$ is the radiation temperature, $3 \%$.

$\theta$ is the angle to the observer's motion.

P.J.E. Peebles has called this cosmological motion of the earth relative to the sources of the $3 \mathrm{~K}$ radiation the new Aether Drift (Pecbles, 1971).

The first sensitive search for anisotropy on a large-angular-scale was performed by Partridge and Wilkinson (Partridge \& Wilkinson, 1967). They placed limits on anisotropy at 3 millidegrees Kelvin $(\mathrm{m} \mathrm{K})$, or one part in 1000 of $3 \mathrm{~K}$ along the celestial equator. This linit on anisotropy raised a theoretical question and an experimental challenge. First, is this high degree of isotropy an inevitable consequence of an evolving expanding Universe (do the Einstein equations predict isatropy?) or, is isotropy the consequence of a special initial conditinn? The answer may be intimately linked with other important theoretical questions in cosmology. Processes that insure the large-scale isotropy of the radiation must at the same time allow inhomogeneities on a small scale from which galaxies can coalesce. Moreover, lice damping processes that isotropise the matter in the early Universe could also generate most or all of the energy in the thermal background radiation, and thereby account for its present temperaiure.

Current ideas cover a spectrum of isctropising mechanisms and philosophical ideas regarding the nature and significance of isotropy. (See for example Misner, 1468, 1969; Rees 1472:; Collins \& Hawking, 1973b; Barrow, 1977, 1978; and references therein.) To pick just iwo examples, strong particle interactions in the first hundred microseconds after the singularity (Barrow: 1978) and dissipative shocks in the first million years (Rees, 1972) have both been proposed as fundamental mechanisms for isolropising the radiation.

Partridge and Wilkinson's lirnit also posed a new experimental question. Their linı ; comparable to the anisotropy that is expected from the motion of the sun about the Milky $W_{\text {ay }}$ Galaxy. It is known that the sun orbits the Milky Way Galaxy at a speed of about $250 \mathrm{~km} / \mathrm{sec}$. or $\beta-10^{-3}$. Thus according to eq. 1.1 , this motion alone should yield a cosine anisotropy of amplitude about $3 \mathrm{~m}$ K. Their limit showed that the radiation is sufficiently isotropic that the detection of the molion of the earth relative to the sources of the radiation would be possible 
with only a modest increase in sensitivity.

This thesis describes the results of measurements that continue the investigation of bargeangular-scale anisotropy in the $3 \mathrm{~K}$ radiation. In eleven flights, an airborne radiomeler operating at $33.0 \mathrm{GHz}(0.89 \mathrm{~cm}$ wavelenglh) collected data that gives significant evidence of anisotropy in the $3 \%$ background at one part in 800 of $3 \%$. The detailed statistical study of the dati shows (1) it is well fit by a cosine anisotropv of amplitude $3.61 \pm 0.54 \mathrm{~m}$ K and thus is readily interpreted as due to the molion of the sun relative to the sources of the $3{ }^{\circ} \mathrm{K}$ backgtounci radiation at $361 \pm 54 \mathrm{~km} / \mathrm{sec}$ toward $11.2 \pm 0.5$ hours right ascension (R.A.) and $19 \pm 8^{\circ}$ declination (Jec.), and (2) that other than this $3.6 \mathrm{~m} \%$ anisotropy there is no other angular distrabution of cosmological significance at one part in 3000 of $3 \%$, or $1.0 \mathrm{~m} \mathrm{~K}$, at the $90 \%$ confidence level. Surprisingly, the motion of the Sun about the Milky Way does not account for the cosine anisotropy. The implication is that the net motion of the Milky Way relative to the $3 \mathrm{~K}$ background is large, over $500 \mathrm{~km} / \mathrm{sec}$. The results from the first eight data flights have been published (Simout, Giorenstrin \& Muller, 1977), and the puper is reproduced as Appendix A. Prelininary results of the detection of cosine anisotropy were announced in 1977 (Smom, 1977a,b; Gorrolstem, Simot \& Mulkr, 1977). Appendix B reproduces a previous publication describing the equipment and its design in detail (Gorensten, Muller, Smoot \& Tyson, 1978).

This ehapter continues with a brief account of the important experimental ohservations and theoretical ideas that form the basis of the modern view of the early Universe. The cmphasis is on the model of the hot hig bang and the manner in which it accounts for the existence and thermal nature of the $3 \mathrm{~K}$ background. Specutation about the nature of anisotropy thal might be observable today is discussed, and a summary of previous linils and nicasurements of anisotropy on a large-angular-scale is presented. The chapter concludes with the organization of the material presented in the thesis.

A history of the development of cosmology in the early 20 th century is presented in North. 1965. Current idcas in cosmology, emphasizing the "standard" models of the cvolutionary hot hig bang can be found in Porbles, 1971: Mismer, Thorme \& Whecler, 1973; and Wemberg. 1972. Partrike, 1969 presents a review of the experimental status of the sjectrum and isotrony measurcmients of the $3 \%$ background, and contains references Jescribing alternate explanations of the origins of the radiation. For a non-technical discussion of the discovery of the $3 \mathrm{~K}$ bickground radiation see Peebles of Wilkinson, 1967. Muller, 1978 describes the Aether Drifi in the context of big bang cosmology, and includes a description of the measurement that is the subject of this thesis. Weimberg, 1977 contains a popular account of the modern picture of Cosmology 


\subsection{Cosmology in the Early 20th Century}

The gravitational properties of matter and energy determine the large-scule behavio: of the Universe. In the early 1920's the Russian mathematician Alexander Friedmann was the first to find the correct cosmological soivtions to Einstein's field equations of general relativity without the Cosmological term $(\Lambda=0)$. He assumed that matter in the Universe is distributed homogeneously in space and isotropically in direction. Isotropy and homogeneity, the Cosmological Principle, was assumed by Einstein, Friedmann and others in theoretical investigations before the existence of galaxies external to our own had been established. Friedmann's solutions were dynamic: he found that the Universe is either in a state of expansion or contraction.

In this same decade galaxies became the survey markers that mapped the geometry of the Universe. In the arly 1920 's, V.M. Slipher measured red shifis of "nebulosities" and found them to be large. In 1924 Edwin P. Hubble, measuring the brightness of Cepheid variable stars in "spiral nebulac", showed that spiral nebulae are external to the Milky Way, at distances of milliois of light-years, and were in fact galaxies similar to our own. Extensive observations of galaxies, their distribution, spectra, and lunjinosity, culminated in Hubble's announcement in 1929 that galaxics recede at velocitics proportional to their distance. Recessional velocities were determined by the observed red sbifts of spectral lines in galactic spectra, and distances were measured from estimates of intrinsic galactic luminosities. Averaged over sufficiently large volumes, the distribution of galaxics in space did seem to conform to the conjectured Cosmological Principle.

The relationship between distance and velocity is known as Huhble's Law, and is linear in the limit of non-relalivistic recessional velocities:

$$
v=H_{n} d
$$

where

$H_{*}$ is Hubble's constant. A current value is $55 \pm 7 \mathrm{~km} / \mathrm{sec} / \mathrm{Meg}$ aparsec, or $\left(17.7 \pm 2 \times 10^{4}\right)^{-1}$ years ${ }^{-1}$ (Sanlage. 1972). A Parsec is 3.26 light-years, and a light-year is $9.46 \times 10^{17} \mathrm{~cm}$.

$v$ is the recessional velocily of the galaxy.

$d$ is the distance to the galaxy.

The immediale interpretation of Hubble's law is that the Universe is expanding, in accord with the theoretical models. A linear extrapolation using this present expansion rate shows that the Universe would have started expanding from a highly compressed state about $1,8 \times 10^{10}$ years ago, a time given approximately by the inverse of the Hubble Constant. In Fricdmann's 
relativistic cosmology the Universe does have a finite age and has in fact expanded 10 the present epoch from a state of infinite density. This infinity, or singularity, is unphysical and precludes knowledge about the Universe before the inilial event. But Friedmann's calculation assumed a highly symmetric, idealized Universe, and perhaps in our real Universe, with its inhomogeneities, this peculiar singular state was never realized. However, Stephen Hawking and others (Hawking \& Penrose, 1969: Hawking \& Ellis, 1973) have shown that if Einstein's equations are valid then the Universe had to pass through a singularity in density at one time or another even if the Universe does nol conform to perfect isotropy.

The desire to avoid the initial singularity has motivated others to search for alternate casmologies without the unsettling infinities of the Friedmann solution. Most notabje has been the Steady State theory, first advanced by Herman Bondi, Thomas Gold, and Fred Hoyle in 1948. Here the Universe has an indeterminate age: maller is created spontaneously, filling the gaps as the galaxies move apart, so an observer cannot distinguish between epochs. Althcugh this model extends the spirit of the Cosmological Principle, by making the Universe homogeneuus in time as well as in space, the observations have not borne out the conjecture. Radio source cuunts indicate a higher density of radio galaxies in the distam regions of space than nearby, demonstrating an cvolution that goes against the basic idea of the steady state. And the existence of the thermal background has proved difficult to account for in a steady-state Universe.

Before reviewing the more recent work in cosmology, we mention two nieasures of time in an expanding Universe that will be useful in the discussion. The first is simply the time elapsed since the singularity as measured by a co-moving observer. By definition a co-moving observer is in a reference frame where the matter in the Universe appears to expand isotropically. The second measure is the red shift parameter $z$. The red shift parameter is defined by the ratio of the wavelength of radiation received by a local observer, $\lambda_{0}$, to the original wavclength emitted by a distant source, $\lambda_{r}$.

$$
1+z=\frac{\lambda_{11}}{\lambda_{c}}
$$

In the expanding Universe the quantily $(1+z)$ is the ratio of the scale size of the Universe dt present to the scale size of the Universe when the radiation was emitted, and is a convenient measure of "time" relative to our present epech. For sources whose recessional velocity is small compared to the speed of light, the relation between velocity and red shift parameter is linear:

$$
\beta=z
$$

where $\beta$ is the recessional velocity expressed as wis fractional velocity of light. 


\section{I.3 Frediction and Discovery of the $3^{\circ} \mathrm{K}$ Radiation}

Astrophysies is concerned with the contents of the Universe. The present evidence suggests that, on a nuclear level, mosi of the matter comes as individual protons - hydrogen nuclei. A lesser amount, perhaps $25 \%$ by weight, is in the form of alpha particles - helium nuclei. Heavier nuclei, electrons, and radiation in various forms, make up the the remaining few percent. The significant abundance of helium se:ms intimately connected with the existence of a primordial background radiation, and played an important role in the preaiction of the thermal background.

The idea that the early Universe would contain a radialion background was first proposed by Georges Lemaitre in the early 1920 's. Tolman (Tolmon. 19.34) Jirst derived the behavior of radiation in an expanding Universe. In the darly 1940's (ieorge Gan:ow tried accounting for the cosmic abundance of the elements by nuclear reactions occuring within minutes after the singularity (Alpher, Berhe \& Gamow; 1448). Gamow postulated an intense radiation background that would modulate nucleosynthesis through the mechanism of pholo dissociation. For (jamows scheme to work, the energy density of the radiation would dominate the matter energy densily, and ti:us deternine the initial axpansion rate of the Universe. In this mantoer the singularity, or the big bang as Gamow called it, becance "hot". Calculations show this wishin the first three minutes after the singularity neutrons and proton.; would combine forming deuterium, and then further synthesis would result in a mass fraction of helium of about $25 \%$, comparable to what is observed today (e.g. Peobles, 1966; Wagoner, Fowker of Hoble. 1967). The production of helium fixes the radialion background temperature near $10^{10} \mathrm{~K}$ at this epoch. Ralph Alpher and Robert Herman, working with Gamow, computed that the radiation, cooling as the Universe expanded. would now have of temperature of $5 \%$ (Alpher \& Herman, $1 \% 50)$.

The discovery of an isotropic, unpolarized, thermal background radiation watied 25 years. In 1964 Robert Dicke independently arrived at the idea of a hol big bang (Peehle's of W'akmson. 1967). He conceived of the Universe ats having oscillated through many cycles of expansion and collapse. In an oscillating Universe stellar nuciecosynlhesis would act te build up heavy nuclei in each cycle, resulting in an over-abundance of heavy nucici unless there were a mechanism that would also destroy the nuclei in each cycle. A weak thermal background radiation, compressed to high temperature as the Universe contracted, would destroy nuclei as the Universe collapsed toward the singular statc. While Dicke and his colleagues at Princeton were developing these ideas and preparing apparatus that would detect a weak background radiation, they were contacted by Arno Penzias of Bell Laboratorics in New Jersey. Arno Penzias and Robert Wilson of Bell Labcratories had spent over a year convincing themseives that an unidentified source of radio static, detected with a receiver at Holmdel New Jersey designed for satcllite communications, had $2 n$ astrophysical origin. The signal's antenna temperature was 
between 2.5 and $4.5 \mathrm{~K}$ at $7.4 \mathrm{~cm}$ wavelength, and was isotropic and unpolarized within the limits of their survey. Bernard Burke of the Massachusetts Institute of Technology knew of Penzias and Wilson's result, and had also heard of the theoretical ideas being developed at Princeton from a talk by P. J. E. Peebles. Burke suggested to Penzias that he contact the group at Princeton. The resuit of this cummunication between the two groups led to back-to-back letters in the Astrophysical Journal (Penzias \& Wilson, 1965; Dicke, Peebles, Roll \& Wilkinson, 1965) announcing the result and providing its interpretation. A consensus quickly formed among most cosmologisls that the background radiation was very likely the thermal remnant radiation from a primordial fireball.

\subsection{The Iast Scattering of the $3^{\circ} \mathrm{K}$ Radiation From Matter}

In the carly Universe the energy densily of the thermal background radiation insured that matter rentained in a highly ionized state. Due to the large scattering cross section of free elecIrons, the mean fres path of the photons was short compared to the scale size of the Universe.

As the Universe expanded the energy densily of the radiation fell as the inverse of the fourth power of the stale size of the Universe (the mean distance belween galaxies for exam. ple), while the cnergy density of matter fell as the inverse third power of the scale size. Thus

$$
\begin{gathered}
\rho_{1} \propto \frac{1}{(1+z)^{4}} \\
\rho_{m} \propto \frac{1}{(1+z)^{3}}
\end{gathered}
$$

where

$n$ is the radiation energy density.

$f_{m}$, is the maller energy densily.

Three powers of $(1+z)$ account for the decreasing number densily of both photons and massive parlicles as the Universe expands. The extra power of $(1+z)$ in eq. 1.5 is due to the additional red shift that the radiation suffers as a result of the expansion. Thus the radiation energy density ultimatcly drops below the energy density of the matler.

It is a peculia coincidence that the Universe became malter-dominated $\left(\rho_{m}>p_{1}\right)$ al about the same epoch when the radiation last had significant interactions with the maller. The "decoupling" occured when the radiation temperature had dropmed enough so electrons and protons could combine forming neutral hydrogen at a raciation temperature of about $4500 \mathrm{~K}$. The photon cross section for scattering from neutral hydrogen is so low that after the decoupting the mean free path for stitterıng became comparabie to the Hubble distance, and the the Universe became transparent to the propagation of photons. 
It is interesting that the spectrum remained Planckjan, even in the absence of thermalizing interactions. This is a geometric effect, in part due to the masslessness of the photons; thus (Peebles, 1971, pg. 12J)

$$
T_{:}=(1+z) T_{o}
$$

So the epoch of decoupling occured at a red shifi of

$$
z=\frac{4500 \mathrm{~K}}{3 \mathrm{~K}^{\circ}}-1=1500
$$

Since the era of decoupling the radiation has evolved independently of the matter and thus provides a direct view of the primordial plasma.

It should be remembered, however, that this is the generally ac "ed view mostly because it has withstood successfut challenge. Alternate explanations usually $; \cdot$.ve the radiation last interact with matter more recently than the decoupling at $z=1500$. How:ver, models at odds with the standard picture invariably have the radiation still arriving from distances comparable to the Hubble radius. Thes even with a more recent urigin, it is unlikely that the cosmological significance of the $3 \%$ background or its angular properties would be much diminished. The $3 \%$ background radjation would still be a powerful probe of the distant matter and energy in the Universe, and the cosine anisotropy would still be a measure of velocity relative to a global reference frame.

\section{I.5 Anisotropy in the $3^{\circ} \mathrm{K}$ Background Radiation}

In the standard Friedmann model a co-moving observer sees an isotropic therntal background radiation. In the real Universe anisotropy in the thermal back zround can arise in two conceptually distinct ways. First, in an otherwise isotropic casmology, an observer's motion at velocity $\beta$ relative to the co-moving frame gives rise to anisotropy of the form $\left(P_{e}\right.$ erbles \& Witkinson, 1968):

$$
T(\theta)=\frac{T_{0}}{\gamma} \frac{1}{1-\beta \cos \theta}
$$

where $\gamma$ is the usual Lorentz factor $\left(1-\beta^{2}\right)^{-1 / 2}$. Thus the spectrum remains thermal but the value of the temperature varies across the sky. In the limit of low velocity, $\beta \ll 1$, this equation reduces to eq. I.1,

$$
T(\theta)=T_{0}(1+\beta \cos \theta)
$$




$$
T(\hat{n})=T_{o}+\vec{T} \cdot \hat{n}
$$

where

$|\vec{T}|=T_{0} \beta, \vec{T}$ points lowards the direction of motion.

$\hat{n}$ is a unit vector pointing in the direction of observation.

The motion of the soiar system about the Galaxy is known to be about $250 \mathrm{~km} / \mathrm{sec}$, and should contribute an anisotropy of about $3 \mathrm{~m} \mathrm{~K}$ to a potential $\cos (\theta)$ anisotropy. Measuring $\vec{T}$ identifies the local frame of rest relative to the distant matter in the Uiniverse.

Anisolropy can also be "intrinsic". Inhomogeneities in the distribution of matter or energy in the early Universe, or anisotropy in the space-time through which the radiation has passed may give rise to measurable effects. Current theoretical ideas leave much room for speculation on possible anisotropy on large-angular-scales, and, in fact, the high degree of isorropy is a source of speculation and debate. Do the Einstein equations predict isotropy? A simple causalIty argument would secm to permit large anisolropy over angular separations of more than a lew degrees. At any epoch since the big bang, an observer receives, holons from distances limited by light travel time since the singularity, defining an event herizon beyond which no cuusal interaction can take place. At the time of the decoupling the event horizon was about one million light years, and this was the largest distance over which isotropising processes could have itcled. But that volume now appears as a circle of only a few degrees in angular size (Weinberg. $1972,(15.525)$ yet the radiation is isotropic to better than one part in 1000 on all angular scales.

Misner has investigated homogeneous modis" that have arbitrarily large initial anisotropies. The idea is that isotropy is a consequence of physical law if it can be shown that all inilially anisotropic models evolve towards isotropy, so the present state of the Universe is insensitive to the initial conditions of its formation. Misner proposed that neutrino interactions occuring within the firsl second after the singularity would isotropise the matter. However, this anproilch hais been challenged (Barrow \& Maszner, 1977, and references in Collins \& Hawkimg. $\langle y\rangle .(b)$ at being incompatible with the finite specific entropy of the Universe. The specific untropy can be expressed as the ratio of the number density of photons in the thermal buckground radiation to the number density of baryons. This ratio has been constant since a feu minutes after the singularity, and is approximately $10^{8}$ pholons per baryon.

Ress and Barrow (Rees, 1972; Barrow, 1977) have pursued Misner's approach along more modest lines. Rees has postulated a 'chaotic' cosmology where shock waves isotropise large inilial inhomogeneities in the matter distribution before the epoch of decoupling. This process 
heats the matter and thereby generates the thermal background radiation. Rees claims that his approach accounts for the approximate equality of the energy density of the radiation field with the matter field at the time of the decoupling.

Is isotropy a consequence of a special initial condition? The nution that isotropy can be explained as a consequence of physical law is challenged by Collins and Hawking (Collins \& Hawking, 1973b) who claim to bave demonstrated the extreme improbabilty of a Universe evolving 10 an isotropic state given the assumption that the Universe could have been created in a wide variety of initial honogeneous but anisotropic states. They account for the present, approximately isotropic, condition as the special situation that allows for the evolution of inteligent life. They claim that gutisies can form only in a Universe that is expanding close to the rate that prevents eventual re-collapse. And it is just this kinematic state that asymptolically approaches isolropy. A Universe with slow initiat expansion will collapse beforc galaxies can coaltsce from the perturbations in the matter. Thus if the liniverse has oscillater through many cycles, it eventually hits one that expands sufficienlly fast approaching isolropy and producing galaxies. In their view our own existence is a consequence of this observed isolropy. Barrow (Barrow, 1978) has questioned the assumption that all initial states of the Universe nccur with equal probability. If a sufficiently stiff equation of state held when matter was at nuclear densities, within $10^{-4}$ seconds after the singularity, then he claims that isotropy was the slable and preferred initial condition. There is much debate on which are the important physicul processes operating in the early Universe. The range of ideas presented here is inlended as illusiratuve of the unsettled nature of present understanding of intrinsic isotropy of the $3 \%$ background.

Global anisotropy in the large-scale space-time structure of the Universe might give rise to anisutropy with sinte angular properties. Collins and Hawking and athers have speculated that matter in the Universe could be rolating with respect to local inertia! frames (Collons \& Hawkmg. 1973a: Hawking 1969a,b; K. Godel 1949,1950: Bataks \& (ohun. 1075). In general this gives rise to a quadrupole $\left(\cos ^{2} \theta\right)$ anisotropy. The limil on the amplieude of guadrupele radialion is the most sensitive test of the rate of universal rotation (Iawkmk, / $169 b)$. An ohservable rotation would violate Mach's principle, the conjecture that the local properties of inertial are determined from the global matter distribution. Limits on quadrupole amplitudes of about $1 \mathrm{~m}{ }^{\circ} \mathrm{K}$ place a limit on the present rolation rite between $10^{14}$ and $10^{17}$ radians per yalr depending on the mass density of the Universe. Thus continued investigation of anisotropy on at large-angular-scale can detect the local co-moving frame and provide a test of the Cosmological Principle by investigating the distribution of nutter and energy in the carly lniverse and the space-time through which the radiation has since triveled 


\section{I.6 Previous Mensurements of Anisotropy in the $3^{\circ} \mathrm{K}$ Radiation on a Large-Angular-Scale}

In their 1965 discovery paper, Penzias and Wilson began by noting that their astrophysical signal was "isotropic, unpolarized, and free from seasonal variations". With their tolal power receiver they deternined the temperalure of the radiation to be within $\pm 30 \%$ of $3.5 \%$ from the different parts of the sky they surveyed. The isotropy identified the radiation as a candidatc for the thermal remnant from the primordial fireball. Partridge and Wilkinson's 1967 resulı was an improvement of over two orders of magnitude from Penzias and Wilson's initial limit. One motivation for further experimental work is that a modest increase in sensitivity should reveal cosine anisoliopy due to the motion of the earth relative to the radiation background.

A decade has passed since the initial measurements were perforned, and the results, listed in Table 1.1, show that success has not been easy. The experiments have been of similar design: a Dicke-type radiometer measures the difference signal between two horn antennas pointing at widely separated directions in the sky. Various switching arrangements cancel intrinsic asymmetry in the equipment. Long integration times reduce statistical uncertainty, and moasurements repeated throughoui the year map the sky.

\begin{tabular}{|c|c|c|c|c|c|c|}
\hline \multicolumn{7}{|c|}{ Measurements of Cosine ( 24 hour) Anisotropy in the $3^{\circ} \mathrm{K}$ Background } \\
\hline Reference & Platform & $\begin{array}{c}\text { Altitude } \\
(\mathrm{km})\end{array}$ & $\begin{array}{c}\nu \\
(\mathrm{GHz})\end{array}$ & $\begin{array}{c}A \\
(\mathrm{cn})\end{array}$ & $\begin{array}{c}\text { Amplitude } \\
\text { (m K) }\end{array}$ & $\begin{array}{c}\text { Directional } \\
\text { error }\end{array}$ \\
\hline Purtridge \& Wilkinson(1967) & ground & 0 & 9.4 & 3.2 & $0.9 \pm 2.1$ & - \\
\hline Conklin $(1909)$ & mounlain & 3.8 & 8.0 & 3.8 & $1.6 \pm 0.75$ & - \\
\hline Boughn e. al. (197J) & ground & 0 & 35.0 & 0.86 & $7.5 \pm 11.6$ & $\cdot$ \\
\hline Homv $(1971)$ & bailoon & 24 & 10.2 & 2.9 & $3.2 \pm 0.8$ & $\pm 35^{\circ}$ \\
\hline Muehher \& We'ss $(1976)$ & balioon & 25 & 100 & 0.3 & $<3.5$ & - \\
\hline $\operatorname{corev}{ }^{*}(/ 978)$ & balioon & 25 & 19 & 1.6 & $2.9 \pm 0.7$ & $\pm 22^{\circ}$ \\
\hline Thss n'ork & $U-2$ & 20 & 33.0 & 0.91 & $3.61 \pm 0.54$ & $\pm 8^{\circ}$ \\
\hline
\end{tabular}

*See Corry \& Wrkinsom. 1976 for preliminary announcement of this result.

The measurements, however, have similar limitations. A tiny signal is being sought in the presence of large terrestrial, atmospheric, and galactic backgrounds. Almospheric a, $;: n$ and water vapor emission limits ground based measurements and impacts the design of all 
experiments performed in the atmosphere. Galactic synchrotron radiation is a spurious signal that fills the celestial sphere, and is particularly bothersome at frequencies below $30 \mathrm{GHz}$. Muehlner and Weiss used bolometric rather than microwave techniques 10 observe at high frequencies and encountered a new class of galactic inf rared emitters.

It was the detailed choice of experinerial design and implementation that atlowed the significant improvement in sensitivity in the work reported here. The strength of this experiment comes from the choice of observation frequency and the use of the airborne platform provided by the U-2 aircraft. At the obseryation frequency of $33 \mathrm{GHz}$ corrections to galactic background radiation is less than $0.2 \mathrm{~m}$ K for most parts of the sky. The U-2 aircraft provided a stable and quiet platform that carried the equipment above most of the interfering atmospherc. and, through its availability, provided the best sky coverage and expesure time from the dala of eleven fights.

The initial threc measurements listed in Table I.I, together with the measurement by Muehlner and Weiss, yielded limits on cosine anisotropy in the $3 \mathrm{~K}$ background. Conklin and Henry found the first clear evidence of anisotropy in the $3 \mathrm{~K}$ radialion, but their meisurements were limited by galaclic backgrounds and they could nut determine the angular propertics of the anisotropy. (Conklin claimed that his measurement of a non-zero amplitude of cosine anisotropy was significant, but he underestimaled the errors on a large galactic background correction to his data.) The measurement of Corey and Wilkinson is an improved version of Henry"s measurement. The work reported here produced the firsl clear evidence for cosine anisotrnpy (Simoot, Goremstein de Muller, 1977).

\section{I.7 Thesis Organization}

The thesis continues with a brief introduclion to the radiometer used in the meatsurements. Chapter II describes the components of the radiometer and their function, with altention to the design features that reduce or cancel systematic backgrounds. The emphasis in this thesis is on those aspects of the experiment which have not been previously mublished, for example, the detialed description of the radiometer design and equipment performance is left to

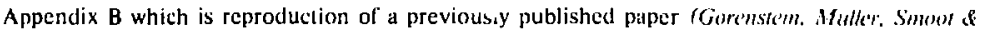
Tys(on, 1978).

The equipment development and data taking proceeded through a sequence of 14 flights. Chapler III describes the initial difficulties encountered with the equipment, their resolution. and the data taking nights. The data analysis of this experiment is, in principle, straightforward. The equipment records measurements of anisotropy once every two seconds. Sinte we are really interested in the average of many thousands of measurements. we resort to computerized techniques that sort, display, and average the data. Chapter IV sescribes the data reduction, 
instrument calibration, checks for systematic effects and spurious mieasurements, and finally presents the list of corrected measurements and the directions in the sky they cover.

Over one hundred reduced measurements of anisolropy were obtained in eleven data flights. Chapter $V$ presents the astrophysical results from ine statistical analysis of the reduecd data. In addition 10 the fit for cosine anisotropy, the sky coverage is sufficiently good that a preliminary limil on quadrupole anisolropy is obtained, together with a limil for "skyroughness" on an angular scale of the antenna beam width, $7^{\circ}$. Most of the detailcd descriptions of equipment performance, llight preparation, radiometer calitration, systematic corrections, and statistical analysis techniques are left for Appendices $\mathrm{C}$ through $\mathrm{H}$. 


\section{Chaptcr II - Experimenial Design and Equipment Description}

A differential microwave radiometer flown on board a U-2 airchait to $20-\mathrm{km}(65,000$ reet) altitude detected the anisotropy in the $3 \mathrm{~K}$ radiation reported in this thesis, Figures II.1 and II.2. The radiometer measures the difference in intensity of microwave radiation collected by two horn antennas pointed $60^{\circ}$ apart in the sky. It operates at $33 \mathrm{GHz}(0.89 \mathrm{~cm}$ wavelength) and features low-noise performance ( $r m s$ sensitivity for differential intensity of $\pm 46 \mathrm{~m} \mathrm{~K} / \sqrt{\mathrm{Hz}}$ ) at room temperature. The $33-\mathrm{GHz}$ operating frequency and the $20-\mathrm{km}$ observation altitude minimize the sum of atmospheric and galactic backgrounds. Additional subsystems include a second radiometer at $54 \mathrm{GHz}$ that monitors anisotropic atmospheric emission, a rotation system that interchanges the horn ante. inas every 64 seconds, canceling instrumental imbalance, and a thermal monitor and control system that insures stable receiver operation.

The equipment is mounted in the U-2 aircraft just aft of the pilot's canopy and forward of the wings, Fig. Il. I. The smaller 54-GHz radiometer is mounted between the two larger horn antennas of the 33-GHz radiometer. Figure II.? shows the equipment with the windshield and RF shields removed, exposing the radiometers and support electronics packages.

The components making up the two radiometers are functionally identical. Figure II. 3 is it schematic drawi.ug of the radiometer design. A ferrite (Dicke) switch, alternating at $100 \mathrm{~Hz}$ between the two antennas, directs the incuining microwave radiation into the low nolse recisiver. A $100-\mathrm{Hz}$ narrow-band amplifier first fillers the detected signal from the receiver The demodulator :iran analyses the signal for a component in phase with the alternation of the ferrite switch. The Datel logger records this signal after 2 seconds of averaging. In flights 8-14, the receiver was a balanced-mixer integrated with an IF amplification stage. The $180^{\circ}$ phase-swilch monitors the offset between the two input arms of the radiometer as described in Section C. 3.

Appendix B reproduces a previously published article (Corenstein, Muller. Smoot \& Tysim. 1978) that discusses the important backgrounds that decisively influenced both the design of the radiometers and the choice of the supporting subsystems, and des . is in detail the major components of th. system. The introduction of this article describes the equipment and its features. The article continues by describing the astrophysical, terrestrial, and instrumental backgrounds that potentially dominate the minute signal we wish to detect. The balance of the article contains a detailed description of the equipment flown in the U-2, focusing on the techniques that reduce or cancel microwave emission from the galaxy, the atmosphere, and the 

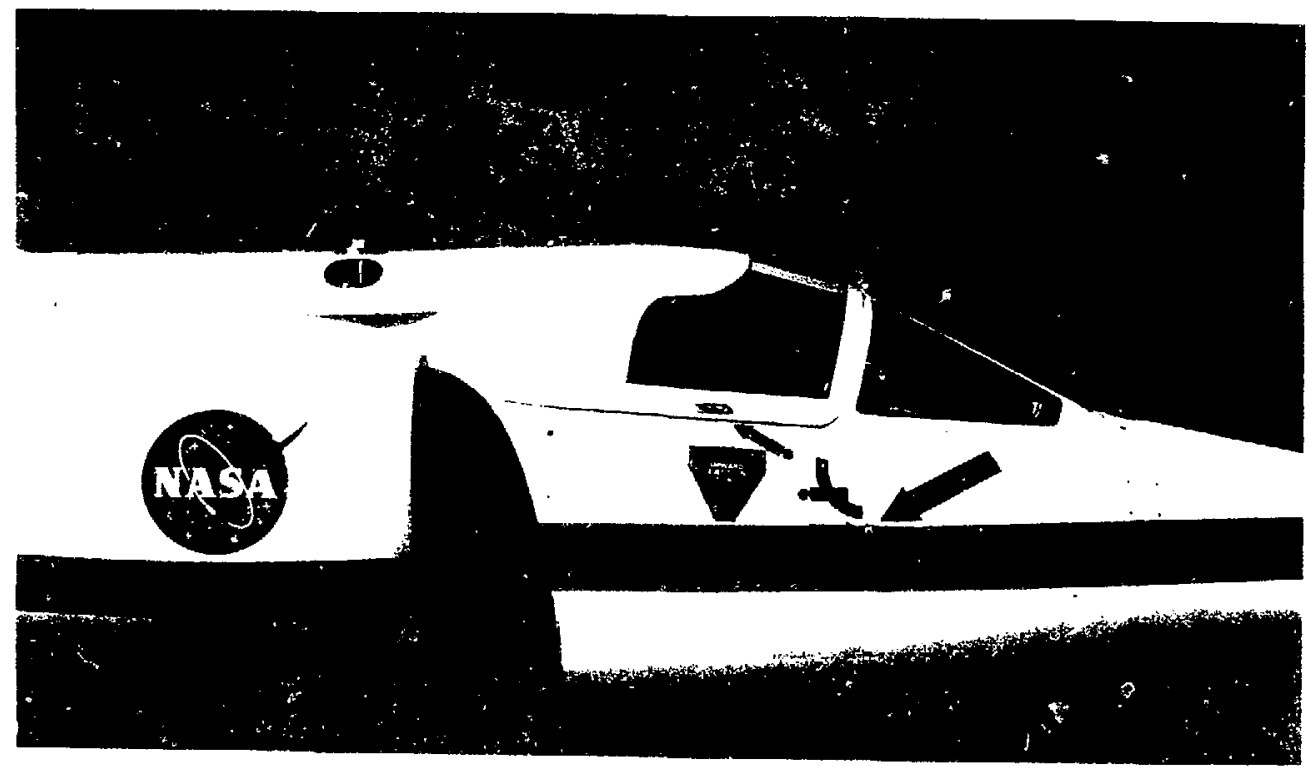

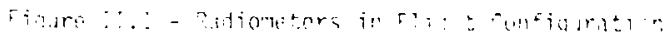




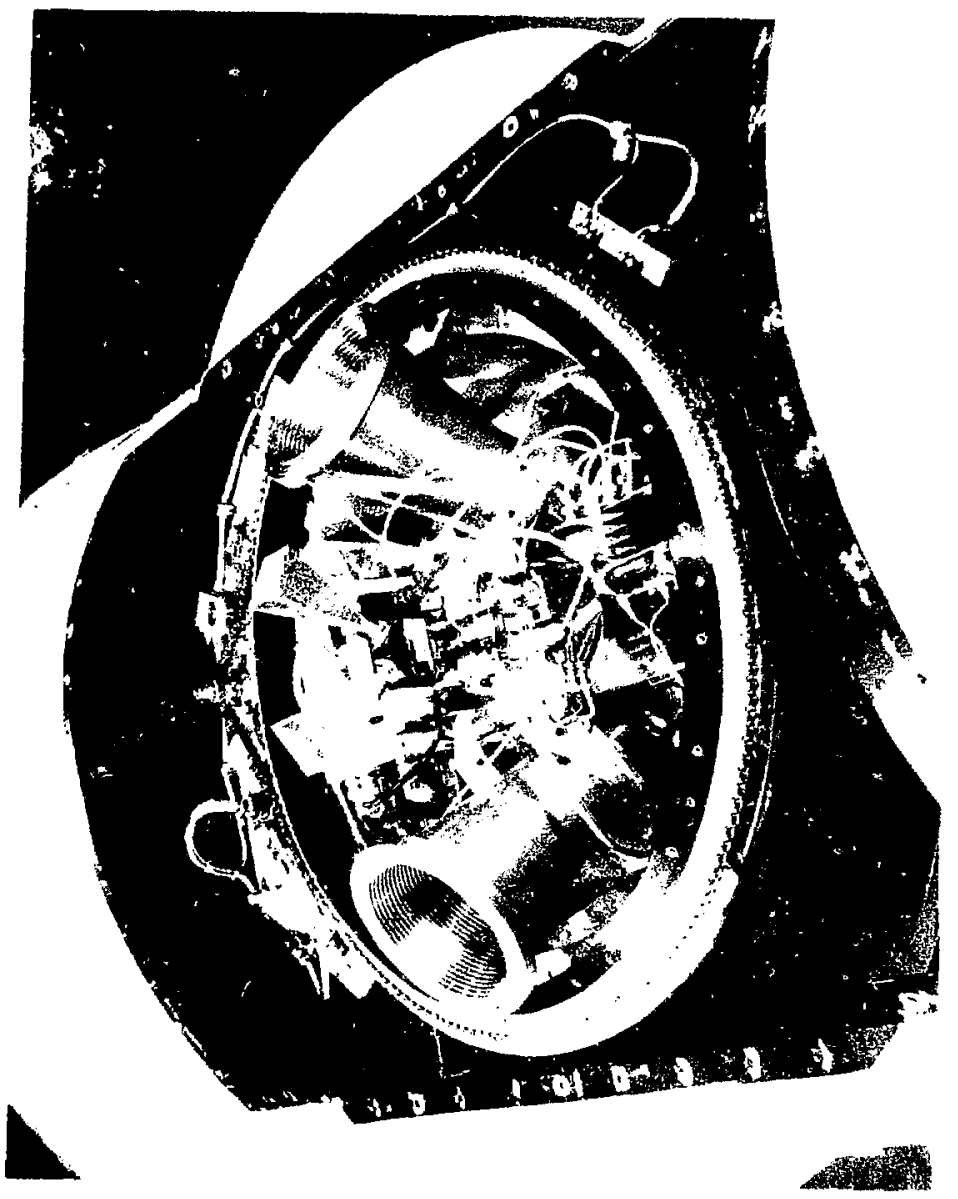




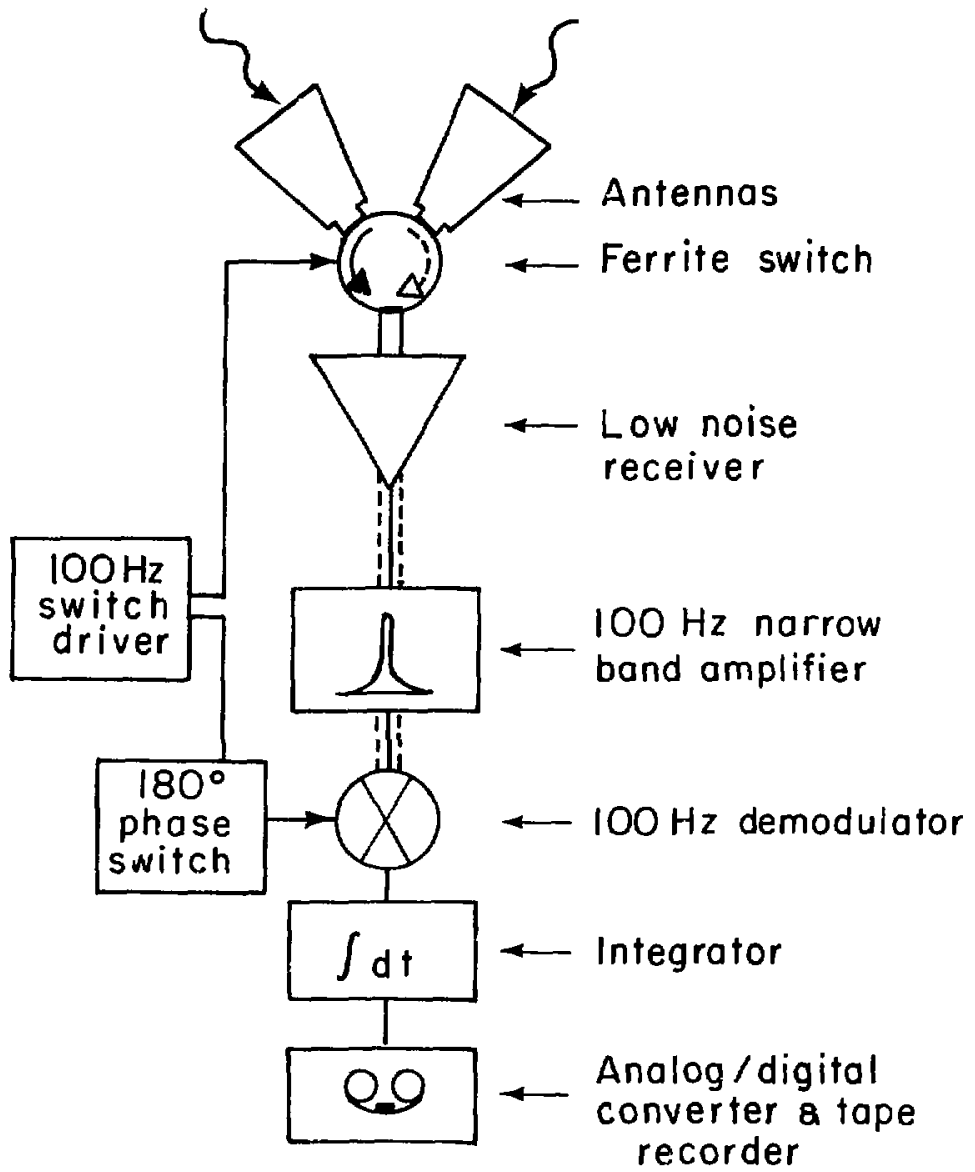

XBL 776-1338A

Figure II. 3 - Schematic Diagram of Radiometer Components 
instrument itself.

Appendix $C$ discusses the performance of the ferrite switch, a crucial component of the radiometers. The Appendix describes the cold-Ioad technique that we use to null unbalanced insertion loss between the inpul ports of the device, and the in-flight phase-switching technique that monitors the insertion loss imbalance between the radiometers arms.

Throughout this thesis we will refer to the intensity of microwave radiation in units of antenna temperature expressed as degrees Kelvin ( $\mathrm{K}$ ). A blackbody radiator, radiates with a brightness $B$ given by

$$
B=k T \frac{2 \nu^{2}}{c^{2}} \frac{\alpha}{e^{\alpha}-1} ; \quad \alpha=\frac{h \nu}{k T}
$$

where

$B$ is brightness expressed in ergs $\mathrm{sec}^{1} \mathrm{~cm}^{-2}$ ster ${ }^{1} H z{ }^{\prime}$.

$k$ is Boltzmann's constant, $1.38 \times 10^{-16} \mathrm{ergs} \mathrm{K}^{-1}$.

1 is the frequency of observation.

is the velocily of light, $3 \times 10^{11)} \mathrm{cm} / \mathrm{sec}$.

$h$ is Planck's consiant $6.63 \times 10^{-27} \mathrm{erg} \mathrm{sec}$.

The low-frequency Rayleigh-Jeans region is defined by $h w / k T<<1$, so for frequencies thill sitisfy this critcrion eq. H.I reduces to

$$
B=k T \frac{2 v^{2}}{\imath^{2}}
$$

We take ildvantage of this simple proportionality between brightness and temperature to detine the amemma immeranre of a source, filling an antenna beam, as

$$
T_{A} \equiv B \frac{1}{k} \frac{c^{2}}{2 s^{2}} \text {. }
$$

Thus in the Rayleigh-Jeans region, $T_{A}=T$, from eq. II.2 and II.3. In general

$$
T_{1}=T \frac{\alpha}{e^{x}-1}
$$

irom eq. 1].1 and II.3. See Kraus, 1966. pg. 76-86 for a complele discussion of antennat temperalturc and thermal blackbody radiation. 


\section{Chapter IJI - Equjpment Development and Data Taking}

\section{III.1 Introduction}

This chapter describes the equipment development and data laking lhrough fourteen flights nown between July 1976 and May 1978. All flights utilized one of the iwo U-2 aircraf 1 based al NASA-Ames at Moffelt Ficld, California. Table Ill.1 summarizes the flight circunnstinces.

The nights divided into three sequences according to equipment perfornance. The first sequence, flights 1,2 and 3 , were engincering flights, and colleeted data on equipment perfiormance anly. The second series, flights 4 through 7 collected useful preliminary data on anisotropy, but was a perind that saw rapud changes and modifications in the original equipment coufiguration In the tinal sequence of llights, 8 through 14, the equipment, in unchanged configuration, collected dala of excellent quality Tables HII.2 lhrough Ifl.5 sunmarize the development of the 3.,-(jlle radiometric systen and its performance for each flight. Suctions iII.3, 4, and 5 dessibe each of the three series in mort delail.

The flight plan for sich dala tlight was arranged so the anichnas would measure anisoiropy between twe pairs of directions in the sky. As an example of the data laking strategy compleyed in most flights. section IIt.5 deseribes the thight plan and the resulting sing coverage for the ninth Night

After the inilial enginecring and development Mights, the execution of a lypical dita tlight full inte a reuline. The routine of pre-flight equipment checks, Might-plan preparation, and the aclual light operations, is described in Appendix 1 .

\section{JJ.2 Enuineering Flights (Flights 1-3)}

The carly flights were directed towards the development and testing of the thermal control and momitoring systems, the rotaticen and data recording systems, and the radio-fratuenty

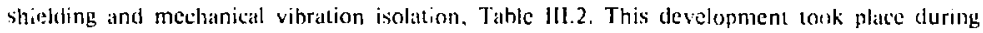
the original fitting and testing of the equipment in the L-2, the wo engineering day-llights in July and August 1976, and the tirst night-1light flown in September 1976.

Prior to the lirst fight, the complete apparatus was mated to NASA U-2 \#709 for tests of mechanical and redio transmission interlerence. On the ground, with the equipment installed and running the pilot sequcntially lurned on the engine and the communication and navigation radio transmilters. The recorded data showed no interference due to engine vibration, or radio interference with the exception of a transmitter not normally used at altitude. During the first engineering hight, the pilot repeated the sequence of transmissions with similar null results. 


\begin{tabular}{|c|c|c|c|c|c|}
\hline \multicolumn{6}{|c|}{ Table III.1 - Flight Circumstances } \\
\hline Flight & $\begin{array}{c}\text { Date } \\
\text { Launch-Land (UT) }\end{array}$ & $\begin{array}{c}\text { Pilot } \\
\text { Aircraft }\end{array}$ & Receiver & $\begin{array}{l}\text { Sensitivity } \\
\left(m^{\circ} K / \sqrt{H z}\right)\end{array}$ & $\begin{array}{c}\text { Exposure }^{2} \\
\text { (hours) }\end{array}$ \\
\hline$\overline{l l}$ & $\begin{array}{c}7 \text { July } 76 \\
1705-1924\end{array}$ & $\begin{array}{l}\text { J. Barnes } \\
\text { NASA \#709 }\end{array}$ & $\begin{array}{l}33.5 \mathrm{GHz} \\
\text { paramp }\end{array}$ & & \\
\hline 2 & $\begin{array}{l}6 \text { Aug } 76 \\
1800-2044\end{array}$ & $\begin{array}{l}\text { R. Williams } \\
\text { NASA \#70 }\end{array}$ & $"$ & & \\
\hline 3 & $\begin{array}{l}23 \text { Sept } 76 \\
0100-0620\end{array}$ & $\begin{array}{l}\text { J. Barnes } \\
\text { NASA \#709 }\end{array}$ & $"$ & & \\
\hline 4 & $\begin{array}{c}3 \text { Dec } 76 \\
0132-0541\end{array}$ & $\begin{array}{l}\text { I. Webster } \\
\text { NASA } \$ 708\end{array}$ & $"$ & $96 \pm 9$ & 2.78 \\
\hline 5 & $\begin{array}{l}10 \text { Dec } 76 \\
0225-0623\end{array}$ & $\begin{array}{l}\text { R. Williams } \\
\text { NASA \#709 }\end{array}$ & $"$ & $119 \pm 19$ & 2.83 \\
\hline 6 & $\begin{array}{c}2 \text { Feb } 77 \\
0130-0615\end{array}$ & $\begin{array}{l}\text { J. Barnes } \\
\text { NASA \#708 }\end{array}$ & $\begin{array}{l}33.0 \mathrm{GHz} \\
\text { 'old' mixer }\end{array}$ & $119 \pm 1.0$ & 3.83 \\
\hline 7 & $\begin{array}{l}18 \mathrm{Mar} 77 \\
0220-0702\end{array}$ & $\begin{array}{l}\text { J. Barnes } \\
\text { NASA \#708 }\end{array}$ & $"$ & $96.4 \pm 1.0$ & 3.85 \\
\hline$\overline{8}$ & $\begin{array}{c}1 \text { Apr } 77 \\
0200-0608\end{array}$ & $\begin{array}{l}\text { R. Williams } \\
\text { NASA \#709 }\end{array}$ & $\begin{array}{l}33.0 \mathrm{GHz} \\
\text { 'new' mixer }\end{array}$ & $44.1 \pm 0.3$ & 3.23 \\
\hline 9 & $\begin{array}{l}14 \text { Apr } 77 \\
0600-1041\end{array}$ & $\begin{array}{l}\text { R. Williams } \\
\text { NASA \#708 }\end{array}$ & $"$ & $43.8 \pm 0.3$ & 3.55 \\
\hline 10 & $\begin{array}{l}20 \text { Apr } 77 \\
0112-0450\end{array}$ & $\begin{array}{l}\text { 1. Webster } \\
\text { NASA \#709 }\end{array}$ & " & $44 . \overline{1 \pm 0.3}$ & 3.87 \\
\hline II & $\begin{array}{l}26 \text { May } 77 \\
0300-0744\end{array}$ & $\begin{array}{l}\text { J. Webster } \\
\text { NASA \#709 }\end{array}$ & $"$ & $43.8 \pm 0.3$ & 3.52 \\
\hline $1 ?$ & $\begin{array}{c}8 \text { Sepl } 77 \\
0230-0705\end{array}$ & $\begin{array}{l}\text { J. Barnes } \\
\text { NASA \#708 }\end{array}$ & $"$ & $44.0 \pm 0.3$ & 3.57 \\
\hline 13 & $\begin{array}{l}24 \text { Feb } 78 \\
0130-0615\end{array}$ & $\begin{array}{l}\text { R. Williams } \\
\text { NASA \#708 }\end{array}$ & $"$ & $44 . \overline{3 \pm 0.3}$ & 3.61 \\
\hline 14 & $\begin{array}{l}16 \text { May } 78 \\
0241-0745 \\
\end{array}$ & $\begin{array}{l}\text { R. Erikson } \\
\text { NASA \#709 }\end{array}$ & $\overline{\prime \prime}$ & $44.8 \pm 0.3$ & 3.54 \\
\hline & TOTAL & & & & 38.18 \\
\hline
\end{tabular}

'Determined from rms fluctuations in $33-\mathrm{GHz}$ data words recorded every 2 seconds.

${ }^{2}$ Includes time during banks and antenna roiations. 


\begin{tabular}{|c|c|c|}
\hline \multicolumn{3}{|c|}{ Table III.2 - Engineering Flights } \\
\hline Flight & $\begin{array}{l}\text { Equipment Configuration } \\
\text { and Improvements }\end{array}$ & $\begin{array}{l}\text { Flight Plan and } \\
\text { Performance }\end{array}$ \\
\hline$I$ & $\begin{array}{l}33.5-\mathrm{GHz} \text { paramp, system sensitivity } \\
\text { on ground is } \pm 44 \mathrm{~m} \mathrm{~K} / \sqrt{\mathrm{Hz}} \text {. } 54-\mathrm{GHz} \\
\text { roll monitor. Antennds interchange } \\
\text { once } / 128 \text { seconds. Housekeeping sys- } \\
\text { tem records equipment temperalures. }\end{array}$ & $\begin{array}{l}\text { Daylight engineering flight, paramp } \\
\text { overheated, data channels over- } \\
\text { voltaged at end of flight. }\end{array}$ \\
\hline 2 & $\begin{array}{l}\text { Increase thermal conduction from } \\
\text { paramp to thermal ballast. Improve } \\
\text { electronics to protect against over- } \\
\text { vollage. }\end{array}$ & $\begin{array}{l}\text { Daylight engineering flight. Improved } \\
\text { paramp regulation. Dalta recording } \\
\text { system works nominally. }\end{array}$ \\
\hline 3 & $\begin{array}{l}\text { Minor mechanical and electronic im- } \\
\text { provements. }\end{array}$ & $\begin{array}{l}\text { Nighttime engineering night. Rotation } \\
\text { system fatls in CCW orientation after } \\
\text { two cycles. Digital recorder fails after } \\
2.5 \text { hours. }\end{array}$ \\
\hline
\end{tabular}

The uriginal task of the thernal comtrol system thas the temperature regulation of the 33 (ill lerrite swich and the baseplate of the paranetric amplifier. Thermal regulation of the parami was necessiry to achieve gain stability because of is large, $-0.4 \mathrm{db} /{ }^{\circ} \mathrm{K}$ thermal gain cueflicient. The heat generated by the regulating circuit and internal electronics in the paramp was dissipated through a mechanicai support piece to the aluminum thermal batlast. This hallist was cooled in turn hy concluction to the 33-GHz horn antenna whose mouths are exposed w the external airstream. The internal heater strips, mounted in the paramp's baseplate, were

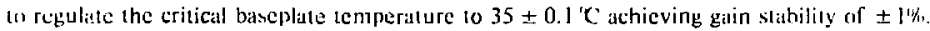

Ine offset of the ferrite switch also varies as a function of temperature. The thermal-drift coefficient of $17 \pm 3 \mathrm{~m} \mathrm{~K} /{ }^{\circ} \mathrm{K}$ (change in offset, per change in physical temperature) was empirically Jetermined from data taken in the laboratory and in flight. Its detailed origin is not understood. The connection of the horn antennas to the input ports of the ferrite switch provides a therma! short to the aluminum ballust, and thus, in principle reduces potential offset drifts. A $2.5 \mathrm{~cm}$ length of gold-plated thin-walled stuinless sted wiveguide, comnected to the switelis output port, thermally isolates the switch from ine parametric antplitier. This greatly reduces the thermid stadient across the body of the switch that would otherwise result if the heated baseplate, the parametric amplifier were thermally shorted to the ferrite switch.

Adequate thermal regulalion wits not achieved in flights 2 through 5 . Only one of three umbedded beater circuits in the puramp baseplate worked; the ortier wo had been danniged by an improper mount. As a resull, the aluminum block temperature cooled a few degrees during the thgh!. causing an amplifier gain drift of about $+0.4 \mathrm{db} / \mathrm{hour}$, and a ferrile switch offset drift of about $90 \mathrm{~m}$ K/hour, or $3.2 \mathrm{~m}$ K per 128 second rotation cycle.

After light 5 , installation of embedded resistive heaters in the aluminum thernal ballast and replatenent of the parametric amplifier with mixer-based receivers improved the situation 
dramatically. The thermal regulation of the a!uminum thermal ballast reduced the temperature drift to less than $0.5 \mathrm{~K} /$ hour, yielding an offset drift of about $0.3 \mathrm{~m} \%$ during a 128 second rotation cycle. The thermal gain coefficient of the mixer-based receivers was about a factor of 10 less than the parametric amplifier. A gain drift of less than $0.04 \mathrm{db} / \mathrm{h}$ cur yields a drift of $00014 \mathrm{db}$ per 128 second rotation cycle. If the ferrite switch offset were as large as $500 \mathrm{~m}{ }^{\circ} \mathrm{K}$ then this would yield a signal drift of less than $0.2 \mathrm{~m}$ K during the rotation cycle.

\section{I1J.3 The Initial Data Flights (Flights 4-7)}

In flights 4 and 5, flown in December 1976, the rms noise fluctuutions were over three times the expected value based on laboratory measurements, Table III.3. Re-measurement after the flight showed that the noise temperature of the amplifier was between 500 and $700 \%$. about twice the original value of 300 K. This degradation in sensitivity partially explained the factor of three increase of the rms fuctuations observed in flipht. The exact cause of the degradation is unknown. The amplifier was shipped back to the manufacturer in Boston. TRG division of Alpha, who re-optimized the pump power level to the varactor diode, and the diode bias current, with oniy marginal results; the noise figure improved some $100 \%$. These flights were the last flown with the parametric anplifier. It became clear that a mixer-based receiver might have significant advantages over the parametric amplifier.

\begin{tabular}{|c|c|c|}
\hline \multicolumn{3}{|c|}{ Table IIJ.3 - Preliminary Data $F$ lights with Parametric Amplifier } \\
\hline$F / h g h t$ & $\begin{array}{l}\text { Equipment Configuration } \\
\text { and Improvements }\end{array}$ & $\begin{array}{l}\text { Flight Plan and } \\
\text { Performance }\end{array}$ \\
\hline$\overline{4}$ & $\begin{array}{l}\text { Regrease rotation bearing, rebuild ro- } \\
\text { lation electronics. Add four tempera- } \\
\text { lure sensors, acceleroneter and vol- } \\
\text { lage monitor to housekecping system. }\end{array}$ & $\begin{array}{l}\text { Firsl data flight. Include an inilial leg } \\
\text { on this and all subsequent hights that } \\
\text { allows the equipment lemperatures to } \\
\text { partially stabilize before data laking } \\
\text { commences. Rotation system and } \\
\text { Datcl work properly. Paramp noise } \\
\text { three times too high. Ferrite switch } \\
\text { cools at } 5 \% / \text { hour. Paramp gain in- } \\
\text { creases at } 0.4 \mathrm{db} / \text { iour. Moon calibra- } \\
\text { tion. }\end{array}$ \\
\hline 5 & $\begin{array}{l}\text { Reducc antenna interchange period to } \\
\text { once } / 64 \text { seconds, reducing spurious } \\
\text { signals due to gain drift. }\end{array}$ & $\begin{array}{l}\text { Similar performance as in flight } 4 . \\
\text { Gather preliminily data. }\end{array}$ \\
\hline
\end{tabular}

A 33.0-GHz balanced mixer made by SpaceKom in Santa Barbara, Calilornia was procured in 1974 as a protolype receiver. Its measured noise temperature is $850 \mathrm{~K}$, for a system tentperature of $920 \%$ including the insertion loss from upstream components. With a $500 \mathrm{MH} s$ IF bandwidth the system sensitivity is $\pm 90 \mathrm{~m} \mathrm{~K} / \sqrt{\mathrm{Hz}}$. We replaced the parametric amplifier with this mixer in flights 6 and 7 (Table III.4) for three reasons. Firs1, the mixer's rms sensitivity is comparable to the degraded sensitivity of the paramp receiver. Secondly, its thermal 
gain coefficient is about one tenth that of the paramp. Finally, its Ciunn oscillator dissipates one third the heat of the parametric amplificr system.

\begin{tabular}{|c|c|c|}
\hline \multicolumn{3}{|c|}{ III.4 Preliminary Data Flights with Old Mixer } \\
\hline Flogh & $\begin{array}{l}\text { Equipnent Configuration } \\
\text { and Inprovements }\end{array}$ & $\begin{array}{l}\text { Flight Plan and } \\
\text { Performance }\end{array}$ \\
\hline 6 & 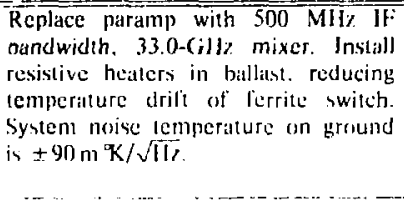 & 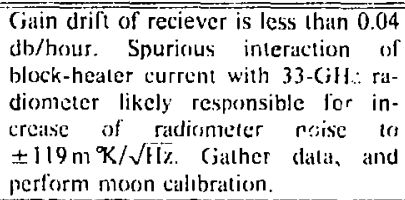 \\
\hline 7 & 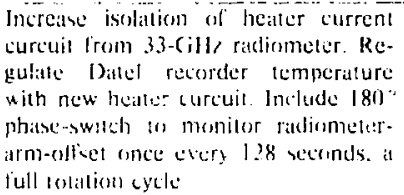 & $\begin{array}{l}\text { Radiometer noise improves la } \\
\pm 100 \mathrm{~m} \mathrm{~K} / \sqrt{\mathrm{H}} / \mathrm{s} \text { (jather data. Phase } \\
\text { switching reveats } 1.4 \mathrm{~K} \text { radiemeter- } \\
\text { arm-olfiel. }\end{array}$ \\
\hline
\end{tabular}

Although the ratlonmeter rostom was undergoing intense development, the data from

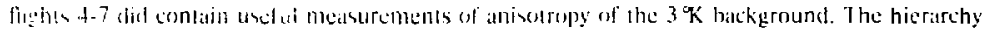

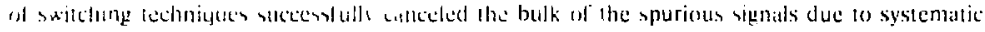
geiln and offset drifts. And the recesver moine, thesgh barger than planned. sill allowed the

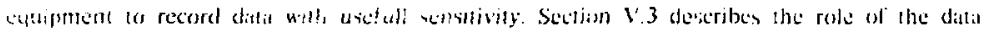

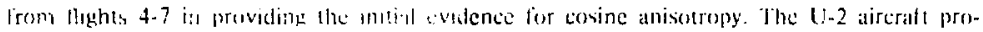

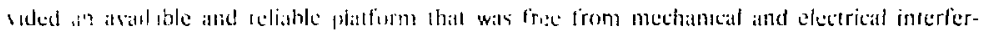
ance to the equipment.

\section{III.4 Final Jhat Flishls (Flighls 8-14)}

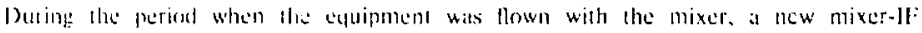

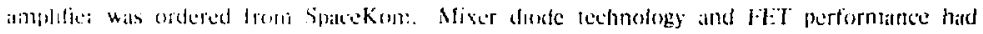
atvanced to the point wise a fruntend mixer hat comparahte sensitivity to the original speciliations of the parametro amplitice receiver. The new mixer has a noise temperature of

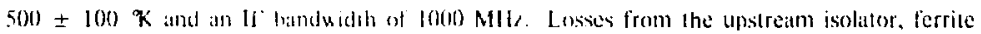
sullch, : nd antemals increaste the system noise temperalure hy $30 \%$, resulting in a meisured system temperature of $670 \pm$ 50 $\mathrm{K}$. lor a sensitisity of $46 \pm 4 \mathrm{~m} \% / \sqrt{1 \mathrm{z}}$.

Flight 8 inflated a xeries of seven llights with lite equipment in an unshanging configurattion. Table III.5. In night 8 the 33-c:lle receiver sensitivity wats within $5 \%$ of the measprements made in the laboratory. The giin drift of the receiver, monitored by the noise power level after the delectur diode, was less than 2"k over the light. 


\begin{tabular}{|c|c|c|}
\hline \multicolumn{3}{|c|}{ Table III.5 - Data Flights with 'New Mixar' } \\
\hline Flighr & $\begin{array}{l}\text { Equipment Configuration } \\
\text { and Improvements }\end{array}$ & $\begin{array}{l}\text { Flight Plan and } \\
\text { Performance }\end{array}$ \\
\hline$\overline{8}$ & $\begin{array}{l}\text { Replace } 500 \mathrm{MHz} \text { IF mixer with } 1000 \\
\mathrm{MHz} \text { IF mixer. Rms Sensitivity on } \\
\text { ground is } 47 \pm 4 \mathrm{~m} \mathrm{~K} / \sqrt{\mathrm{Hz}} \text {. Add mu- } \\
\text { metal shielding to ferrite switch as a } \\
\text { precaution against the earth's magnet- } \\
\text { ic field. Null offset below } 30 \mathrm{~m} \% \text { in } \\
\text { laboratory. Reduce } 180^{\circ} \text { phase-switch } \\
\text { period, monitoring radiometer-arm- } \\
\text { offset every } 24 \text { seconds. }\end{array}$ & $\begin{array}{l}\text { Sensitivily of } 33-\mathrm{GHz} \text { receiver com- } \\
\text { parable to ground calibrations. Ferrite } \\
\text { switch offset } 30 \mathrm{~m} \mathrm{~K} \text { in tight. Rota- } \\
\text { tion offset } 2.2 \pm 0.5 \mathrm{~m} \mathrm{~K} \text {. Moon cali- } \\
\text { bration. Data quality much improved. } \\
\text { Evidence of cosine anisotropy in ciata } \\
\text { from flights } 4-8 \text {. }\end{array}$ \\
\hline 9 & $\begin{array}{l}\text { Equipment 'can' unopened since pre- } \\
\text { vious flight }\end{array}$ & $\begin{array}{l}\text { Late evening take-of at } 10 \text { PM } \\
\text { (PST). Check for sign change of } \\
\text { cosine anisolropy. }\end{array}$ \\
\hline (1) & $"$ & $\begin{array}{l}\text { Sunset launch re-checks sign change } \\
\text { of cosine anisolropy. Announcement } \\
\text { of results at Washington APS meei- } \\
\text { ing, April } 1977 \text { and at AAS meeting } \\
\text { June } 1977 \text { (Smoor, } 1977 a \text {; Gomensicin. } \\
\text { Smoor \& Mull(r, } 1977) \text {. }\end{array}$ \\
\hline 11 & 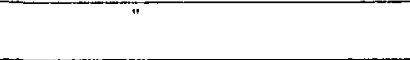 & $\begin{array}{l}\text { Publish results (Simuot. Gorensfein d } \\
\text { Mulker, } 1977) \text {. }\end{array}$ \\
\hline$\therefore$ & $"$ & $\begin{array}{l}\text { Radiomeler-arm-offsel increased to } \\
130 \mathrm{~m} \% \text {. Rotation offset drops to } \\
0.2 \pm 0.5 \mathrm{~m} \% \text { K. }\end{array}$ \\
\hline 13 & $\begin{array}{l}\text { Open can for first time since closed } \\
\text { for } 8^{\text {th }} \text { flight. Null ferrite switch offset. }\end{array}$ & $\begin{array}{l}\text { Orient flight plan to measure largest } \\
\text { signal predicted from cosine anisotro- } \\
\text { py. }\end{array}$ \\
\hline 14 & Open can again to null offset. & $\begin{array}{l}\text { Collect aniso1ropy data, include moon } \\
\text { calibration. }\end{array}$ \\
\hline
\end{tabular}

An ideal radiomeler has a nult output signal for balanced input signal to the antennas; a non-zero output is called the radiometer-arm-offset. The offset is mostly due to the imbalanced insertion loss between the two circulation directions of the ferrite switch that alternates at 100 Hz. Nulling the insertion loss imbalance of the ferrite switch below $20 \mathrm{ml}$ \% during pre-flight preparations reduces the radiometer-arm-offset below $60 \mathrm{~m} \mathrm{~K}$ for most hights; periodic interchange of the antennas, once per 64 seconds, cancels the offset, and reduces spurious signals due to slow drifts in the offset below $0.2 \mathrm{~m} \mathbf{K}$. The ferrite switch offsel drift was a lew millidegrees Kelvin during Iwenty minute periods of data taking. The radiometer-arnı-offset was less than $50 \mathrm{~m}$ \% during flight 8 . The succeeding llights yielded comparable performance, as shown in Figuse III.1, with the exception of flight 12. For an unknown reason the radiometer-armoffset increased to about $140 \mathrm{~m}$ K, requiring the ferrite switch imbalance to be re-nulled after the flight. 
Mean $33-\mathrm{GHz}$ radiometer-arm- of fset

Flight $7-14$

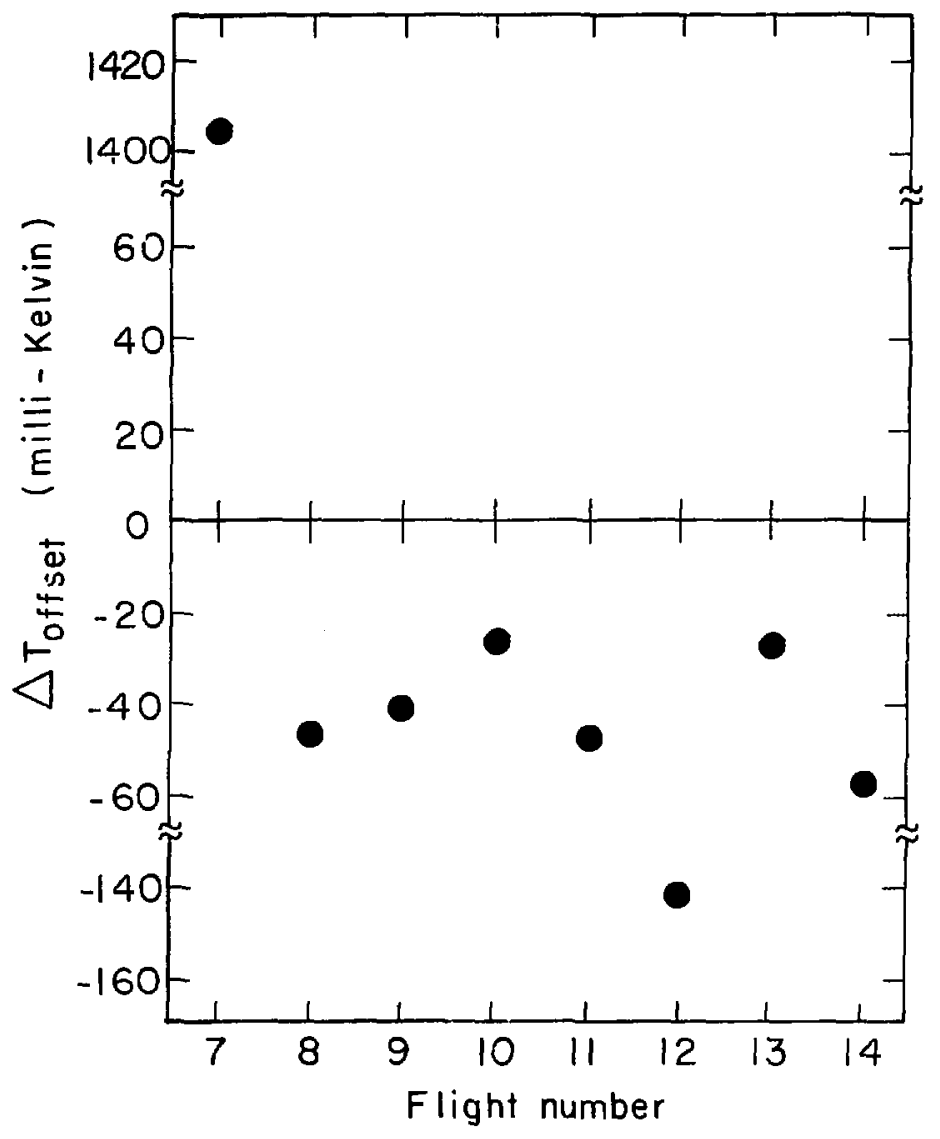

X日L789-1786

Figure III.1 - Mean 33-GHz Radlometer-arm-offget, Flight 7-14 


\section{HI.5 Flight Plan and Sky Covernge}

The flight plan for the ninth flight was a typical example of the data taking strategy used in llights 4-14. As in all data flights, this plan for the ninth flight was organized into segments called "legs", where a leg is a 17 to 20 minute period of straight-and-level flight terminated by a bank that re-orients the aircraft." Legs are flown in pairs with opposing headings that cancel systematic effects intrinsic to the $\mathrm{U}-2$ and $33-\mathrm{GHz}$ radiometer system. Most data flights are composed of iwelve legs. In the ninth flight, Fig. III.2, the U-2 first flew three pairs of legs, with alterrate east-west headings, then after a $90^{\circ}$ bank, the aircraft flew three additional pairs of legs, in alternate north-south headings.

Figure 111.3 shows the sky coverage for flights 4-14 that resulted from this strategy. The latitude of the airfield, $37^{\circ}$ north, and the $60^{\circ}$ opening angle between the antennas restricts the expanse of the sky coverage to a region between $+67^{\circ}$ dec. and $+7^{\circ}$ dec. in the northern celesliat hemisphere. The east-west oriented legs in flight nine measured anisotropy between areas in the sky separated $60^{\circ}$ in declination; the corresponding sky coverage is illustrated as a pair of shaded capsules, one at 13.0 hours R.A., $+7^{\circ}$ dec. for the southward pointing antenna, and one at 13.0 hours R.A., $+67^{\circ}$ dec. for the northward pointing antenna. In the north-south legs the antennas point at the same declination. The eastward antenna points towards 16.8 hours R.A., $+32^{\circ}$ dec. and the westward antenna points towards 12.0 hours R.A., $+32^{\circ}$ declination. The FWHM of the antennas determines the $7^{\circ}$ width of each capsule, and the earth's rotation iı six 20 minute legs determines the 2 hour length of each capsule. We took care in the latter series of flights tu avoid the galactic plane, a source of synchrotron radiation and HII emission.

-The combination of the earth's rolution and the aircrafi's velocity sweeps an anterina beam 2 to $5^{\circ}$ across the celestial sphere in 20 minutes. This swath is comparable to the $7^{\circ}$ beam (FWHM) of the antennus, so litthe angular resolution is lost. 


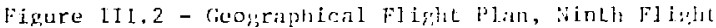

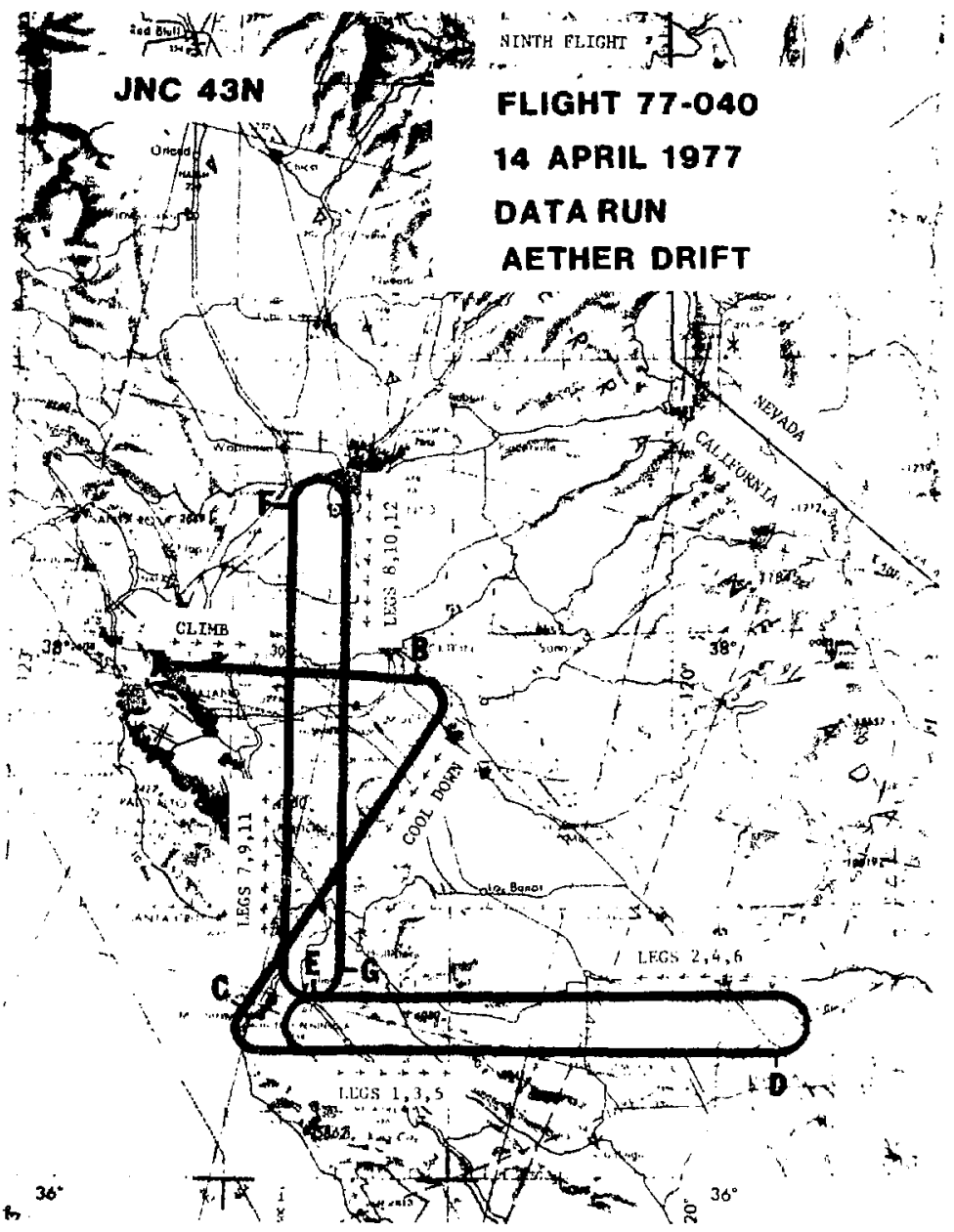


Figure III.3 - Sky Coverage, Flights 4-14

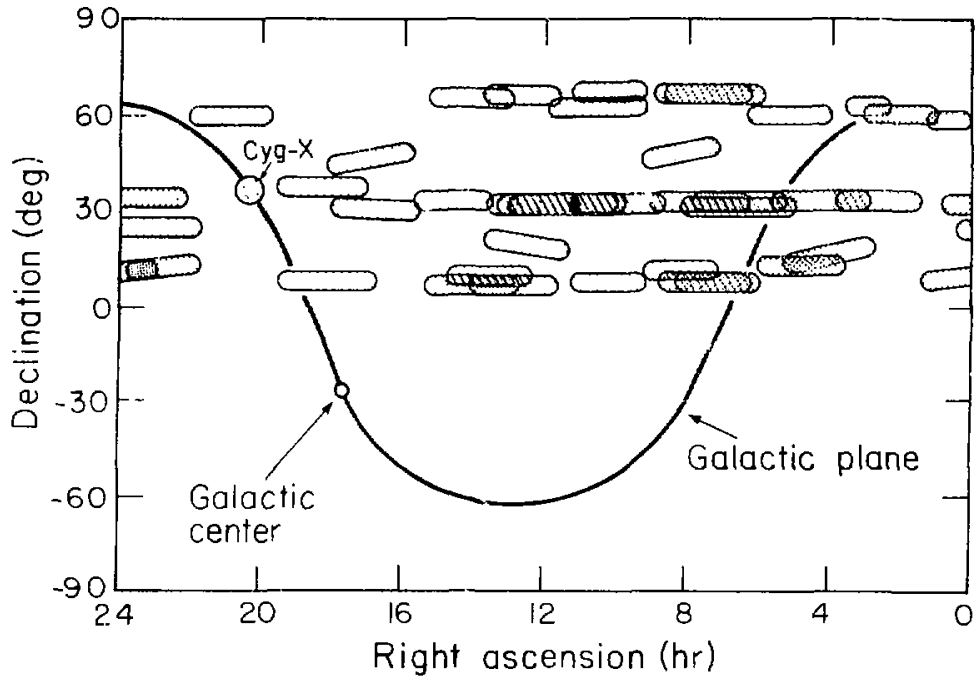

Flights 4-7

Flights 8-14 


\section{Chapter IV - Data Reduction}

\section{IV.1 Introduction}

The reduction and analysis of the Dight data proceeds in three stages. In the first stage, computer programs display the $33-\mathrm{GHz}$ data, the $54-\mathrm{GHz}$ data, and the housekeeping data. This prccedure, though crucia! in the early phases of equipment development, mostly verified proper equipment operation in the later series of data flights and documented the equipment performance.

In the second stage, the inspected $33-\mathrm{GHz}$ data are edited for spurious signals - mostly words recorded during antenna rolations - and then averaged. The averaging procedure groups the words according to the leg in which they were recorded. Each average - called a "leg-measurement" - is then a measurement of anisotropy between the directions that the antennas pointed at during the leg. Section IV.2 describes these stages in detail. The rms fiuctuations for each leg-medsurement are compuled as described in section IV.4.

The final stages in the reduclion process prepares the leg-measurements for the subsequem astrophysical analysis:

(1) A catioration constant converts the leg-measurements, recorded in empirical units, to units of antennat temperature in milli-degrees Kelvin. A series of pre-flight measurements detcrnined the catibration cons:ant for each receiver configuration.

(2) A computcr program compules the directions that the antennas pointed at during each leg and assigns these directions, expressed in celestial coordinates, to the corresponding legneasurement.

13) Slight adiusiments to the ieg-neasurements corrects for spurious galactic and atmospheric emission.

(4) A final correction converts the calibraled and corrected measurements from differential antenna temperature to differential physical temperature of a $3 \mathrm{~K}$ radiation spectrum.

Section IV.3 and its subsections describe these steps in detail.

The procedures that monitor radiometer gain and deternine radiometer calibration are dexirthed in Appendix E. Appendix F documents the slight corrections applied to the legmeasurements for galactic and atmospheric emission. A constant oflset, of unknown origin. subiracted from the leg-measurements prior 10 astrophysical analysis is discussed in section IV.3c and is the subject of Appendix G. Section IV.5 describes the deletion of several spurious leg-mesurements, and Section IV presents the reduced dala from flights 4 through 14. The effect of spurious terfcstrial thermal emission on the data is diseussed in section IV.7. 


\section{IV.2 Editing and Averaging the 33-GHz Anisotropy Data}

Figure IV.I diagrams the data reduction process from acquisition to the final stage of astrophysical analysis. This section concentrates on the Edit, Average, and Display procedures which extract measurements of anisotropy from the flight data.

In the post-night analysis, Average reduces the $33-\mathrm{GHz}$ data recorded in each leg into a single measurement of anisotropy. The units are empirical, determined by the lock-in amplifier gain setling, and the 12 bit resolution of the Datel LPS-16 data logger. In the following discussion, these averages will be referred to as $\Delta T_{\text {lep }}$, both individually and collectively, depending on the context.

Every two seconds at altitude the Datel logger digitizes the integrated 33-GHz anisotropy signal and records it on a cassette tape. This yields one 33-GHz data word. In the Edit stage, data words recorded during antenna rotations and aircraft banks are automatically removed. The Edit routine retains 56 seconds of data taken during the 64 seconds between rotations. Data words are deleted by hand if inspection of the $54-\mathrm{GHz}$ roll monitor indicates a spurious roll of more than $1^{\circ}$, or if there appears to be fluctuation in the $33-\mathrm{GHz}$ data which are inconsistent with Gaussian statistics. Only 5 minutes of spurious data were deleted from the 38 hours collected in flights 4.14 due to spurious rolls. A deletion of 40 seconds of data from flight 10 removed two spikes in the $33-\mathrm{GHz}$ data inconsistent with receiver noise fluctuations. The 33$\mathrm{GHz}, 54-\mathrm{GHz}$, and housekeeping data are Display-ed in time plots or scatter plots. These plots, made at various stages in the editing process facilitate inspection for spuricus signals and allow a graphical check of proper equipment performance.

In averaging the data, account must be taken of the $180^{\circ}$ phase reversal which occurs every 12 seconds. If we first consider onlv the data taken in one phase state, then the difference between the $33-\mathrm{GHz}$ data words recorde $\&$ when the antennas were oriented clockwise ( $\mathrm{CW}$ ) and those recorded when the antennas we:e oriented counterclockwise ( $\mathrm{CCW}$ ) is the desired measurement of anisotropy, or $\Delta T_{t t y}$.

Thus.

$$
\Delta T_{\text {teg }}=\left[\Delta T_{\mathrm{cll}}-\Delta T_{\mathrm{Cr} w}\right] / 2
$$

where

$\Delta T_{C H}$ and $\Delta T_{C C H}$ are the mean of the 33-GHz data words recorded in the $\mathrm{CW}$ or $\mathrm{CCW}$ antenna orientations, respectively, during the legs.

The subtraction cancels the fixed radiometer-arm-offset, $\Delta T_{u / \text { sut }}$, which is mainly due to the insertion loss imbalance belween the input arms of the ferrite switch. 

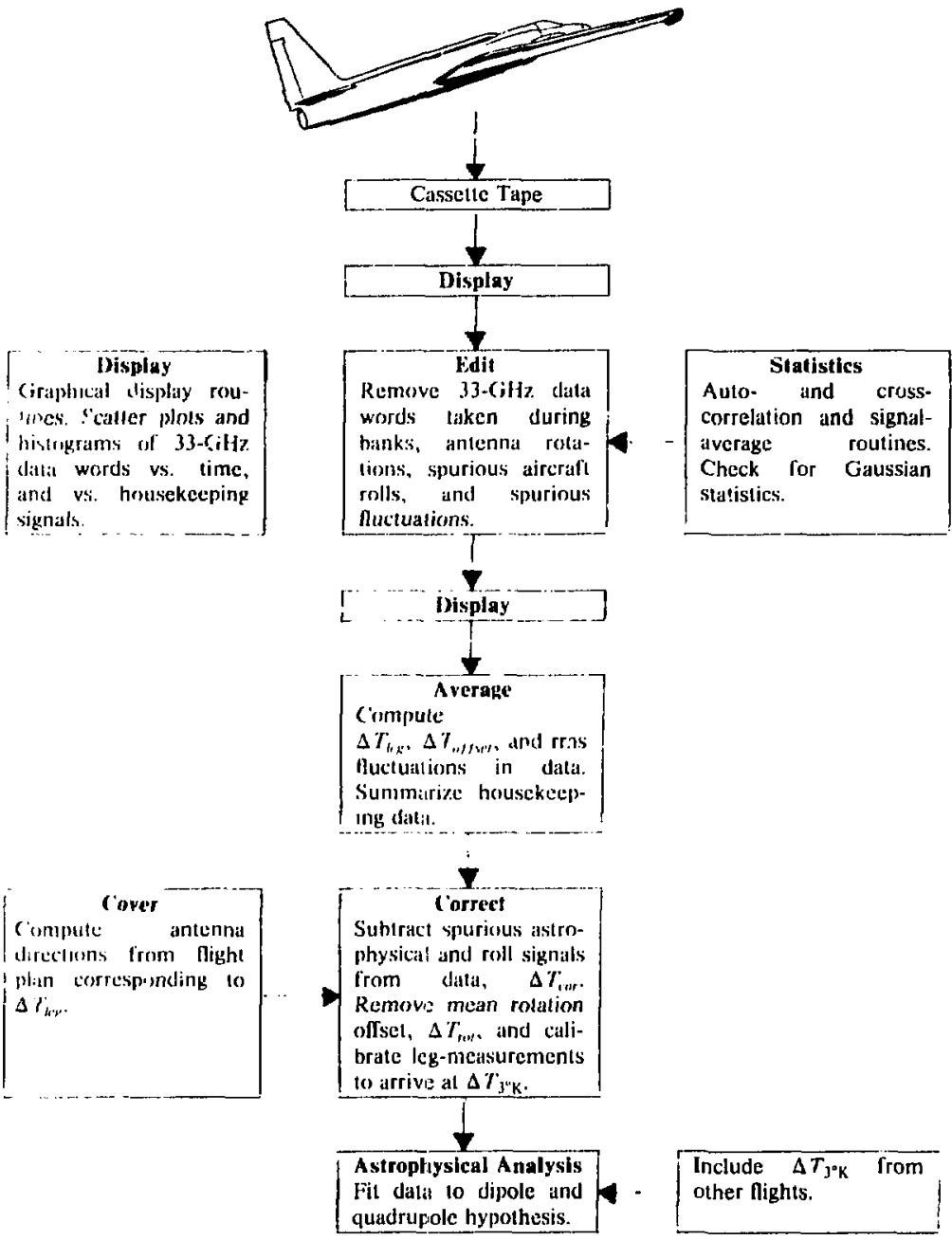
The $180^{\circ}$ phase switching complicates the data reduction but allows $\Delta T_{1 / / s \mathrm{~s}}$ to be determined more accurately. The switching is performed automatically every 12 seconds, resulting in an independent determination of $\Delta T_{t r k}$ for the data collected in each phase state. We now give the complelc algebraic expressions computed in the $A$ verage stage that extract $\Delta T_{\text {lex }}$ and $\Delta T_{u / 1,}$ from the dala.

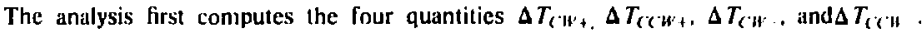
The quantily $\Lambda T_{\boldsymbol{C}} \boldsymbol{H}_{+}$is given by

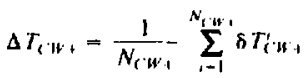

where

$N_{\mathrm{f}} \mathrm{a}$, is the number of measurements recorded in the leg wilh antennas in $\mathrm{CW}$ orientittion, and with lac lock-in demodulation phase set at $0^{\circ}$.

$\delta T_{\mathrm{r}}^{\prime}$, is the ${ }^{\text {th }}$ 2-steond integration of the 3.3-GiHz signal (33-Gilz data word) recorded on casselle tape wilh the radiometer in tice $\mathrm{CW}+$ stale.

$\Delta T_{11}$, is the mean measurement of anisotrepy with the equipment in the $\mathrm{CW}+$ stite.

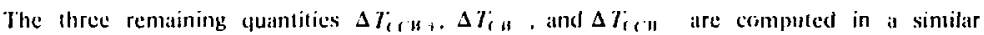
manner.

These quantities are exual to the following suns:

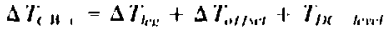

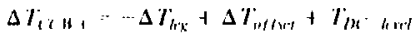

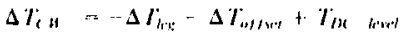

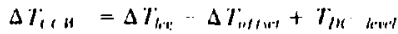

where

$T_{\text {II }}$ "w. is the mean radiomeler output in the absence of all signals.

The leg-averages are combined extracting these quantities as follows these expressions

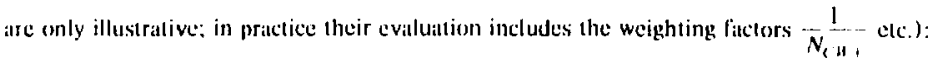

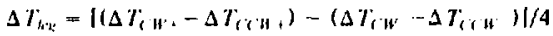

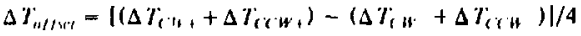

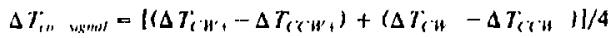

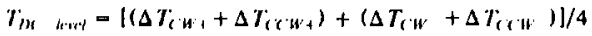


$\Delta T_{t a-1, m u l}$ is a check of the DC level. It has an expectation value of zero.

Figure IV.2 displays the four quantities defined in eq. IV.4 for the twelve legs in the ninth Night. The error bars are statistical only, and indicate the one-standard-deviation limits. There are three things to note: (1) Anisotrony in the cosmic background radiation is evident in the last six legs as an alternation of $\Delta T_{h \mathrm{~g}}$ by about $2 \mathrm{~m} \mathrm{~K}$ about the mean. These legs were flown in alternate north-south headings. (2) The mean value of $\Delta T_{l{ }^{\prime} \mathrm{x}}$ for all legs in the flight is $2.5 \pm 0.5 \mathrm{~m}$ 'K. This non-zera mean is called the rotation offset, $\Delta T_{n / *}$ and is discussed in seclion IV.3c and Appendix (i. (3) The radiumeter-arr -offset, $\Delta T_{\text {ufw, }}$, drifts from $-72 \mathrm{~m} \mathrm{~K}$ in the first leg to about $-25 \mathrm{~m}$ K hy the end of the twelfth icg.

\section{IV.3 Calibrations and Corrections to the Jeh-measurements}

The correct stage calibrales and modities each leg-measurement $\Delta T_{\text {tew }}$, arriving ill a set of measurenents of anisolropy in the 3 ' $\mathrm{K}$ radiation. Thus

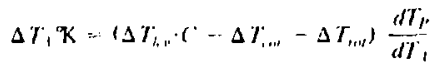

where

$\Delta T_{3}{ }^{2} \mathrm{~K}$ is lhe measured anjsolropy in milli-degrues Kelvin from al leg's worth of datit.

( is the calibration constant that converts the empirical unils that $\Delta \psi_{\text {tex }}$ are digilized in to antennil lemperature expressed in milli-degrees-Kelvin. The calibritton procedure is described in section IV.3a.

$\Delta I_{\text {i. a }}$ are gatactic and atmospheric corrections of a few lenths of I millt-degrete that are discussed in section IV.3b.

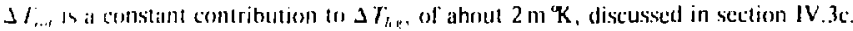

$\frac{d I_{1}}{d \bar{H}_{1}}$ is a seale change that converts intennat tenperature, measured by the radiometer, to the change in th: physicil lemperature of the $3^{\prime} \mathrm{K}$ spectrum. $\frac{d T_{l}^{\prime}}{d T_{1}}=1.024$ for $f_{r},-3 \mathrm{~K}$ ind $r=3.36$ ill $/$, ats aliscusiced in IV.3d.

\section{IV..3a The C'ulibration Constant (' for the 33-CiHz Radiometer}

Bufore the Datel logger records a measurement of anisotropy the 33-6ill receiver amplities the $3 \%$ radiation over 120 db while processing it through three stiges of mixing, delection, and demodulatiom. Useful measurements of anisolropy require that the systen gain be stable during the data flights and constant from Might to flight. Also, the measurement technique smployed in measuring the system gain, i.l'. radiometer calibration. be accurate and reproducible. 
Ninth flight 14 April T7
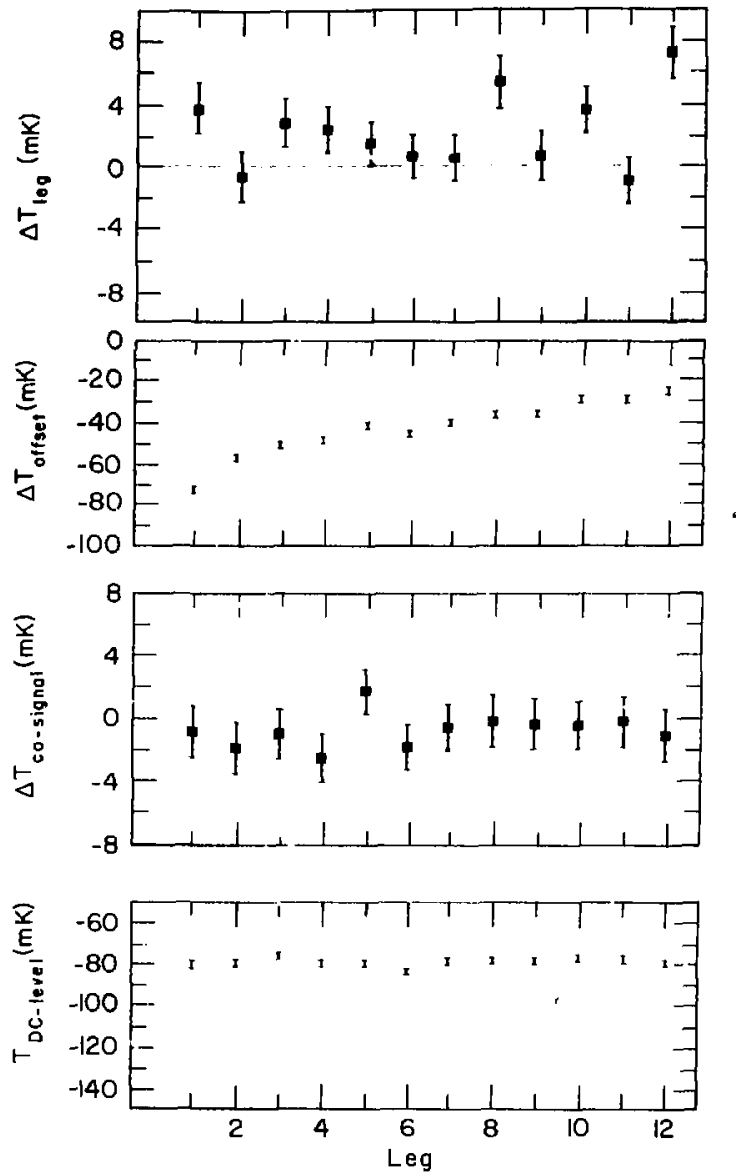

XBL $\quad 788-1593$

Figure IV.2 - Mean Radiometer Signals by Leg, Ninth Flight 
The mixer-based receiver is a stable device: in-flight measurement of its relative gain and noise temperature are measured to be constant within $\pm 1 \%$ during flights, and from flight to Might. Ground based measurements, performed with blackbody targets filing the antenna beam patterns, determine the calibration constant $C$, eq. IV.S, with a $\pm 3 \%$ error

The ground based measurement involves covering the $33-\mathrm{GHz}$ antenna mouths with blick-body targets at room teıperature $(290 \%)$ and at liquid nitrogen temperatus $(77 \%)$. The radiometer configuratio.1 using the SpaceKom receiver was calibrated in this manner during the pre-flight preparations for flights 8,13 , and 14 , and three more times after flight 14 . The six neasurements fluctuate $\pm 2 \%$ about their mean; this fluctuation, the primary uncertainty in recr ver calibration, is small compared to the $\pm 10 \%$ statistical error on the amplitude of cosine anisolropy, presented in the next chapter.

The moon legs provide an important in-flight cross-check on the receiver calibration. Uncertainty in the emission temperature across the Junar surface limits the accuracy of the moon cilibration $10 \pm 5 \%$. Within these errors, it confirms the ground based calibration prowedures. Appendix $\mathrm{E}$ describes in more detait the in-flight monitoring of receiver noise temperaturc and relative gain, and the procedures, crrors, and the techniques and results of the arvund based and lunar radiometer calibrations.

\section{IV.3b The Galactic and Atmospheric Corrections, $\Delta T_{c u}$}

Corrections to the leg-measurements for microwave emission from the galaxy and from unbalanced emission from atmospheric oxygen has small impact on the astrophysical results reported here. In the worst case thesc corrections, in the data from fights 8-14, are IS $\%$ of the one is errors in the leg-measurements, and, as shown in Chapter $V$, change the nieasurcd tosine anisotropy by less than $30 \%$ of its one-slandard deviation error.

The nel correction, $\Delta T_{i n}$, applied 10 the data in the Correct stage is the sum of the following quantities:

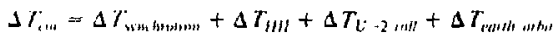

The corrections for galactic synchrotion and HII enission, $\Delta T_{\text {ymetmmin, }}$, and $\Delta T_{h l}$, are extrapolatinns from maps made at lower frequency to our observation frequency of $33 \mathrm{GHz}$. The data is also slightly modified hy the $0.3 \mathrm{~m} \%$ anisotropy due the motion of the earth about the sun. $\Delta T_{\text {trith }}$ whu. Appendix $F$ describes these corrections in more detail. 


\section{IV.3e The Rotation Offset Correction, $\Delta T_{r o t}$}

The rotation offset is a spurious oscillation in the $33-\mathrm{GHz}$ data words at the antenna rotation period. It appears as a constant signal in $\Delta T_{f e g}$ in the absence of celestial anisotropy. In flights 8-14 the mean value of the rotation offset was about $2 \mathrm{~m}$ K and stable throughout a night; its origin is not yel understood despite several determined investigations.

The periodic reversal of the aircraft headirig throughout the flight allows us to measure $\Delta T_{\text {rat }}$ and subtract it from the data in the Correct stage. Although this empirical correction is the largest one applied to the leg-rneasurements, the subtraction of a constant does not significantly alter the best fit parameters of cosine anisolropy. Figure IV.3 plots the value of $\Delta T_{w}$, for each flight, 4-14, and Appendix $G$ discusses passible origins for the rotation offset.

IV.3d Conversion of Antenna Temperature to Thermodynamic Tenperature, $\frac{d T_{A}}{d T_{p}}$

A final $2.4 \%$ correction accounts for the departure of the $3 \mathrm{~K}$ spectrum from the ciasisical Rayleigh-Jeans spectrum at $33 \mathrm{GH}$. For $T_{p}=3 \mathrm{~K}$ and $t^{\prime}=33 \mathrm{Gills}, \frac{h y}{k T_{p}}=0.53$, and the delailed Planckian spectrum must be laken into account. Thus, from the relitionship between physical temperature. $T_{p}$, and antenna temperature, $T_{t}$, given in eq. 11.4 ,

$$
T_{1}=7_{P} \frac{r}{r^{*}-1}
$$

where

$$
x=\frac{h w}{k T_{p}}
$$

We find for $\%=3 \mathrm{~K}, v=336 \mathrm{H} \%$, thit

$$
\frac{d T_{1}}{d T_{j}}=\frac{\left(x^{2} e^{\prime \prime}\right.}{\left(e^{\prime \prime}-1\right)^{2}}=-\frac{1}{1.024}
$$

\section{IV.4 Radiometer Sensitivity}

Programs in the Average and Statistics slage compute the rms fluctuations of the recorded 33-GHz data words about the means given in eq. IV.3. Combining the measurenzents recorded during all legs of flights $8-14$ we find the 33-GHz receiver sensitivity to bc

$$
\sigma_{31-G H^{*}}=45.58 \pm 0.09 \pm 1.8 \mathrm{n} \mathrm{K} / \sqrt{\mathrm{HL}}
$$

where the initial error is statistical, and the final error comes from uncertainty in the radiometer 


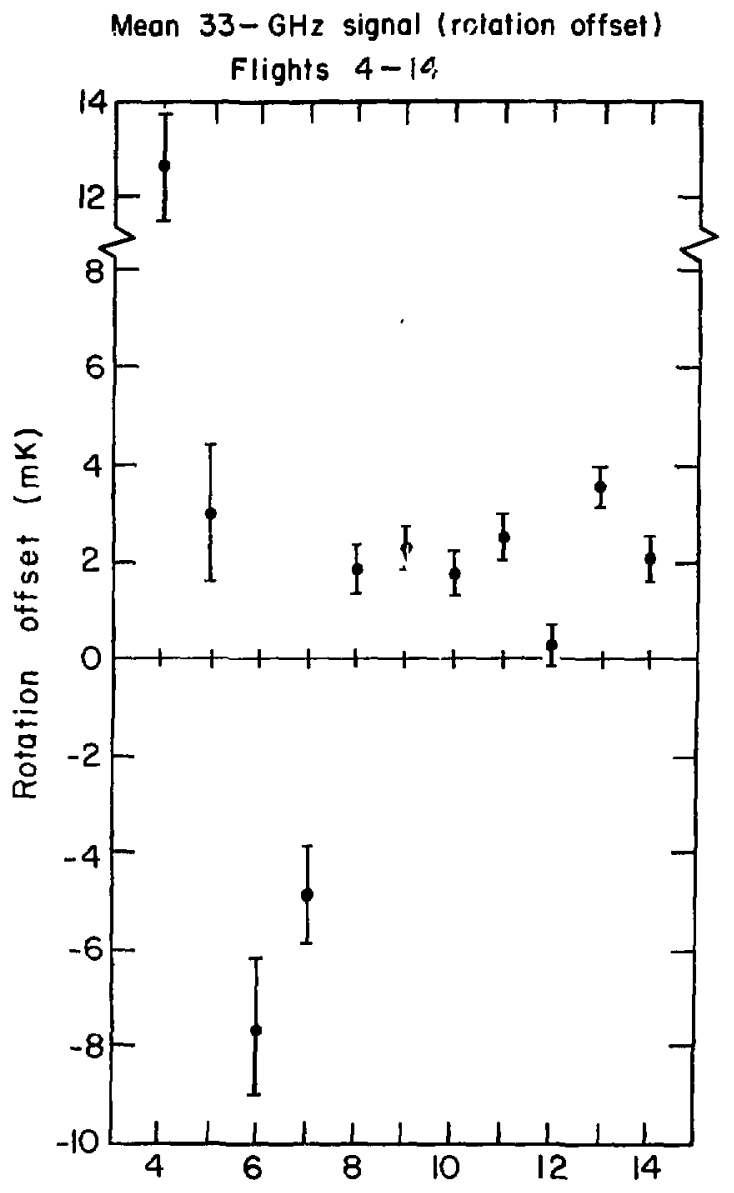

Flight no.

XBL $\quad 78 B-1556$

F1gure IV.3 - Mean 33-GHz S1gnal (Rotation Offset), Flights 4-14 
calibration. The initial error agrees with the expected uncertainty due to receiver noise and is evidence that the receiver gain between flights is stable to about $\pm 0.2 \%$. The residual fluctuations about the mean values in eq. IV.3 are expected to be uncorrelated and distributed as Gaussian noise. The programs in Statistics contain auto- and cross-correlation routines that analyze the $33-\mathrm{GHz}$ data words recorded in each flight.

In flights 8-14 the auto-correlation coefficients for time displacements for 2 to 128 seconds were consistent with zero, with a statistical sensitivity of $\pm 4 \mathrm{~m} \%$. The signal-averaging, performed at the rotation period, yielded a sensitivity of $\pm 3.7 \mathrm{~m}$ K for each bin that corresponded 10 a $33-\mathrm{GHz}$ data word. The signal-average results were consistent with uncorrelated noise. The earlier nights produced anomalous results in these tests. In flights 4-7, auto-corrclation of the 33-GHz data words revealed oscillations with time periods of 40 to 120 seconds, and amplitudes that varied from 10 to $45 \mathrm{~m} \mathrm{~K}$. In the latter 4 legs of flight 6 , these osciliations were synchronous with the rotation period of 128 seconds. The block-heater current also sitowed periodic behavior in these latter legs, indicating a likely connection. (These correlations are not understood in detail.) The repiacement of the parametric amplifier with the SpaceKom mixer and improvements in the isolation of the heater circuits seem to have corrected this problem. We believe that the data is still useful without a definitive identification of the source of these oscillations. Systematic signals in $\Delta T_{t-1}$ tend to cancel as the aircraft heading is periodically reversed throughout a flight. The mean values of $\Delta T_{l c k}$ for nights 4-7 are used for some astrophysical analysis with the rms errors empiricilly determined from the data. The final analysis in Chapter $V$ concentrates on the data from Aights 8-14 because it is the data of the best quality taken with the equipment in unchanged contiguration.

\section{IV.5 Spurious Leg-measurements}

The data from the first six legs of flight 10 are excluded from the final astrophysical analysis because of slight contamination due to the sun. Take-off for the tenth flight preceded sunset on the ground, and at the $20-\mathrm{km}$ altitude the sun was above the horizon for a prolonged period. The sun was far enough from the main beam of the antenna that microwave radiation into that antenna sidelobes was minimal. However the direct heating from the sun caused an oscillation of the antenna mouth temperature as the antermas rotated. The datil from the temperature sensors in the mouths of the horn antennas clearly show the effect of the warning due to the sun, during the initial six legs, and the abrupt cessition of anomalous heating at sunset. A rough upper limit to the resulting spurious signal would be a few tens of milli-degrees Kelvin, as the antennas are heated about $1 \mathrm{~K}$ and the net emissivity of the antenna is about 0.03 . Examination of the leg-medsurements shows that the effect is less than about $4 \mathrm{~m}$ K. 
The data from the initial two legs from flight 6 are also deleted from the data analysis. The value of the initial leg-measurement is inconsistent with the succeeding measurements, probably because of the rapid temperature changes that trok place at the first exposure of the equipment to the environment.

\section{IV.6 Anisotropy Data from Flight 4-14}

fable IV.I presents the measurements of 33-GIJz anisotropy from nights 4-14. The sign convention is

$$
\Delta \Gamma_{3} \mathrm{~K}=T\left(\hat{n}_{1}\right)-T\left(\hat{n}_{2}\right)
$$

where

$r\left(j, j_{1}\right.$ is the temperature of the $3 \mathrm{~K}$ background radiation in the $\tilde{n}_{1}$ direction.

$\hat{n}_{1}$ is the direction of the antenna on the pilot's right. $\hat{n}_{2}$ is the direction of the antenna on the pilost's left.

Cover determines the $\bar{n}_{1}$ and $\hat{n}_{2}$ directions from the fight plan. The input data are the gecgraphla:d position at the start of a leg, the heading of the U-2, its ground speed, and the slirt and and times of the leg. Table IV.1 also lists these mean antenna directions in celestial coordinstess that Cover determines from these dala.

Another useful set of enordinates that wilt be referred to in Chapter $V$ are called the reclangulitl celestial coordinutes. They are an orthonormal set of vectors pointing along axes detlus: in terms of the eelestial coordinates, Table IV.2.

\begin{tabular}{|c|cc|}
\hline Table IV.2 - Rectangular Celestial Coordinates \\
\hline $\begin{array}{c}\text { unit } \\
\text { vector }\end{array}$ & $\begin{array}{c}\text { R.A. } \\
\text { (hours) }\end{array}$ & $\begin{array}{c}\text { dec. } \\
\text { (degrees) }\end{array}$ \\
\hline$n_{1}$ & 0 & $0^{\circ}$ \\
$n_{t}$ & 6 & $0^{\circ}$ \\
$n_{i}$ & - & $+90^{\circ}$ \\
\hline
\end{tabular}

Two cross-checks verify the sense of the sign given for $\Delta T_{3} \mathbf{K}$ in eq. IV.11. First, rightbanks of the aircraft inject a "hot" $23 \mathrm{~m}$ \% atmospheric signal into the $33-\mathrm{GHz}$ antenna direction on the pilot's right, and left-banks give a similar "hot" signal in the untenna direction on the pilot's lefi. The bank dati are reduced in the Average program along with the anisotropy dala, and give the sign of $\Delta T_{\text {trimk }}$ as positive for a "hot" signal on the pilot's right, and negative for a "hol" signal on the pilot's left, checking the sign conventions. 
Table IV.1 - Measurements of Anisotropy of $3^{\circ} \mathrm{K}$ Radiation, Flights 4-14

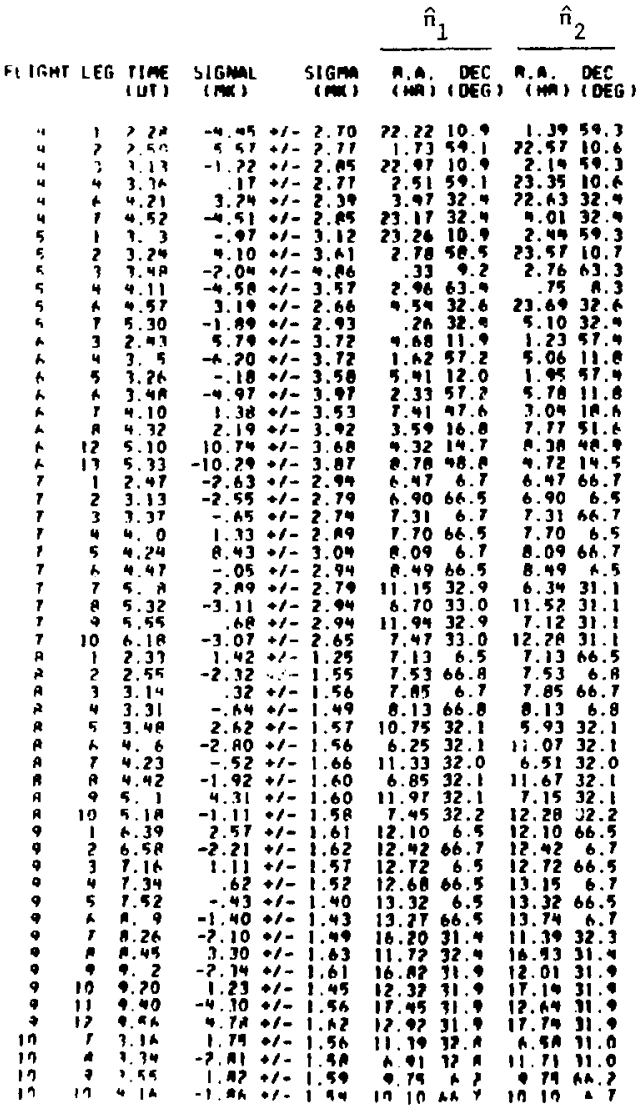


Table IV.I (continued)

\begin{tabular}{|c|c|c|c|c|c|c|c|c|}
\hline \multirow[b]{2}{*}{ 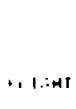 } & \multirow[b]{2}{*}{$1 E$} & \multirow[b]{2}{*}{$\begin{array}{l}\text { IIME } \\
\text { (IIT) }\end{array}$} & \multirow[b]{2}{*}{ (IGNAL } & \multirow[b]{2}{*}{$s(\mathrm{gm})$} & \multicolumn{2}{|c|}{$\hat{n}_{1}$} & \multicolumn{2}{|c|}{$\hat{n}_{2}$} \\
\hline & & & & & Rini & $\begin{array}{l}\text { DEC } \\
\text { (DEG) }\end{array}$ & ( & $\begin{array}{l}\text { OEC } \\
\text { (OEG) }\end{array}$ \\
\hline $\begin{array}{l}19 \\
13 \\
11 \\
11 \\
11 \\
11 \\
11 \\
11 \\
11 \\
11 \\
11 \\
11 \\
11 \\
11 \\
17 \\
17 \\
17 \\
17 \\
17 \\
12 \\
17 \\
17 \\
17 \\
17 \\
17 \\
17 \\
13 \\
13 \\
13 \\
17 \\
13 \\
17 \\
17 \\
13 \\
13 \\
17 \\
17 \\
13 \\
14 \\
14 \\
14 \\
14 \\
10 \\
14 \\
14 \\
14 \\
14 \\
14 \\
14 \\
14\end{array}$ & $\begin{array}{r}11 \\
1 ? \\
1 \\
3 \\
4 \\
5 \\
1 \\
1 \\
10 \\
11 \\
12 \\
1 \\
2 \\
3 \\
4 \\
5 \\
4 \\
1 \\
1 \\
12 \\
11 \\
12 \\
1 \\
2 \\
1 \\
4 \\
5 \\
6 \\
1 \\
1 \\
10 \\
10 \\
12 \\
1 \\
2 \\
3 \\
5 \\
1 \\
1 \\
0 \\
10 \\
11 \\
12\end{array}$ & 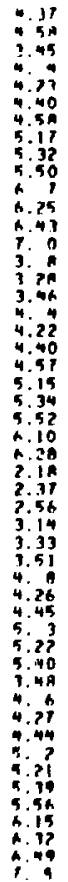 & 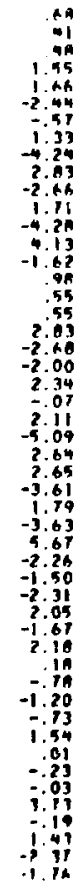 & 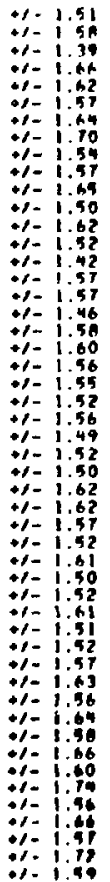 & 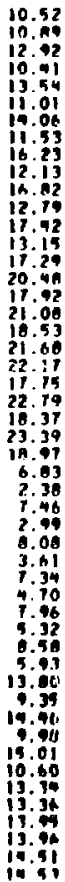 & $\begin{array}{r}6.3 \\
44.7 \\
10.1 \\
61.3 \\
10.1 \\
61.3 \\
9.5 \\
60.4 \\
46.1 \\
19.2 \\
15.4 \\
18.1 \\
45.9 \\
21.4 \\
59.6 \\
6.9 \\
59.6 \\
6.9 \\
59.6 \\
25.1 \\
39.0 \\
25.1 \\
39.0 \\
25.1 \\
39.0 \\
31.5 \\
31.4 \\
31.5 \\
31.4 \\
31.4 \\
31.4 \\
9.7 \\
94.5\end{array}$ & 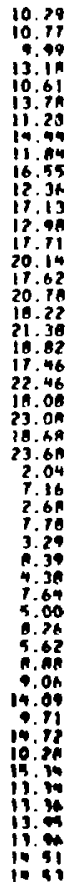 & 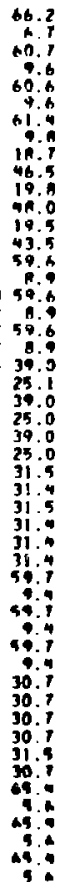 \\
\hline
\end{tabular}


The moon legs provide an additional check of the sign convention. Cover computes $\dot{n}_{1}$ and $\hat{n}_{2}$ for the moon legs, and Average determines the value of $\Delta T_{\text {, marn }}$. Again, the moon on the pilot's right gave a positive signal as expected. The astrophysical analysis in the next chapter uses $\Delta T_{\text {muatm }}$ as a check of the sign convention for the fit to cosine anisotropy.

\section{IV.7 Systematic Errors due to Earth-Shine}

Anisotropic terrestrial cmission (carth-shine) into the antenna's sidelobes is a poteritial source of spurious signals. The carth's surface emits thermal radtation near $300 \mathrm{~K}$ inlo the sidelobes of the 33-GHz horn antennas. Variations in the enissir ity between features of the earth's surface that illuminate the sidelobes preverts the complete tancellation of the terrestrial signal belween the antennis. Becuuse anisolropic earth-shine is correlited with geography, reversing the beading of the $1-2$ between diata legs does not cancel this signill. Rather the low sidelobes of the 33-GH) corrugated horn antennas reduce this signal on a low level. Integration of the measured antenna prower patterns sbow that the sidelobes shoukd reduce anisolropic cmission below $0.2 \mathrm{n} \%$.

Two tesis performed with the datil confirm this result to about the $0.5 \mathrm{~m}$ " $\mathrm{K}$ level. First, the leg-measurenen'; were fit 10 a model of cosine anisotropy and terrestrial emission. For example, a fit to the datal for a signal with fixed east-west geograthical orientation gave a measurement ol $0.3 \pm 0.5 \mathrm{~m}$ K, westwat dirsction cold. The seesond test investigated the dattil taken during the banks of the U-2. During at bank, one antenna is lowered about $20^{\circ}$ in clevaltion. thereby receiving addditional radiation in its earth-directed sidelobes. But the errors on terrestrial emission extracted from the dala collected during banks is comparable to the expected magnilude of the terrestrial signal. The resulting measurement. illthough consistent with our expectillions, does not criticilly test the measurement of the intenna sideobes. Thus we consider what effect at $0.2 \mathrm{~m} \mathrm{k}$ signal would have on the datia, in parlicular on the fit for cosine anisotrons.

A $0.2 \mathrm{~m}$ K spurious signal added in an uncorrelated fashion 10 the leg-meisurements would result in a neg!igible l'/ increase in the $\pm 1.6 \mathrm{~m} \mathrm{~K}$ slatistical noise. However the $0.2 \mathrm{~m} \mathrm{~K}$ sidelobe signal is corretated with geographical fee. ures so during the course of al thight it would not tend to cancel as would a fluctuating signal. Fits were perlormed for il cosine anisotropy hypothesis that included the effects of terrestrial emission. The results were that at $0.2 \mathrm{~m} \mathrm{~K}$ sidelobe signal correlated wilh the geographicial featues contributes a vecior of mignitude $0.1 \mathrm{~m}$ K. Rather than try building a detailed model of the terestrial emission. we increase the statislical errors on the parameters of cosine anisolropy presented in the next chapter hy $25 \%$. from $0.4100 .5 \mathrm{~m} \%$ K. We feel this adequalcly takes into account the present uncertainty on the magnilude of conlansination due to anisotropic terrestrial enission. 


\section{Chapter V - Astrophysical Analysis}

\section{V.1 Introduction}

The results of a fit for cosine (dipole) anisotropy to the data listed in Table IV.1, flights 8-14, are presented in Section V.2. A significant dipole amplitude of $3.6 \pm 0.5 \mathrm{~m} K$ gives clear evidence of anisotropy in the cosmic background radiation. This result is consistent with other sclections of data from Table IV.1, as shown in sertion V.3. Tests that cross-check the analysis and verify the sign of the anisotropy are also presented. The cosine anisotropy found in this data is compared with other radiometric measurements of anisotropy on a large-angular-scale, Section V.4. Statistical tests performed on the data, described in Sections V.5 and V.6, place a $1 \mathrm{~m} \mathrm{~K}$ limit on most components of quadrupole anisotropy and a $0.5 \mathrm{~m} \mathrm{~K} \mathrm{limit} \mathrm{on} \mathrm{uncorrelated}$ Auctuations in sky temperature (sky-roughness) on a $7^{\circ}$ angular scale set by the antenna beam width.

A cosine anisotropy of about $3 \mathrm{~m} \%$ was anticipated from the sun's motion about the Milkj' Way Galaxy. Surprisingly, the anisotropy presented here points away from this motion. The inferred motion of the Milky Way Galaxy is over $500 \mathrm{~km} / \mathrm{sec}$ relative to the sources of the $3 \mathrm{~K}$ background radiation. Section V.7 compares this result to other measurements of solar motion with respect to various selections of nearby groupings of galaxies. The conclusion to this thesis. Section V.8, summarizes the results of this work and describes flture investigations of the angular properties of the $3 \%$ background radiaticn.

\section{V.2 The Cosine (Dipole) Anisotropy Measured in Flights 8-14}

We now wish tu measure the amplitude of cosine anisotropy present in the reduced data of Table IV.1. The following expression descri'ses cosine (dipole) anisotropy in the $3 \mathrm{~K}^{\circ}$ background radiation:

$$
T(\hat{n})=T_{o}+\vec{T} \cdot \hat{n}
$$

where

$T(\hat{n})$ is the radiation temperature in the direction $\hat{n}$.

$\vec{T}$ is the amplitude and direction of a $\cos \theta$ anisotropy.

$T_{0}$ is the mean temperature, not measured in this experiment.

Since the 33-GHz radiometer measures the difference temperature between the directions $\hat{n}_{1}$ and $\hat{n}_{2}$, the following equation models cosine anisotropy for the data in Table IV.1:

$$
\Delta T\left(\hat{n}_{1}, \hat{n}_{2}\right) \equiv T\left(\hat{n}_{1}\right)-T\left(\hat{n}_{2}\right)=\vec{T} \cdot\left(\hat{n}_{1}-\hat{n}_{2}\right)
$$


The sum of the squared deviations of the data from this model, $S$, is given by

$$
S=\sum_{i=1}^{M} \frac{\left[\Delta T_{3 \kappa}^{\prime}-\vec{T} \cdot\left(\hat{n}_{1}^{\prime}-\hat{n}_{2}^{\prime}\right)\right]^{2}}{\sigma_{1}^{2}}
$$

where

$M$ is the number of leg-measurements included in the fit.

$\Delta T_{3 \mathrm{~K}}^{\prime}$ is the $i^{\text {th }}$ leg-measurement in the fit.

$\hat{n}_{i}^{\prime} \hat{n}_{2}^{\prime}$ are the antenna directions of the $i^{\text {th }}$ measurement.

$\sigma_{1}$ is the one-standard-deviation uncertainty in the $i^{\text {th }}$ measurement, scaled from the rms fluctuations of the $33-\mathrm{GHz}$ data words.

The vector $\vec{T}$ that minimizes $S$ gives the best estimate of cosine anisotropy. Section H.1 describes the fitting procedure that computes $\vec{T}$ and its errors.

Minimizing $S$ in eq. V.3 for the data from flights 8-14 determines $\bar{T}$ to be

$$
\begin{gathered}
|\vec{T}|=3.61 \pm 0.43 \mathrm{~m} \mathrm{~K}^{\circ} \\
\dot{r}=11.23 \pm 0.37 \text { hours R.A., } 19 \pm 6^{\circ} \mathrm{dec} .
\end{gathered}
$$

The unit vector $\hat{T}$ points towards the "hotter" hemisphere. The errors in eq. V.4 are statistical only. Table V.1 summarizes the purameters that describe cosine anisotropy in the data from flights 8-14 together with their errors and correlation coefficients. These parameters are expressed in celestial coordinates, galactic coordinates, rectangular celestial coordinates, and finally for the rectangular diagonal coordinates that have uncorrelated errors. Errors expressed in reclangular coordinates have Gaussian distribution. Their compulation is described in Appendix H. Section H.l. The errors on all parameters listed in this table are $25 \%$ larger than the statistical errors. As described in Section IV.7 this accounts for uncertainty in terrestrial emission into the antenna sidelobes.

Table V.2 compares each leg-measurement with the value of anisilropy calculated from the cosine fit. The value of $S$ computed for the fit is 71.0 for the 76 measurements. The probability that $S$ equals or exceeds 71.0 is given by the integral of a $x^{2}$ distribution for $76-3=73$ degrees-of-freedom (DOF). We call this probability the confidence level. The confidence level for $S$ of 71.0 for 73 DOF is about $55 \%$. Figure V.1 plots $\Delta T_{3 \mathrm{~K}}$ versus the angle between $\vec{T}$ and the difference vector $\left(\hat{n}_{1}^{\prime}-\hat{n}_{2}^{\prime}\right)$. The curved line is the cosine anisotropy drawn in for comparison. In contrast to the cosine anisotropy, the horizontal line, $\Delta r=0$, gives a puor fit to the data. The value of $S$ for this null hypothesis is 171 , and gives a confidence level, for 76 DOF, of less than $10^{-9}$.

Figure $V .2$ is a sky map of the fitted cosine anisotropy summed with galactic backgrounds. 


\begin{tabular}{|c|c|c|c|c|c|c|}
\hline \multicolumn{7}{|c|}{$\begin{array}{l}\text { Table V.1 - Parameters of Cosine Anisotropy - Flights 8-14 Correct } \\
\qquad x^{2} / \text { degrees of freedom }=71.0 / 73 \text {, confidence level }=55 \%\end{array}$} \\
\hline & \multicolumn{3}{|c|}{ Best fit Parameters } & \multicolumn{3}{|c|}{ Correlation Coefficients ${ }^{2}$} \\
\hline $\begin{array}{l}\text { Celestial } \\
\text { Coordinates }\end{array}$ & $\begin{array}{l}\text { amplitude } \\
\left(\mathrm{m}^{\circ} \mathrm{K}\right) \\
3.61 \pm 0.54\end{array}$ & $\begin{array}{l}\text { R.A. } \\
\text { (hours) } \\
11.23 \pm 0.46\end{array}$ & $\begin{array}{l}\text { dec. } \\
\text { (deg.) } \\
19.0 \pm 7.5\end{array}$ & $\begin{array}{l}C_{\text {(anns. dec })} \\
+0.57\end{array}$ & $\begin{array}{l}C_{\text {(ump.R.A. }} \\
-0.07\end{array}$ & $\begin{array}{l}C_{(d n, R . A .)} \\
+0.06\end{array}$ \\
\hline $\begin{array}{c}\text { Galactic } \\
\text { Coordinates }\end{array}$ & $\begin{array}{l}\text { amplitude } \\
\left(\mathrm{m}^{\circ} \mathrm{K}\right) \\
3.61 \pm 0.54\end{array}$ & $\begin{array}{c}l \prime \prime \\
(\text { deg. }) \\
229 \pm 19\end{array}$ & $\begin{array}{c}b^{\prime \prime} \\
(\text { deg. }) \\
+66.6 \pm 6.9\end{array}$ & $\begin{array}{l}C_{(a m p, b)} \\
+0.24\end{array}$ & $\begin{array}{l}C_{(a m p, n)} \\
-0.56\end{array}$ & $\begin{array}{l}C_{(b, f)} \\
-0.17\end{array}$ \\
\hline $\begin{array}{l}\text { Retrangular } \\
\text { Coordinates }\end{array}$ & $\begin{array}{c}T_{1}\left(m^{\circ} \mathrm{K}\right) \\
-334 \pm 0.44\end{array}$ & $\begin{array}{c}T_{y}\left(\mathrm{~m}^{\circ} \mathrm{K}\right) \\
0.68 \pm 0.40\end{array}$ & $\begin{array}{c}T_{\Sigma}\left(\mathrm{m}^{\circ} \mathrm{K}\right) \\
1.18 \pm 0.49\end{array}$ & $\begin{array}{l}C_{(x, y)} \\
-0.04\end{array}$ & $\begin{array}{l}C_{\left(x_{x: z}\right)} \\
-0.56\end{array}$ & $\begin{array}{l}C_{(y, z)} \\
-0.01\end{array}$ \\
\hline $\begin{array}{c}\text { Diazonalized } \\
\text { Coordinates }\end{array}$ & $\begin{array}{c}T\left(\mathrm{~m}^{\circ} \mathrm{K}\right) \\
3.07 \pm 0.59\end{array}$ & $\begin{array}{c}T_{1}\left(\mathrm{~m}^{\circ} \mathrm{K}\right) \\
1.72 \pm 0.30\end{array}$ & $\begin{array}{c}T_{\mathrm{h}}\left(\mathrm{m}^{\circ} \mathrm{K}\right) \\
0.80 \pm 0.39\end{array}$ & $\begin{array}{c}C_{(1, i)} \\
0.0\end{array}$ & $\begin{array}{c}C_{(1, \Lambda)} \\
0.0\end{array}$ & $\begin{array}{c}C_{(1, \ldots)} \\
0.0\end{array}$ \\
\hline
\end{tabular}

'Slatisticul crors have been uniformly increased by $25 \%$ to takc into account systematic errors ats described in text.

'Sec Appendix H, eq. H.16 for definition and normilization of correlation coefficients.

'Unit vectors point along rectangular celestial coordinate axes. Expressed in celestial coordinates. (hrs. R.A, dec) , these unit vectors point along $\hat{x}=(0,09, \bar{y}=(6,09)$ and, $\hat{z}=(+90,-)$.

'Unil veclors point along axes where errors are uncorrelated. Expressed in celestial coordinates, (hrs. R.A., $\mathrm{dec}$ ), these unit vectors point alang $\hat{i}=(11.94,49.59, \hat{j}=(12.5,-39.89$ and, $\hat{k}=(6.23,-4.0)$. 
Table V.2 - Comparison of Data to Cosine Anisotropy, Fiights 8-14

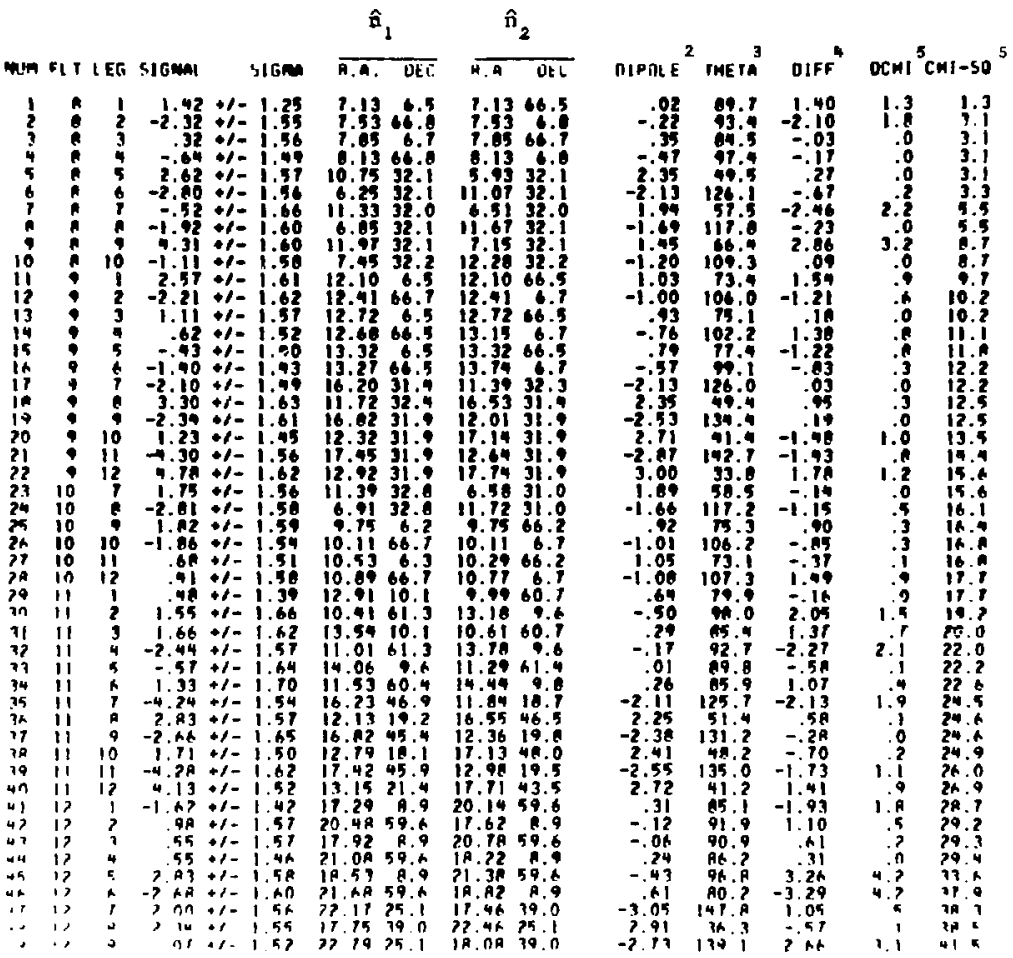

${ }^{1}$ The first nine columns are the data reproduced from Table IV.I. ${ }^{2}$ DIPOLE $1 s \vec{T} \cdot\left(\hat{n}_{1}-\hat{n}_{2}\right)$, the fitted signal for the leg-measurements.

${ }^{3}$ THETA is the angle between $\vec{T}$ and $\left(\hat{n}_{1}-\hat{n}_{2}\right)$, plotted on the horizontal axies of Figure V.1.

"DIFF is the difference between SIGNAL and DIPOLE, in mill1-degrees Kelvin.

${ }^{5} \mathrm{DCHI}$ and CHI-SQ are, respectively, the contribution to $S$ (eq. V.3) and the cumulative value of $S$. ( $S$ is distributed as $\chi^{2}$ of 73 DOF if the cosine hypothesis correctly models the data.) 
Table V.2 (continued)

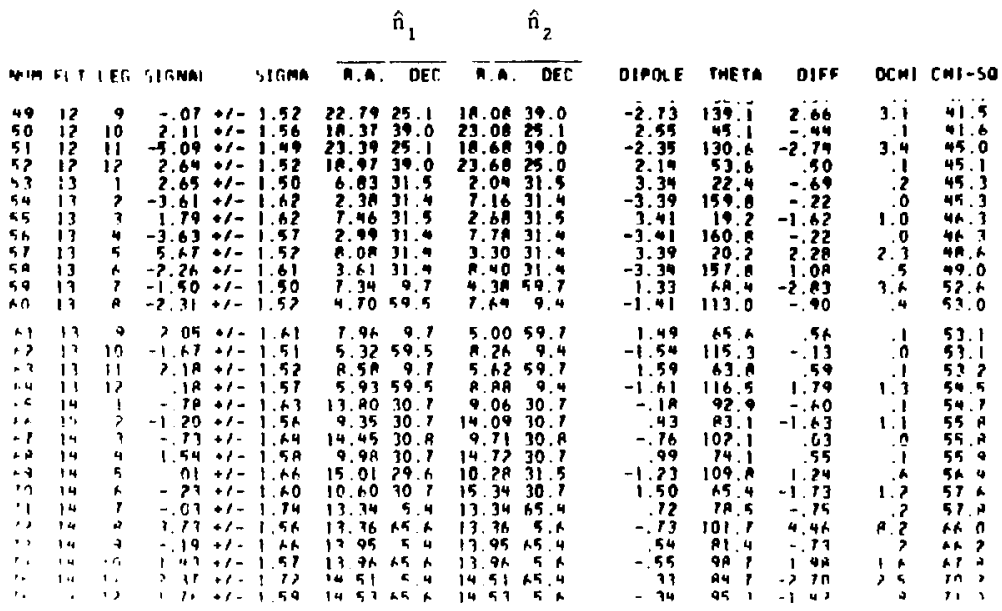




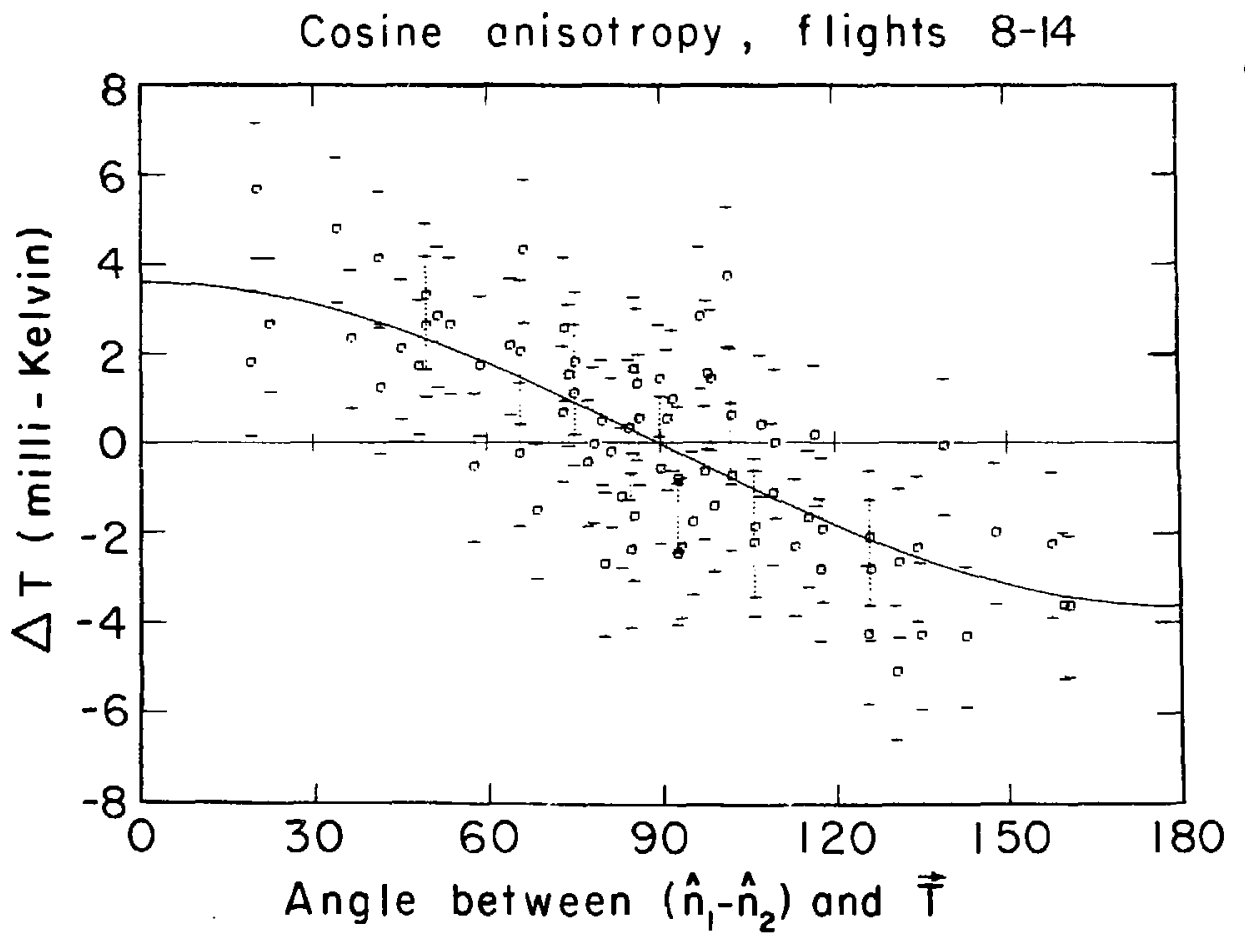




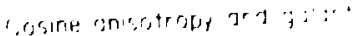

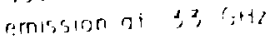
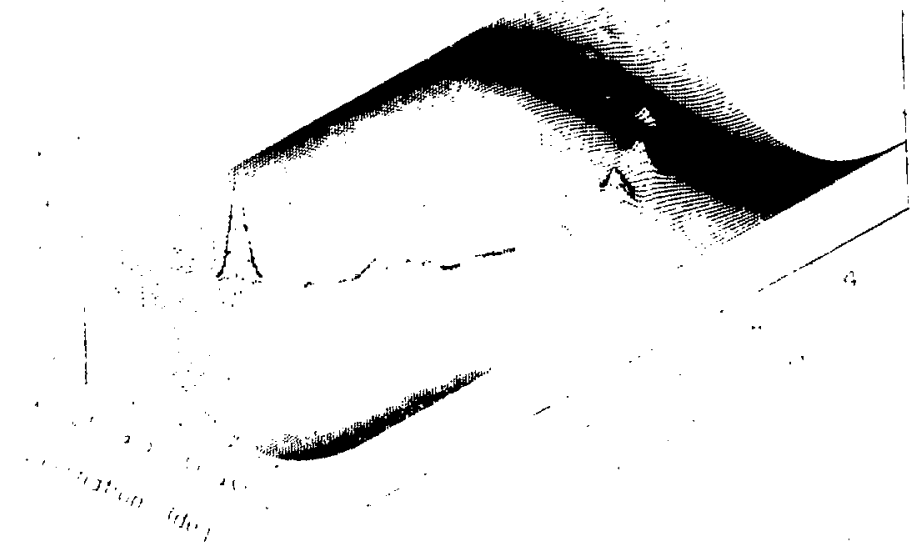


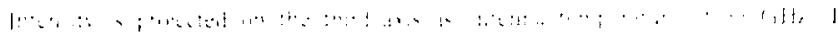

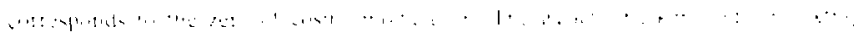

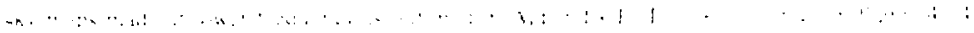

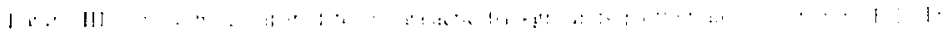

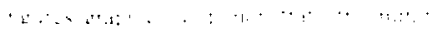

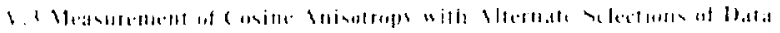

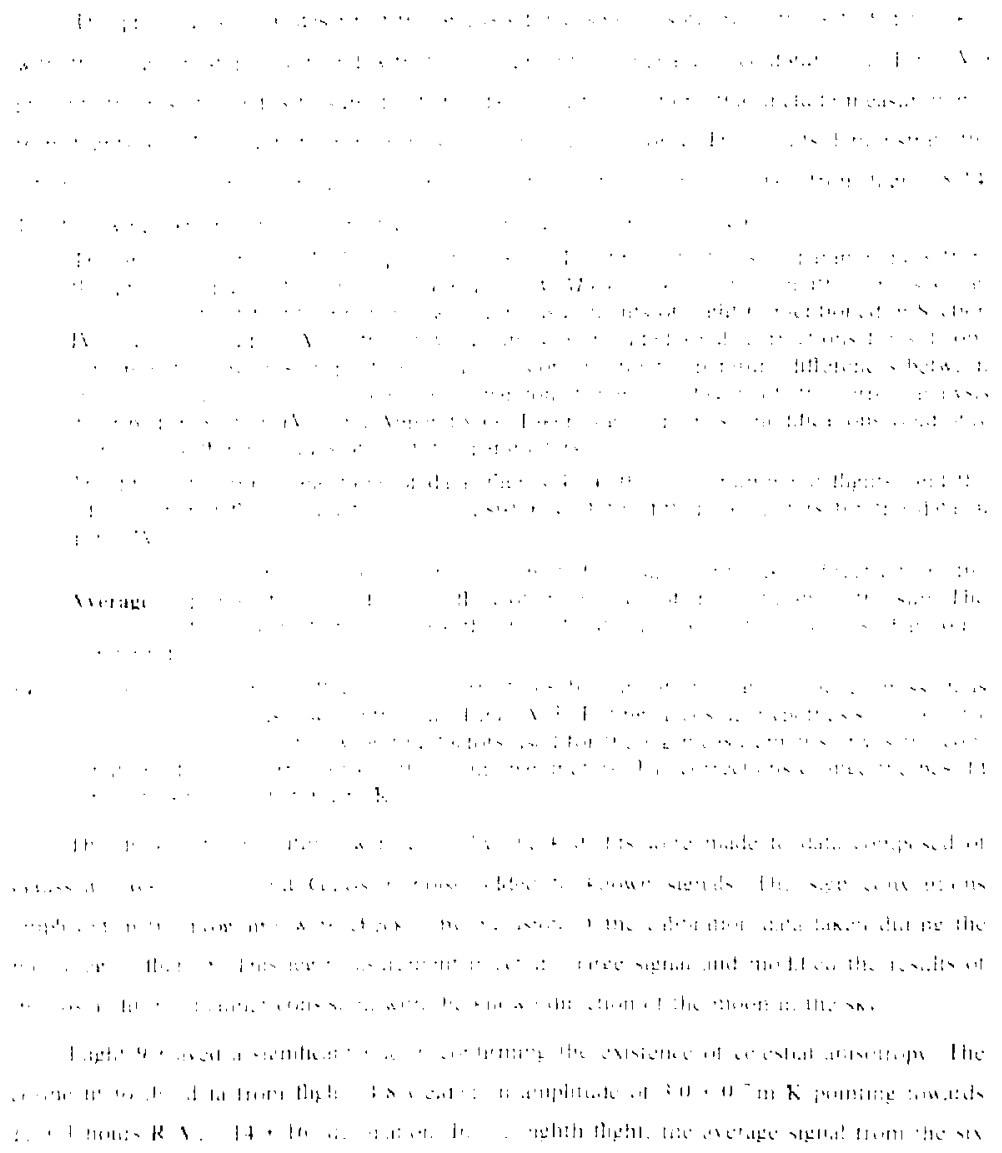




\begin{tabular}{|c|c|c|c|c|c|}
\hline \multicolumn{6}{|c|}{ Table V.3 - Fit to Cosine Anisotropy for Alternate Selections of Data ${ }^{\top}$} \\
\hline $\begin{array}{c}\text { Data } \\
\text { Selection }\end{array}$ & $\begin{array}{c}\text { Amplitude } \\
\left(\mathrm{m}^{\circ} \mathrm{K}\right)\end{array}$ & $\begin{array}{c}R . A . \\
\text { (hours) }\end{array}$ & $\begin{array}{c}\text { Dec. } \\
(9)\end{array}$ & $\overline{S I D O F}$ & $\begin{array}{c}\text { contidence } \\
\text { level }\end{array}$ \\
\hline $\begin{array}{l}\text { Fit. } 8 \cdot 14 \\
\text { Fit. } 4-11^{2} \\
\text { Flt. } 4-11 \\
\text { Fit. } 4-14 \\
\text { Fit. } 4,6,8, \\
10,12,14 \\
\text { Flt. } 5,7,9 \\
11,13\end{array}$ & $\begin{array}{c}3.61 \pm 0.43 \\
3.5 \pm 0.6 \\
3.37 \pm 0.47 \\
3.23 \pm 0.32 \\
2.51 \pm 0.68 \\
3.61 \pm 0.54\end{array}$ & $\begin{array}{c}11.23 \pm 0.37 \\
11.0 \pm 0.6 \\
10.57 \pm 0.50 \\
10.95 \pm 0.38 \\
11.25 \pm 0.72 \\
10.97 \pm 0.72\end{array}$ & $\begin{array}{c}19.0 \pm 6.0 \\
6 \pm 10 \\
5.0 \pm 6.6 \\
13.3 \pm 5.3 \\
13.8 \pm 10.5 \\
14.8 \pm 7.4\end{array}$ & $\begin{array}{c}71.0173 \\
91 / 77 \\
72.9 / 67 \\
121.5 / 1113 \\
79.3 / 51 \\
39.9 / 49\end{array}$ & $\begin{array}{l}55 \% \\
13 \% \\
29 \% \\
10 \% \\
0 \% \\
82^{5 \%}\end{array}$ \\
\hline $\begin{array}{l}\text { F/t. 8-14 } \\
\text { uncorrected dana } \\
\text { F/t. } 8-14 \\
\text { roll correction } \\
\text { Flt. } 8-14 \\
\text { salaxy correction }\end{array}$ & $\begin{array}{l}0.04 \\
0.13\end{array}$ & 20.4 & $\begin{array}{l}77.1 \\
-21.5\end{array}$ & & \\
\hline
\end{tabular}

'Errors quoted in this table are statistical only.

${ }^{2}$ Smoot, Gorenstein \& Muller, 1977

${ }^{3}$ Fit to data with no corrections for aircraft roll, galactic backgrounds, and no subtraction of motation offset.

${ }^{4}$ Results of cosine fit to corrections only. Inclusion of corrections changes cosine paramelers by less than one-standard-deviation. 
legs flown with north-south headings gave $2.41 \pm 0.65 \mathrm{~m} \%$ for the anisotropy between easiwest directions. The "east-ward" antenna direction, towards 11.5 hours R.A. and $+32^{\circ}$ declination, gave the hotter signal. This right ascension was determined by the take-off time cf $6 \mathrm{pm}$ PST, just at sunset. The ninth flight checked the $\cos \theta$ hypothesis by investigating the anisotropy of a new part of the sky. We arranged the take-off to be at $10 \mathrm{pm}$ PST so the east-ward antenna direction now point ed toward a region of the sky away from the (expected) hotter direction. The average of the six legs gave $-2.76 \pm 0.65 \mathrm{~m} \mathrm{~K}$, with the expected sign reversal.

The sign reversal ver fied the celestial origin of the anisolropy; it is unlikely that spurious signals inherent in the aircraft, or due to the earth's magnetic field or thermal microwave emission from the earth's surface would occur at this magnitude and exhibit this sign change. Moreover, the measurements taken in the east-west headings were small and consistent with the $\cos \theta$ effect from previous fights. Finally, the tenth flight was flown as a check of the results of the eighth flight. Take-off was at sunset, and the easl-ward antenna gave the hotter signal, as predicted.

\section{V.4 Comparison with Other Measurements}

Table V.4 compares two olher microwave measurements of cosine anisotropy with the results of this work. Corey and Henry employed balloon-borne platforms and collected their data with twin-antenna Dicke-type microwave radiometers. Both radiometers operatizd at frequencies where synchrotron emission from the Galaxy required substantial milli-degree Kelvit: corrections to the data. Their values of cosine anisotropy agree with the result reported here in magnitude and in right ascension, but disagree in declination; Corey's measuremen! points $40^{\circ}$ more to the south than our own, and Henry's points $50^{\circ}$ to the south. Corey's data were collected at the higher frequency and is probably less contaminated by systematic errors from the galactic synchrotron corrections.

We quantitatively compare our measurements with Corey's, checking the consistency of the results. The difference vector between the measurements should be statistically consistent with a vector of zero length. Combining the error matrices of the measurements yields the error matrix for this difference vector. We compute a quantity $S$ in analogy with eq. V.3 whose value is distributed as $3 x^{2}$ distribution for three DOF if the two measurements are consistent. This calculation is conveniently carried out in rectangular conrdinates where the errors are Gaussianly distributed. The details are described in Section H.2. Subtracting the measurements yields a difference vector whose magnitude is $2.5 \mathrm{~m} \mathrm{~K}$. The value of $S$ for this vector is 8.5 , for a confidence level of $3.5 \%$. This indicates that the measurements agree, but perhaps either or both experiments underestimate their errors by about $\sqrt{8.5 / 3}=1.7$ 


\begin{tabular}{|c|c|c|c|c|}
\hline Reference & $\begin{array}{l}\text { Frequency } \\
\quad(\mathbf{G H z})\end{array}$ & $\begin{array}{l}\text { Amplitude } \\
\left(\mathbf{m}^{\circ} \mathrm{K}\right)\end{array}$ & $\begin{array}{c}\text { R.A. } \\
\text { (hours) }\end{array}$ & $\begin{array}{l}\text { Dec. } \\
\text { (deg.) }\end{array}$ \\
\hline Henry, 1971 & 10.2 & $3.2 \pm 0.8$ & $10.5 \pm 4$ & $-30 \pm 25$ \\
\hline Corey, 1978 & 19.0 & $2.9 \pm 0.7$ & $12.3 \pm 1.4$ & $-21 \pm 21$ \\
\hline This work & 33.0 & $3.61 \pm 0.54$ & $11.23 \pm 0.46$ & $19 \pm 7.5$ \\
\hline \multicolumn{5}{|c|}{$\begin{array}{l}\text { Table V.4a-Corey's result in reciangular celestial coordinates } \\
\text { (Corey, 1978) }\end{array}$} \\
\hline & $\Gamma_{x}(\mathrm{~m} \mathrm{~K})$ & $T_{y}(\mathrm{~m} \mathrm{~K})$ & $T_{z}(\mathrm{~m} \mathrm{~K})$ & \\
\hline & $-2.70 \pm 0.85$ & $-0.22 \pm 1.00$ & $-1.02 \pm 0.92$ & \\
\hline \multicolumn{5}{|c|}{ Correlanion Coefficients } \\
\hline & $C_{(x, 1)}$ & $C_{i, 2}$ & $r_{1, .21}$ & \\
\hline & 0.39 & -0.44 & -0.55 & \\
\hline
\end{tabular}

\section{V.5 Limits on Quadrupole Anisotropy}

One of the motivations for investigating angular variations in the $3 \%$ background radiation is the search for higher order multipoles in $7(\hat{n})$. As discussed in Chapter $I$, the existence of multipole anisutropy higher than dipole would present a challenge to the Cosmological Prınciple. We have analyzed the data for evidence of a quadrupole anisotropy.

The quadrupole distribution, $Q(\hat{n})$, is formed from a linear combination of five basis functions, $g_{i}(\hat{n})$,

$$
Q(\hat{n}) \equiv \sum_{i=1}^{5} A_{i} \varphi_{1}(\hat{n})
$$

Table V.S defines the basis functions in terms of the second order, $l=2$ spherical harmonics. The five parameters, $A_{i}$, are the rms amplitudes of quadrupole anisotropy expressed in millidegrees Kelvin. Adding $Q(\tilde{n})$ to eq. V.I models the sky temperature as the sum of dipole plus quadrupole anisotropy. Thus,

$$
T(\hat{n})=T_{0}+\vec{T} \cdot \hat{n}+Q(\hat{n})
$$

Minimizing the following expression for $S$ yields the three dipole and tive quadrupole parameters:

$$
S-\sum_{i=1}^{M} \frac{\left\lfloor\Delta T_{3 \mathbf{x}}-\vec{T} \cdot\left(\hat{n}_{1}-\hat{n}_{2}^{\prime}\right)-\left(Q\left(\hat{n}_{i}\right)-Q\left(\hat{n}_{2}^{i}\right)\right)\right]}{\sigma_{i}^{2}}
$$




\begin{tabular}{|c|c|c|}
\hline \multicolumn{3}{|c|}{$\begin{array}{l}\theta \text { is the polar angle measured from north celestial pole. } \\
\phi \text { is the azimuthal angle, measured from } 0 \text { hours } R \text {.A. }\end{array}$} \\
\hline Funrtion & Spherical Harmonir & Angular dependence \\
\hline$q_{1}(\theta, \phi)$ & $\sqrt{4 \pi} Y_{20}$ & $\sqrt{5}\left(\frac{3}{2} \cos ^{2} \theta-\frac{1}{2}\right)$ \\
\hline$\varphi_{2}(\theta, \phi)$ & $\sqrt{4 \pi} \frac{Y_{21}+Y_{2-1}}{\sqrt{2}}$ & $-\sqrt{15} \sin \theta \cos \theta \cos \phi$ \\
\hline $4,3(\theta, \phi)$ & $\sqrt{4 \pi} \frac{Y_{21}-r_{2-1}}{1 \sqrt{2}}$ & $-\sqrt{15} \sin \theta \cos \theta \sin \phi$ \\
\hline$\varphi_{4}(\theta, \phi)$ & $\sqrt{4 \pi} \frac{Y_{22}+Y_{2 \cdots i}}{\sqrt{2}}$ & $\frac{\sqrt{15}}{2} \sin ^{2} \theta \cos 2 \phi$ \\
\hline $4 s(\theta, \phi)$ & $\sqrt{4 \pi} \frac{Y_{22}-Y_{2-2}}{i \sqrt{2}}$ & $\frac{\sqrt{15}}{2} \sin ^{2} \theta \sin 2 \phi$ \\
\hline
\end{tabular}

Table V.6 presents the fitted resuits for this eight parameter hypothesis for data from flights 8 14. II Is worthwhile comparing the cosine (dipole) parameters in Table V.] with the dipole parameters listed in Table V.6. For the dipole fit alone, $T$ : dominates the anisotropy signal with a value of $-334 \pm 0.44 \mathrm{~m} \mathrm{~K}$. In the combined fit of dipole with quadrupole, the $T_{z}$ parameter retains its significance in the presence of the competing quadrupole hypothesis, with a value of $-2.32 \pm 0.66 \mathrm{~m} \mathrm{~K}$. This is evidence that the major component of global anisotropy is correctly interpreted as a dipole signal, and cannol be due to a quadrupole signal from a partially surveyed sky.

The $A$, parameters do not indicate the presence of quadrupole anisotrop,:

(1) The values of the parameters $A$, listed in Table V.6 are consistent with zero. (The large correlated errors in $A_{1}$ and $T_{2}$ will be explained presently ds due to the restriction of sky coverage to one hemisphere.) 


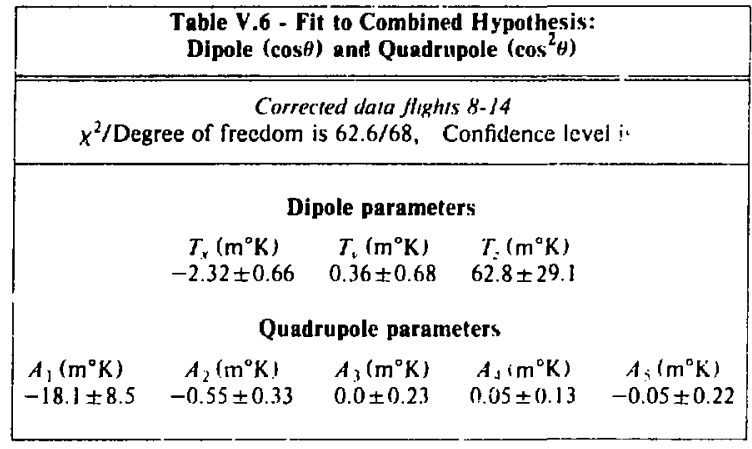

\begin{tabular}{|c|c|c|c|c|c|c|c|c|}
\hline \multicolumn{9}{|c|}{ Correlation coefficients } \\
\hline$T_{1}$ & $T_{r}$ & $T_{i}$ & $A_{1}$ & $A_{2}$ & $A_{3}$ & $A_{4}$ & $A_{5}$ & \\
\hline 1.0 & $\begin{array}{l}0.12 \\
1.0\end{array}$ & $\begin{array}{c}-0.04 \\
-0.29 \\
1.0\end{array}$ & $\begin{array}{r}0.03 \\
0.29 \\
-1.00\end{array}$ & $\begin{array}{r}0.80 \\
-0.34 \\
0.01\end{array}$ & $\begin{array}{r}-0.24 \\
-11.68 \\
0.31\end{array}$ & $\begin{array}{r}0.38 \\
-0.03 \\
-1180\end{array}$ & $\begin{array}{r}0.12 \\
0.76 \\
-0.119\end{array}$ & $\begin{array}{l}T \\
T \\
I\end{array}$ \\
\hline & & & 1.0 & $\begin{array}{l}0.00) \\
1.0\end{array}$ & $\begin{array}{c}-0.31 \\
0.30 \\
I .0\end{array}$ & $\begin{array}{c}0.30 \\
-0.23 \\
-0.24 \\
1.0\end{array}$ & $\begin{array}{c}1.08 \\
-(1.42 \\
-11.34 \\
-0.14 \\
1.0\end{array}$ & $\begin{array}{l}A_{1} \\
A_{2} \\
A_{3} \\
A_{4} \\
A_{3}\end{array}$ \\
\hline
\end{tabular}


(2) The value of $S$ for the 8 parameter fit is 62.6 compared to $S=71.0$ for the fit to the three parameter cosine hypothesis alone. This demonstrates, without refe:ence to a particular parametrization, that the inclusion of the quadrupole hypothesis is not required by the data. The change in $S$ belween these fits is distribuled as $\chi^{2}$ for five DOF if the quadrupole amplitudes have zero mean (Marin, 1971, pg. 146). Since the confidence level for $S$ of 8.4 with five DOF is $15 \%$, we conclude that the data is consistent with zerc mean quadrupole amplitude.

(3) The dipole parameters listed in Table V.6 are consistent with those in Table V.l. This was directly checked by evaluating the difference vector of cosine anisotropy belween the data fitted to the cosine hypothesis alone and for the data fitted to the combined hypothesis of cosine and quadrupole. The rms errors on the vector difference was then computed by repeatedly "jittering" the input leg-measurements and re-evaluating the difference vector each time. The resulting difference and errors, in milli-degree Kelvin, are:

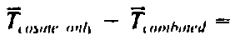

$(-1.03 \pm 0.54) \hat{x}+(0.31 \pm 0.61) \hat{i}+(-602 \pm 30.3)=$

It is natural then to ask what limit the data places on quadrupole anisotropy in the cosmic background radiation. The lack of sky coverage in the southern hemisphere complicales this calculation " fata flights were flown from $37^{\circ}$ north latitude where the most southernly declinaเo: $\quad$ the artennas pointed was about $+7^{\circ}$, Figure 1ll.3. Sky coverage restricted to the northein hemisphere cannot distinguish between a $\cos \theta$ angular dislribution ( $z$ component of dipole) and a $\cos ^{2}$ o distribution $\mathrm{iz}^{2}$ component of quadrupole). This is because the sum of these functions cancels (within the arors) in the northern hemisphere, while adds with opposite sign in the suuthern hemisphere. Thus the amplitude of the z component of the dipole fit, $T_{z}$, and the $z^{2}$ component of the quadrupole fit, $A_{1}$, have large correlated errors*. A fit that included simulated sky coverage in the southern hemisphere showed that only one flight from an airfield situated telow the earth's equator is enough to break this correlation, yielding millidegree Kelvin significance for all eight parameters.

Despite the correlation between $A_{1}$ and $T_{2}$, the lata does place a significant limil on the remaining 4 amplitudes of the tasis functions $\varphi_{t}(\hat{n})$. In general we caln express this limit as the rms amplitude of a quadrupole distu ibution, defined as

$$
Q \equiv\left(\frac{1}{4 \pi} \iint Q^{2}(\hat{n}) d \Omega\right)^{1 / 2}=\left(\sum_{i=1}^{5} A_{i}^{2}\right)^{1 / 2}
$$

Restrictirg eq. Y.10 to the four amplitudes determined with good sensitivity, we define $Q^{\prime}$ as

"The Jata in Table V.6 does neasure the sum of the amplitudes of $T_{2}$ and $A_{1}$ with small errors. To find the sum of a $\cos \theta$ and $\cos ^{2} \theta$ anisotropy, we firat renormalize $A_{1}$ according to the definition of $a_{1}$ given in Table $\checkmark$.5. The sum of the components is then given by

$$
T_{2}+\sqrt{5} \frac{3}{2} A_{1}=(62.8 \pm 29.1)+\sqrt{5} \frac{3}{2}, 18.1 \pm 8.51=2.1 \pm 0.6 \mathrm{~m} \mathrm{~K}
$$

The nearly complete anti-correlation between the $T_{2}$ and $A_{1}$ parameters accounis for the small errorj on their sum. 


$$
Q^{\prime} \equiv\left(\sum_{i=2}^{5} A_{i}^{2}\right)^{1 / 2}
$$

The data from Table V.5 gives

$$
Q_{\text {data }}^{\prime}=0.56 \mathrm{~m} \mathrm{~K}
$$

A monte-carlo simulation generates the distribution of $Q^{\prime}$ by first adding independent error signals to each leg-measurement, simulating the effect of receiver noise. Repeating this procedure generates several thousand sets of "jittered" leg-measurements, and the best fit solution for $A$, and $\vec{T}$ from each set yields values of $Q^{\prime}$. The distribution of these values shows that $90 \%$ of the time $Q^{\prime}$ is less than $1.1 \mathrm{~m}$ K. Thus at the $90 \%$ confidence level we expect that future measurements of these four quadrupole amplitudes will yield a net rms amplitude of less than $1.1 \mathrm{~m} \mathrm{~K}$.

The lack of quadrupoie anisotropy puts a limit on global deviations from isotropy. As mentioned in Section 1.5, rotation of the distant matter in the Universe relative to the local inertial frame would yield a quadrupole distribution. For a present mass density of $2 \times 10^{-29} \mathrm{gm} / \mathrm{cm}^{3}$, the limit of quadrupole anisotropy at one part in 3000 yields a limit of $10^{-11} \mathrm{rad} / \mathrm{yr}$ (Hawking, 1369). In inother cortext Burke has speculated that the Universe may be permeated by gravitational radiation with wavelengths encompassing galaxies. If the Milky Way is embedded in a megaparsec wavelength gravitational wave, then that would give rise to a distortion of the microwave background with a quadrupole component (Burke, 1975). According to Burkes's formula, the limit on quadrupole anisotropy means that the energy density of long wavelength gravitational radiation is insufficient to close the Universe (Smoot, Gorensicin \& Muller, 1977).

\section{V.6 Limit on Sky-roughness on a $7^{\circ}$ Angular Scale}

The following analysis places a $0.5 \mathrm{~m} \mathrm{~K}$ upper limit on the amplitude of uncorrelated fluctuations (sky-roughness) in the $3 \%$ background on an angular scale of the antenna beam width, about $7^{\circ}$. Including a term for sky-roughness in eq. V.1 gives

$$
T(\hat{n})=T_{o} \cdot \vec{T} \cdot \hat{n}+T_{s}(\hat{n})
$$

where $T_{s}(\hat{n})$ is the term describing sky-roughness. We take $T_{s}(\hat{n})$ to have the following statistical properties (the indicated averages are understood to be taken over areas in the sky separated by more than the $7^{c}$ antenna beam width):

$$
\begin{aligned}
& <T_{s}(\hat{n})>\equiv 0 \\
& <T_{s}^{2}(\hat{n})>\equiv \sigma_{s}^{2}
\end{aligned}
$$




$$
<T_{s}\left(\hat{n}_{i}\right) T_{s}\left(\hat{n}_{j}\right)>\equiv 0 \quad \text { if } \hat{n}_{i} \cdot \hat{n}_{j}>\cos ^{-1}(79
$$

Note that $\sigma_{s}$ is the rms fluctuation of the absolure sky temperature. This means that the difference temperature between two directions in the sky, which is what the radiometer measures, will fuctuate by $\sqrt{2} \sigma_{s}$.

If there is reason to expect, a priori, a sky-roughness $\sigma_{s}^{2}$ on $7^{\circ}$ angular-scale, then we should quadrature the errors on the points in Figure V.1 with $2 \sigma_{s}^{2}$ before we compute $S$, the cumulative squared deviation from the fit. This will obviously reduce $S$ :

$$
S_{\text {rouph }}=S \frac{\sigma^{2}}{\sigma^{2}+2 \sigma_{s}^{2}}
$$

where

$S$ is 71.0 from the cosine fit.

$\sigma^{2}$ is $(1.6 \mathrm{~m} \mathrm{X})^{2}$, the mean value of $\sigma_{1}^{2}$ from the leg-measurements in flights 8-14.

$2 \sigma_{s}^{2}=\left\langle\left[T_{s}\left(\hat{n}_{s}\right)-T_{s}\left(\hat{n}_{j}\right)\right]^{2}\right\rangle$ from eq. V. 14 .

Now assuming that the estimate of receiver noise is correct, we put a limit on $\sigma_{s}$ by increasing its value in eq. V.15 until the confidence level approaches $100 \%$. Table V.7 lists the values of $\sigma_{s}$ for corresponding values of the confidence level. The tabulation shows that increasing $\sigma_{s}$ by more than $0.5 \mathrm{~m} \mathrm{~K}$ increases the confidence level past $90 \%$. Thus, if the skyroughness is $0.5 \mathrm{~m}$ K or more, we would measure $S=71.0$ or greater $90 \%$ of the time (rather than $55 \%$ for $\sigma_{s}=0$ ). Thus we rule out a prediction of sky-roughness greater than one part in 6000 of $3 \mathrm{~K}$ on a $7^{\circ}$ angular-scale with $90 \%$ confidence.

\begin{tabular}{|l|ll|l|}
\hline \multicolumn{3}{|c|}{$\begin{array}{r}\text { Table V.7 - Limits on Sky-roughness } \\
\text { on a 7 }\end{array}$ Angular Scale } \\
\hline \hline$\sigma_{5}(\mathrm{~m} \mathrm{~K})$ & $\frac{\sigma_{s}}{\sigma}$ & $S_{\text {ruug }}$ & Confidf nce level \\
\hline & & & \\
0 & 0 & 71 & $55 \%$ \\
0.50 & 0.31 & 59 & $90 \%$ \\
0.60 & 0.37 & 55 & $95 \%$ \\
0.77 & 0.48 & 48 & $99 \%$ \\
& & & \\
\hline
\end{tabular}

The lack of sky-roughness re-emphasizes the problem of accounting for the high degree 
of isotropy in the microwave background radiation. In section 1.5 it was pointed out that in the standard picture it seems impossible for physical processes acting prior to the decoupling to isotropise the radiation on distances that now appear a few degrees apart in the sky. The amplitude and angular structure of the as yet undiscovered sky-roughness may be crucial in understanding the physical isotropising mechanisms, and will likely fix the initiai conditions determining galaxy formation subsequent to the epoch of decoupling.

\section{V.7 The Motion of the Sun and Nearby Groups of Galaxies Relative to the $3^{\circ} \mathrm{K}$ Background}

After setting limits on higher order multipole anisotropy we return to the cosine anisotropy and interpret it as due to the motion of the sun relative to the sources - "last scat'erers" might be $\mathrm{tl}$. more appropriate term - of the $3 \mathrm{~K}$ radiation. It may seem that discussing the peculiar motion of the earth takes us away from cosmology proper, but this is not the case. The cosine anisotropy identifies the local co-moving coordinate frame, and is tl.i prime link in computing the peculiar motions of the Milky Way, the local group, and perhaps even larger "super clisters" spanning cosmological distances.

We begin by interpreting the cosine anisotropy as due to the motion of the sun. The following expression, from eq. 1.1, gives the magnitude of a velocity relative to an isotropic thermal background radiation given the radiation temperature and the magnitude of cosine anisotropy:

$$
|\vec{V}|=\frac{|\vec{T}| \cdot c}{T_{0}} \quad ; \quad|\vec{T}| \ll T_{0}
$$

where

$|\vec{b}|$ is the magnitude of velocity relative to the thermal background.

$|\vec{T}|$ is the amplitude of cosine anisotropy.

$c$ is the velocity of light.

$T_{0}$ is the temperature of the thermal background in the frame of isotropy.

Thus from the data in Table V.1, we arrive at

$$
\begin{aligned}
|\bar{V}| & =\frac{3.61 \pm 0.54 \times 10^{-3} \mathrm{~K}}{3 \mathrm{~K}}\left(\frac{3 \mathrm{~K}}{T_{0}}\right) 3 \times 10^{5} \mathrm{~km} / \mathrm{sec} \\
& =361 \pm 54\left(\frac{3 \mathrm{~K}}{T_{0}}\right) \mathrm{km} / \mathrm{sec}
\end{aligned}
$$

Table V.8 summarizes the jarameters of cosine anisotropy interpreted as due to the motion of the sun relative to the sourzes of the $3 \mathrm{~K}$ background radiation. 


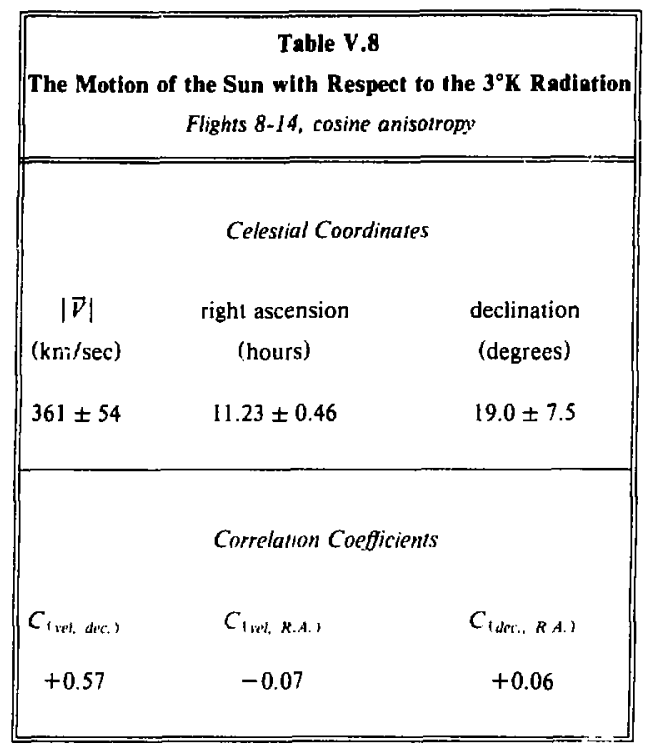

From analysis of motions of globular clusters and nearby stars the inferred value for the circular velocity of the sun about the center of the Milky Way Galaxy is about $250 \pm 40 \mathrm{~km} / \mathrm{sec}$ toward $I^{\prime \prime}=90^{\circ}$, and $b^{I I}=0^{\circ}$ (Schmid, 1965). The motion of the Milky Way relative to the centroid of the "local group" of galaxies is also known, and is about $50 \mathrm{~km} / \mathrm{sec}$, small by comparison to the sun's motion about the Milky Way. The local group (LG) is a collection of about 20 galaxies generally taken to be within a radius of about 1 Mpc from the Milky Way. The net motion of the sun relativi to the centroid of the LG is reasonably well established to be 300 $\mathrm{km} / \mathrm{sec}$ in the direction $l=90^{\circ}, b=0^{\circ}$ (de Vaucouleurs \& Peters 1968, de Vaucn'leurs 1972; Yahl, Tammann \& Sandage, 1977). Unless otherwise specified, $(I, b)$ are underslood as the new galactic coordinates $\left(/^{\prime \prime}, b^{\text {Il }}\right)$.

Although the speed of the sun relative to the local group is comparable to that of the sun relative to the $3 \%$ background, inspection of Table $\%$ shows that the directions differ, the angle of separation $\mathrm{r}^{-i n g}$ about $110^{\circ}$. Thus the cosine anisotropy of the $3 \mathrm{~K}$ radiation is not accounted for by the motion of the sun about the Milky Way, or relative to the LG. The resulting difference velocity, the motion of the LG relative to the $3 \%$ background, is large, over 500 $\mathrm{km} / \mathrm{sec}$, Table V.10. 


\begin{tabular}{|c|c|c|c|c|}
\hline Speed & \multicolumn{2}{|c|}{ Celestial coordinates } & \multicolumn{2}{|c|}{ Galactic coordinates } \\
\hline$(\mathrm{km} / \mathrm{sec})$ & R.A.(hrs.) & dec. $(9)$ & $f^{\prime \prime \circ}$ & $b^{\prime \prime \circ}$ \\
\hline \multicolumn{5}{|c|}{ Motion of Sun relative to Local Group } \\
\hline $300 \pm 50$ & 21.2 & $+48^{\circ}$ & $90^{\circ}$ & $0^{\circ}$ \\
\hline \multicolumn{5}{|c|}{ Motion of Sun relative to Galaxies ${ }^{1} ; 600<c z<1800 \mathrm{~km} / \mathrm{sec}$} \\
\hline $350 \pm 50$ & 11.5 & $+32^{\circ}$ & $200^{\circ}$ & $72^{\circ}$ \\
\hline \multicolumn{5}{|c|}{ Molion of Sun relative to Galaxics ${ }^{2} ; 3500<c z<6500 \mathrm{~km} / \mathrm{sec}$} \\
\hline $600 \pm 125$ & $2.13 \pm 1.33$ & $53^{\circ}$ & $135^{\circ}$ & $-8^{\circ}$ \\
\hline & & . & & \\
\hline 1977. & & & & \\
\hline
\end{tabular}

${ }^{2}$ Ruhin et. al., $1976 b$.

What are the motions of larger groupings of galaxies relative to the $3 \% \mathrm{~K}$ radiation? De Vaucouleurs (de Vaucouleurs, 1977, and references therein) and Rubin (Rubin et, al., 1976a,b) have each analysed the red shifts and brightnesses of galaxies external to the LG for evidence of anisolropy in the velocity field. They both choose galaxies of selected morphological types, restricled to a specified range of red shifts. Table V.9 also lists the results of their analyses of the local motion relative to each shell of galaxies and the range of red shifts that their samples span.

Interpreting these results as true measures of motion, we subtract the velocity of the sun with respect to the galactic groupings from the velocity of the sun with respect to the $3 \mathrm{~K}$ radiation. Table V.10 presents these vector differences, listing the velocily of the sun and the velocities of the galactic groupings relative to the $3^{\circ} \mathrm{K}$ background. Both the LG and the two galactic shell samples have motions relative to the $3 \% \mathrm{~K}$ background of comparable magnitude and all are significantly different from zero. This is surprising, because one might expect that the larger the 
group of galaxies sampled the smaller their velocity relative to the $3 \mathrm{~K}$ background should he. The more distant shell analysed by Rubin et. al. encompasses a volume containing some 50 million galaxies. But the analyses of de Vaucouleurs and Rubin et. al. are disputed. Schechter (Schecher, 1977) has criticized the statistical analysis of the Rubin resuit, claiming that they have underestimated their errors. And there has been a continuing dispute concerning the existence of anisotropy in the local galactic velocity field out to red shifts, $c z$, of about 6000 $\mathrm{km} / \mathrm{sec}$ (e.g. Sandage \& Tammann, 1975; de Vaucauleurs, 1976).

\begin{tabular}{|c|c|c|c|c|}
\hline \multirow{2}{*}{$\begin{array}{c}\text { Speed } \\
(\mathrm{km} / \mathrm{sec})\end{array}$} & \multicolumn{2}{|c|}{ Celestial coordinates } & \multicolumn{2}{|c|}{ Galactic coordinates } \\
\hline & R.A. (hrs.) & dec. $(9)$ & $l^{110}$ & $b^{1 / 0}$ \\
\hline \multicolumn{5}{|c|}{ Motion of sun relative to $3 \mathrm{~K}$ background radiation } \\
\hline $362 \pm 54$ & $11.2 \pm 0.5$ & $19 \pm 8^{\circ}$ & $229 \pm 19^{\circ}$ & $66.6 \pm 7^{\circ}$ \\
\hline \multicolumn{5}{|c|}{ Motion of Local Group Relative to $3 \mathrm{~K}$ Radiation } \\
\hline $534 \pm 75$ & 10.47 & $-1 i^{0}$ & $257^{\circ}$ & $+38^{\circ}$ \\
\hline \multicolumn{3}{|c|}{ Motion of Galaxies ${ }^{1}, 600<c z<1804$} & \multicolumn{2}{|c|}{ Relative to $3 \%$ Radiation } \\
\hline $381 \pm 75$ & 9.3 & $-49^{\circ}$ & $270^{\circ}$ & $0^{\circ}$ \\
\hline \multicolumn{5}{|c|}{ Motion of Galaxies ${ }^{2}, 3500<c z<6500$. Relative to $3 \mathrm{~K}$ Radiation } \\
\hline $745 \pm 140$ & $12.7 \pm 1.33$ & $-29^{\circ}$ & $300^{\circ}$ & $30^{\circ}$ \\
\hline
\end{tabular}

' Combine velocity from cosine anisotropy with measurement of de Vaucouleurs, 1977.

${ }^{2}$ Combine velocity from cosine anisotropy with measurement of Rubin et. al., $1976 b$.

It is worth pointing out that these large velocities of galactic groupings cannot be reasonably accounted for as a residual motion from the time of galaxy formation at about $z=1500$. In an expanding Universe that is isotropic and homogeneous the momentum of a test particle 
decreases in time relative to the co-moving coordinate system. Drifting past co-moving observers, the test particle asymptotically approaches the coordinate point whose recessional velocity equals its own peculiar velocity (Pechles, 197/, pg. 169). A present speed of 500 $\mathrm{km} / \mathrm{sec}$ would require relativistic velocity at the epoch of decoupling, $z=1500$.

De Vaucouleurs has claimed that the LG is a member of a larger super-cluster which makes its presence known by a distortion of the local Hubble flow fde faucoulewrs, 1958, 1972 ; 4. Vourutieurs \& Peters, 196\%). The supercluster is centered on the Virgo Clusicr (12 hrs. 28' R.A., $12^{\circ} 40^{\circ}$ dec.) of some thousind salaxies. The cluster's mean recessional velocity is about $1050 \mathrm{~km} / \mathrm{sec}$ (de Vaucouleurs \& de Vaucouleurs, 1973; Sundage \& Tammam, 1976), and it is at a distance of about 20 Megaparsecs. From Table V.10 the velocity of the LG relative to the $3 \%$ background points within $38^{\circ}$ of the direction towards the Virgo cluster, yielding a velocily

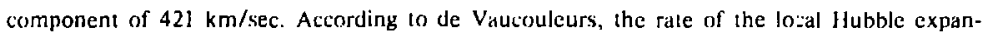
sion in the direction of the Virgo cluster is reduced some $250 \mathrm{~km} / \mathrm{sec}$ (de Vaucouleurs \& Polars. (96, $\$$ I. ISut Visyanathar, and Sandage have analysed the relationshop between the color and absolute magnitude for type $\mathrm{E}$ and $\mathrm{SO}$ galaxies in nine nearby clusters, including Virgo, thal have $r_{i}$ ssional velocilies of up $1010,000 \mathrm{~km} / \mathrm{sec}$. In the Hubble ri ugram generaled by their analysis they find that the Virgo cluster departs from the mean solution by less than $\pm 25 \mathrm{~km} / \mathrm{sec}$

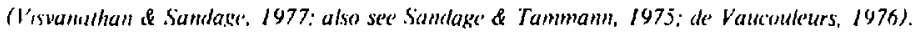

\section{V.8 Conclusion}

The principal result of this work is the detection of cosine unisolropy in the $3 \mathrm{~K}^{\mathrm{K}}$ cosmic ackerouna radiation. The magnitude of the anisotropy is $3.61 \pm 0.54 \mathrm{nt} \mathrm{K}$, one part in 800 of $3 \mathrm{~K}$, in a direction not accounted for by the velocity of the sun abuut the Galaxy or relative to the local group. The inferred motion of the sun relative to the $3 \mathrm{~K}$ radiation is $36 \mathrm{l} \pm 54 \mathrm{~km} / \mathrm{sec}$, 1owards $11.23 \pm 0.46$ hours R.A., $19.0 \pm 7.5^{\circ}$ declination.

The limits the data places on most components of quadrupole anisolropy are aboul 1 part in 3000 of $3 \%$, or less than one part in 3 of the amplitude of cosine anisotropy. The limits the data places on "sky-roughness" on a $7^{\circ}$ angular scule is aboul one part in 6000 of $3 \%$, less than ore part in 6 of the cosine amplitude. The cosine anisotropy identifies the local co-moving frame with respect to which the dynamics of the neighboring galaxies should be best understood. However, the "discovery" of the local frame of rest seems to exacerbate the already existing conflicts in the determinution of the local velocity field of galaxies. The lack of additional anisotropy re-emphasizes the theoretical problem of accounting for the extreme isotropy of the radiation.

Two important extensions of this work are being planned. Olsservations in the southern hemisphere arc a crucial check of the global nature of cosine anisotropy, and would complete 
the measurement of the quadrupole parameters. These fights will take place pending final approval from the National Aeronautics and Space Administration (NASA).

Secondly, a next generation experiment is being designed as pari of a proposed satellite, the Cosmic Background Explorer (COBE). Preliminary design studies are being undertaken by a collaboration including the astrophysics group at the Lawrence Berkeley Laboratory, which is responsible for the work reported here. The plan is for a year long survey of the entire celestial sphere at four microwave frequencies. With increased sensitivity afforded by the long exposure ant improvements in receiver design, it will be possible to search for higher moments of anisotropy with a sensitivity of about one part in 50 of the $3.6 \mathrm{~m}$ K cosine amplitude.

The discovery of the $3 \mathrm{~K}$ cosmic background radiation continues inspiring vigorous experimental investigation. We are privileged to live and work in an era when our fundamental origins have become open to scientific inquiry. 


\title{
Detection of Anisotropy in the Cosmic Blackbody Radiation
}

\author{
G. F. Smoot, M. V. Gorensteln, and R. A, Muller \\ Laurence Berkelev Labovalory and Space Sripmces Labovalory. Vintersity cf Califonia. \\ Berkelev. Califomia 91720 \\ (Recetved o July 1977 )
}

\begin{abstract}
We have detected antsotropy In the cusmic blackbody radiat lon with a $39-6 \mathrm{~Hz} 10.4 \mathrm{~cm}$ twin-antenne Dicke radiometer fown to an altitude of $20 \mathrm{~km}$ aboard a l:-2 aircraft. In data distributed over two-thirds of the northern hem'sphere, we vhecrve an anisutropy

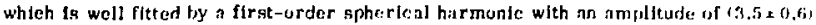

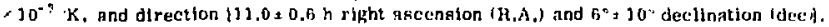
Thls observation is readily interproted as due to motion of the carth relative to the radiation with a velocity of $390,5,0 \mathrm{~km} / \mathrm{sec}$.
\end{abstract}

The observed isoiropy of the $3{ }^{5} \mathrm{~K}$ cosmic black!ndy radiation to about one part in $10^{3}$ is the strongest ayldence in support of the cosmological principle, the basic assumption of cosmology that the universe is isotropic and homogeneous on at large scale. Anisotropy at the $10^{-7}-10^{-1}$ level is expected to exist from the Doppler shift ine in the molion of the earth with respect to the arejet matter which emitted the radiation.' Aniisen r.,pie's would also exist if the re were nonsymnotric expansion of the universe nr large-scale irrepularities in the distribution of matter or enc.5y. Until recontly, interference from galactic rolitsions had preventer anicratropy in the cosme blickloxdy radiation from being unambiguously nbserved. ${ }^{2}$ Prelimitary reports of a positive effect have been made now by Corey and Wilkenson" itrid t:v this group." We present here the results c.f . survey spanning approximately two-thirds of ihe northrern hemisphere, taken at $0.9 \mathrm{~cm}$, it wavelength at which the galactic background is smitl.

The experiment was conducted in a series of eight flights aboard the NASA-Ames Earth Survey (U-2) Aircraft. Anisotropy in the cosmic ridiation was detected at $33 \mathrm{GHz}$ with a twin-antennia Dirke radioneter which measured the difference in s. ky temperature between two regions 60 apart anci on rpposite sides of the zenith. The best recciver, used on the final four flights, has a sensitivily limited by thermal noise with an rms fluctuation of $0.044^{\circ} \mathrm{K} / \mathrm{Hz}^{1 / 2}$. The receivers used on the earlier flights had rmg fluctuations about twice as large. The apparatus is shown schemat ic ally in Fig. 1; detalle of its design and construction will be given elsewhere."

Fffort was made in the design of the apparatus to reduce all expected systematic errors well below the millikelvin level. To achieve the desired sensllivity, the apparatus was radio-frequency and magnetically shielded, and carefully thermally stabilized," The antennas were specially designed (dual-mode corrugated cones) with a beam pattern $7^{0}$ wide full width at half-maximum (FWHM). The measured antenna gain in the direction of the earth was below $10^{-7}$; anisotropic emission frnm the earth and aircraft contributed less than $0.2 \mathrm{~m} \mathrm{~K}$. A second twin-antenna radiometer operating at $54 \mathrm{GHz}$ was used to monitor and eliminate anisot ropic atmospheric backfround. This second system was sensitive to the strong-oxygen-emission region centered at 60 $\mathrm{GHz}$ and was calibrated at altitude by banking the airplane at angles of 5 to 25 . The monitor showed that the autopilot mitintained level flight during datis-tiking periods to better than $0.2^{*}$ of bank; the resulting spurious signal at $33 \mathrm{GHz}$

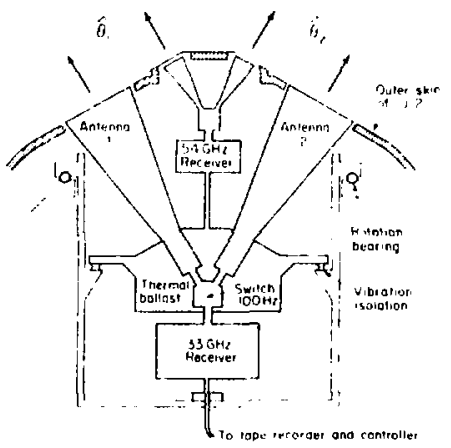

FlG. 1. Schemattc view of the apparatus mounted in the U-2 aircraft. The anisolrupy reported in this 1.0 ter was detected with the $9.1-\mathrm{GHz}$ radlometer; the $54-\mathrm{GHz}$ radiometer monitored the uxjoren anisotropy above the nirernft. 
due to aircraft tilt is less than $0.2 \mathrm{~m}^{\circ} \mathrm{K}$.

Spurious anisotroples were detected and eliminated through a hlerarchy of reversals. Rapid switching $(100 \mathrm{~Hz})$ between the two antennas reduced the effects of gain fluctuations (1/f notse). Spurious anisotropy generated by Imbalance in the two arms of the radiometer $\left(\approx 60 \mathrm{~m}^{\circ} \mathrm{K}\right)$ was canceled by interchange of the two antennas through a rotation of the apparatus by $180^{\circ}$ about the vertical every $64 \mathrm{sec}$. Spurious anisotropy assoclated with the rotation state of the antenuas ( $\approx 2 \mathrm{~m}^{\circ} \mathrm{K}$ ) was eliminated by reversing the flight path of the airplane every $20 \mathrm{~min}$.

The data reported here were taken on elght flights between December 1976 and May 1977. Each flight yielded about $3.5 \mathrm{~h}$ of data taken at altitude; Fig. 2 shows the total sky coverisge. A typlcal flight plan conststed of six pairs of "legs" flown in opposite di rections along the ground. In addition to the data legs, when possible the flights included a "moon leg" In which one antenna point ed directly at the moon for a few minutes; this allowed us to determine our absolute caltbration at altitude to about $5 \%$.

Before the data were analyzed for astrophysical content, the signals recorded during atrcraft banks, equipment rotation, woon-looking legs, and other "contaminated" data were eliminated. The "contaminated" data consisted of a total of of 6 min when the roll monitor indicated a bank angle of more than $1^{\circ}$ or when the rms fluctuations in the 33-GHz stgnal were abnormally high. The remaining $21 \mathrm{~h}$ of observations were fitted by a

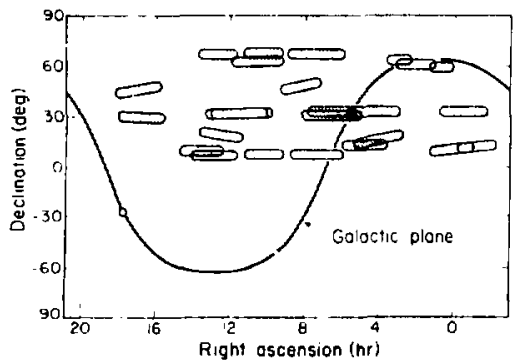

FIG. 2. Sky coverage for the eight nights is Indicated by the shaded reglons. Each oval reglon consists of sevoral "lega" frum tha aame night. The width of each region was determined from the antensa pattern $17^{\circ}$ FWHML, and the length was set by the motion of the U- 2 and the rolation of the earth. least-squares method to a sum of spherical harmonics. Only the first spherical harmonic is necessary to obtain a good fit $\left(x^{2}=91\right.$ for 80 data points). Thus the temperature in the direction $\hat{\theta}$ is given by

$$
T(\bar{\varepsilon})=T_{0}+T_{1} \cos (\bar{\theta}, \hat{n}) .
$$

Here $T_{0}$ is the average biackbody temperature (noi measured in this experiment), $T$, and $i$ are the parameters of the $t i t$, and $(\hat{\theta}, n)$ is the angle made by the unit vectors $\dot{\theta}$ and $\hat{n}$. The best $f$ it is obtained for $T_{1}=3.2 \pm 0.6 \mathrm{n}$ K and $\hat{n}=[10.8 \pm 0.5 \mathrm{~h}$ right ascension (R.A.), $5 \pm 10$ declination (dec)]. In galactic coordinates $\bar{n}=\left(54{ }^{\circ} \pm 10^{\prime \prime}\right.$ lat., $245^{\prime \prime}$ $\pm 15^{\circ}$ long. . .

Inclusion of second-order spherical harmonics in the $f \mathrm{st}$ changes the values of $T_{1}$ and $\hat{n}$ by much less than 1 standard deviation. An additional fit was made in which background contributions from the galaxy, the atmosphere, the motion of the earth around the sun, the antenna side lobes, and residuals in the apparatus were caleulated and subtracted for each lef prior to the least-squares minimization. These corrections individually and cumulatively were less than $0.5 \mathrm{~m} \mathrm{~K}$ per leg and were small compared to the signal. We will discuss these corrections 1 " wore detail in a subsequent paper. 'l'he resulting best-fit values were $T_{1}=3.5 \pm 0.6 \mathrm{~m}^{\prime \prime} \mathrm{K}$ and $\bar{n}=11: 0 \pm 0.5$ h R.A., $6^{n}+10$ dec).

The data, with and without corrections, are plotted in Fig. 3, along with the best-fit curve to the uncorrected data. The residuals are small; to a $70 \%$ confidence level they are $>10^{-3} \mathrm{~K}$. Thus, except for a component that varies as $\cos (\hat{\theta}, \hat{n})$, the cosmic blackbody radiation is isotropic to 1 part in 3000 .

The cosine anisot ropy is most rcadily interpreted as belng due to the motion of the earth relative to the rest frame of the cosmic blackbody radiation-what Peebles calls the "new aether drift." Using $2.7^{\circ} \mathrm{K}$ for $T_{0}$ and the fit to the corrected data, we calculate that the earth is noving at a velocity of $v=\left(T_{1} / T_{0}\right) c=390 \pm 60 \mathrm{~km} / \mathrm{sec}$ in the direction $\hat{n}$ towards the conslellation Leo. This result differs from the preliminary result reported by Corey and Wilkinson by less than twice their reported errors." In addition it differs substantially from the values of the peculiar velocity for the motion of the sun measured with respect to nearby galaxies by Rubln $t \cdot l a l{ }^{7}$ and by Visvanathan and Sandage. ${ }^{A}$ If we subtract fronl our measured velocity the component due to the rotation of the Milky Way galaxy, ${ }^{0}=300 \mathrm{~km}$; $s e c$, we calculate 


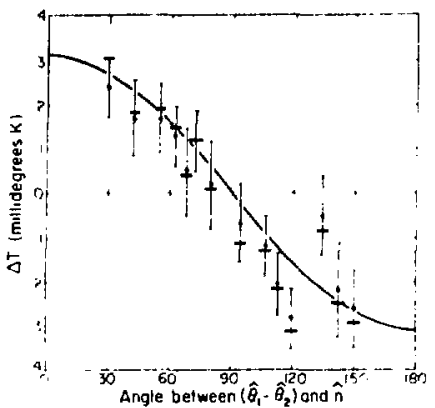

FIC. 3. Comparison of the data with the fit to Eq. (1). The temperature difference $\Delta T=T\left(\hat{\theta}_{1}\right)-T\left(\hat{\theta}_{2}\right)$ is plotted vergus the angel between the vectors $\left(\hat{v}_{1}-\hat{b}_{2}\right)$ and $\hat{n}$

10.8 h R.A., 5 "dec, the direction of maxlmum temperature. Data from legs at nearly equal angles wore com blond; tinch datum polnt plotted represents - 2 h of data. The large dots represent the uncorrocted data; thi hurlaontal hars show the data with expected systemal. effects aubracted put. The crora shown are itatistical only.

flee net motion of the Milky Way with respect to the canonical reference trame of cosmology to be - $600 \mathrm{~km} / \mathrm{sec}$ in the direction $(10.4 \mathrm{~h}$ R.A., - 18 " dec). These various velocities are summarized in Table I. The large peculiar velocity of the
Milky Way galaxy is unexpected, and presents a challenge to cosmological theory.

The limits on the second- and higher-order spherical harmonics place new constraints on several phenomena of cosmologlcal importance. Collins and Hawking have shown ${ }^{13}$ that vorticity, equivalent to a net rotation of the universe, can contribute a second-order spherical harmonic due to the transverse noppler shift. The limit which one can place on this rotation depends strongly on the model of the universe that is assumed. Using a semiclassical model, and assuming the blackbody radiation has not scattered since it was emitted at a redshift $z$, the rotation of the universe contributes a second-order harmonic of amplitude'

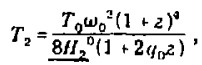

where $w$ is the present value for the anfular velacity of the universe. If we take $H_{0}^{-1}=2 \times 10^{1 n}$ $\mathrm{yr}$ for the present value of Hubble's constant, $4 \mathrm{~b}$ $=0.03$ for the deceleration parameter, $T_{n}=2.7 \mathrm{~K}$ for the present temperature of the radiation, $z$ $=1500$, and $T_{2} \cdot 10^{-1} " \mathrm{~K}$, we calculate that the rotation of the universe is presently less than $10^{-9}$ sec of arc per century.

Our limit on the second-order spherical harmonic also puts a constraint on the existence of large-wavelength gravitation radiation. Using the calculation of Burke," we conclude that the mass

TABI.E 1, I'ecullar velocitions $(\mathrm{km} / \mathrm{sec}$.

\begin{tabular}{|c|c|c|c|c|c|}
\hline \multirow[b]{2}{*}{ Reference } & \multirow[b]{2}{*}{ (knn/sec) } & \multirow[b]{2}{*}{$\begin{array}{l}\text { R.A. } \\
\text { (h) }\end{array}$} & \multirow[b]{2}{*}{ dec } & \multicolumn{2}{|c|}{ Galactic. } \\
\hline & & & & llong.) & (hat.) \\
\hline \multicolumn{6}{|c|}{ Motion of sun relative to cosmic blackbody ralliation } \\
\hline 3 & $270+70$ & $13+2$ & $-25^{\circ}, 20^{\circ}$ & $306^{\circ}$ & $38^{\circ}$ \\
\hline $\begin{array}{l}\text { This work } \\
10\end{array}$ & $\begin{array}{l}390: 60 \\
\leq 350\end{array}$ & $11+0.6$ & $6^{\circ}+10^{n}$ & $246^{\circ}$ & 56 \\
\hline \multicolumn{6}{|c|}{ Motion of sun relative to nearby galiades } \\
\hline 11 & $299+45$ & 7.3 & $51^{\circ}$ & $167^{\circ}+13^{\circ}$ & $25^{\circ} \pm 6^{\circ}$ \\
\hline 7 & $600 \pm 125$ & 2,1 & $53^{\circ}+11^{\circ}$ & $135^{\circ}$ & -8 \\
\hline 8 & $300=25$ & 23.2 & $46^{\circ}$ & $90^{\circ}$ & $0^{*}$ \\
\hline 9 & 308 & 23.1 & $51^{\circ}$ & $105^{\circ} \times 4^{0}$ & $-7^{\circ}+5^{0}$ \\
\hline 12 & $346 \pm 76$ & 18 & $45^{\circ}$ & $72^{\circ}$ & $28^{n}$ \\
\hline \multicolumn{6}{|c|}{$\begin{array}{l}\text { Motion of sun in orlitt around Milky Way galaxy } \\
\text { (rotation of galaxy) }\end{array}$} \\
\hline 8 & $\mathbf{3 0 0}+\mathbf{5 0}$ & 21.2 & $48^{\circ}$ & $9 u^{\circ}$ & $\mathbf{u}^{\circ}$ \\
\hline \multicolumn{6}{|c|}{$\begin{array}{l}\text { Motfon of Milky Way galaxy rolative to cosmic blackbody } \\
\text { (this work and rotation of gataxy) }\end{array}$} \\
\hline & 609 & 10.4 & $-18^{\circ}$ & $261^{\circ}$ & $\mathbf{3 3}=$ \\
\hline
\end{tabular}


dengity of such radiation in the universe is $\leqslant \rho_{f}$, where $p_{c}$ is the critical mass density necessary to close the universe.

In oummary, we have observed anisotropy that varies as $\cos (\hat{\theta}, \hat{n})$. Excluding this component, the cosmic blackbody radiation is isotropic to 1 part in 3000 . The cosine component is most readily interpreted as due to the molion of the earth with respect to the radiation with a velocity of $390=60 \mathrm{~km} / \mathrm{sec}$ (the "new aether drift"), but we cannot eliminate the possibility that some of the anisotropy is due to an intrinsic yariation of the cosmic blackbody radiation itself.

This work was supported by the U. S. Energy Research and Development Administrition and the National Aeronautics and Space Administration. We gratefully acknowledge contributions to the design of the experiment by $L$. W. Alvarez, T. S. Mast, H. B. Dougherty, J. H. Gibson, J. S. Aymong, and R. G. Smits, and participation in the experiments by $J$. A. Tyson and S. Pollaine. The experiment was made possible by the support and encouragement of H. Mark, A. Sessler, R. Btrge, R. Cameron, and N. Boggess, Important contributions and suggestions were made by A. Buffington and C. D. Orth, and by the members of the Earth Survey Aircraft facility at NASA-Ames, including $M$. Knutson, J. Barnes, C. Webster, R. Williams, R. Erickson, and S. Norman. This experiment was inspired by J. Peebles's book, Physical Cosmology (Ref. 1).

\footnotetext{
'1'. J. h. Peubles, Phusical Cosmologv (J'rinceton Cnjv. Press, Princuton, N. J, 1971); S. Weluberg. Groulation and Cosmology: Principles and Applica-
}

lions of the General Theary of Relolinity (Whey, New York, 1972).

${ }^{2}$ Both E. K, Conklin (Nature (London) 222, 971 (1969)] and P. Henry (Nature (London) 231, 516 (1971)] claimed to obgerve a first-order harmonlc. However, in both experiments backgrounds were much larger than the observed effect, and the resulting fits were very poor leee A. Webster, Mon. Not. Roy. Astron, Soc. 166, 355 (1974). In both experiments the 1-standard-devlation errors In the direction of the earth's velocity cover a large part of the sky. (Conklin quotes probable errore, not standard devlations.)

${ }^{3}$ B. E. Corey and D. T. Wilkinson, Bull. Ast ron. Astrophys, Soc, 8,351 (1976).

${ }^{4} G . F, 5$ moot, in Troceedings of the Spring Meeting of the American Physical Soclety, Washington, D. C. 1977 (unpublished); $M$. V. Gorenstejn, G. F. Smoot, and R. A. Muller, Bull. Astron. Astrophys. Soc. 9.431 (1977).

'M. V. Gorensteln, R. A. Muller, G. F. Smoot, and J. A. 'lyson, to be published.

${ }^{6}$ The repurted errors in the preliminary results of Corey and Wilkinson (Ref. 3t at 19 (iHz were statitical only. New results $\left(300 \pm 70 \mathrm{~km} / \mathrm{sec}, 12 \pm 2 \mathrm{~h},-10^{\circ} \pm 20^{\circ}\right)$ from their group (D. Wilkinson, private communication) are in cluser agreement with our results.

${ }^{7}$ '. G. Rubjn, W. k. Ford, N. Thonaard, M. S. Roberts, and .J. A, (oordon, Astron, J, 81, 687 (1976).

${ }^{8} \mathrm{~N}$. Visvanathan and $A$. r.indage, to be publishec.

"A. Yahii, G. A. Tammanu, "id A. Sandage, to be published.

${ }^{10} \mathrm{D}$. Muehlner and $\mathrm{R}$, Weiss, In/rared and Submillimeter Astronom. Astraphysics and Space Sciences Library (Reldel, Hinfham, Mass,, 1876), Vol. 63.

${ }^{\text {"G. }}$, deVaucouleurs and W. L. Peters, Nature (Iondon) 220, 868 (1968).

${ }^{12}$ P. L. Schecter, to be published.

${ }^{13}$ C. B. Collins and S. W. Hewking, Mon. Not. Roy. Astron. Soc. 162, 207-320 (1973).

${ }^{14} \mathrm{~S}$, l'ollaine and G, F. Smoot, Lawrence Berkley Laboratory, Astrophysical Note No, 343,1977 (unpublished).

${ }^{13}$ W. L. Burke, Ast rophys, 1. 196, 329-394 (1975). 


\title{
Radiometer system to map the cosmic background radiation
}

\author{
Marc V. Gorenstein, Fichard A. Muller, George F. Smoot, and J. Anthony Tyson ${ }^{\text {ar }}$ \\ University of California, Lowrence Berkeley Lahoratory und Space Sciencei Laboratory, Berkeley. Culifornus 44720 \\ (Received 14 November 1977)
}

We have developed a $33-\mathrm{GHz}$ airborne radiometer system to map large angular heale variations in the temperature of the $3 \mathrm{~K}$ cosmic background radiation. A ferrite circulator switches a room-temperature mixer between two antennas pointing $60^{\circ}$ apart in the sky. In 40 min of observing, the radiometer can measure the anisotrnpy of the microwave background with an accuracy of $\pm 1 \mathrm{mK} \mathrm{mms}$, or about 1 part in 3000 of $3 \mathrm{~K}$. The apparatus is flown in a U-2 jet to $20 \mathrm{~km}$ altitude where $33-\mathrm{GHz}$ thermal microwave emission from the atmosphiere is at a low level. A second radiometer, tuned to $54 \mathrm{GHz}$ near oxygen emission lines, monitors purious signals from residual atmospheric radiation. The antennas, which have an extremely low stde-lobe response of less than $-65 \mathrm{~dB}$ past $60^{\circ}$, reject anisotropic radiation from the carth's surface. Periodic interchange of the antenna positions and reversal of the aircraft's flight direction cancel equipment-based imbalances. The system has been operated untcessfully i) V.2 aircraft nown from NASA-Ames at Moffetl Field, CA.

\section{INTAOSUCTION}

Wo has developesl and te aled an airborne radiuneter to

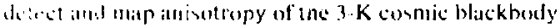

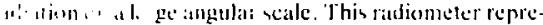

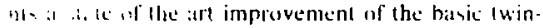
atmennat !ocke: sandinmeter used by several grutups' "to vel previnus limite an the anisoterony.

Amsermpe is the baskeround radiation of a fow

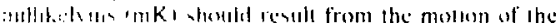

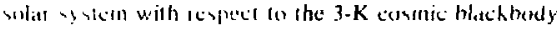

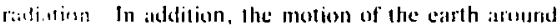
the ston produce an annually varying anisotropy of 0.3 in shisoropice would also he expected from arym-

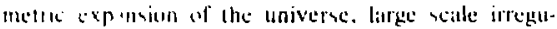
laside, in th, distrihution of matter or energy, or various

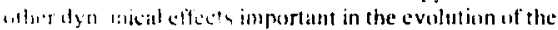
amivertic

'Jur ladiumetrio system is designed to detect ansotonptic radiation in the cosmic background with a ionsiavily of a few tellth of a millikeivin. The design incouperites several new features that reveal ar cancel intematic effech. In this section we shall briefly ar.esithe the system operation. In the halance of the f'upel wo expant wh this description, detail the design - Ille lis and document the sysieni's perlor mance.

1: a anlenniss that poinl $30^{\circ}$ from the zenith and uppositcly in aximuh collect the $33-\mathrm{GHz}$ radiation (see Fig. $1-3$. Thus the sky provides hoth the suures and the reference for differential detection of anisotropy. [1ic 33-cill fleoucncy is in "window" where the sum If almonpheric and galactic microwave backgrounds is miajinal. The antennas are dual-mode corrugated horns thit reject side-lobe illumination from the direction of the earlh by more than $-65 \mathrm{~dB}$ and thereby reduce signals duc to anisol ropic terrestrial radiation below the 0.2 ink level.

A su itching ferrile circulator, ahernating between the anlecisas at $100 \mathrm{~Hz}$, directs the radialion to at room- temperature mixer. Rapid switching helseen antentas

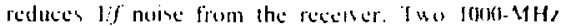
bandwidth i.f. gain hages amplify the sigmal. and a lock in amplitier inalyos the detected wutput los at compunent syochenom, walh the witchirit. Thus the radioneler detects anl: the dilference in thy lemperas.

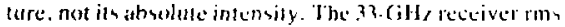
sensitivity is $44 \mathrm{mK}$ KIll, :

The equipment is carrace un hoard a $2: 2$ jel $\mathrm{kr} 20 \mathrm{~km}$ alletude where allmoupheric microuate emisson in greally reduced. Pointing the antennas it the sitme serith angle cancels most of the rematining thermal emission from the residual atmosphere. Slight departures fiom level flight atre the primaty sallse of the tembining im. balance in almoupheric riddiation received by the antennas. A second rationmeter. finclionatly identical to

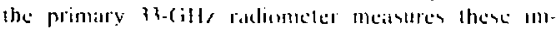

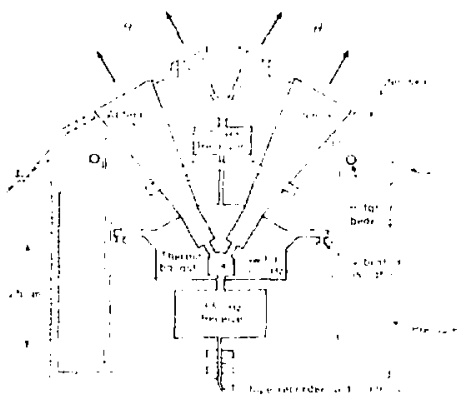

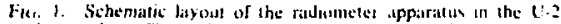
equipmeat bay. The main electronics and mechinical compuncal. of the system are illustraled. The antenals are shown th the dalis laking pusituon, with the ditestron of Bight porpemdicular on the

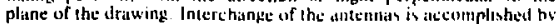

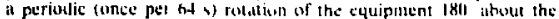
vertical senter-line 


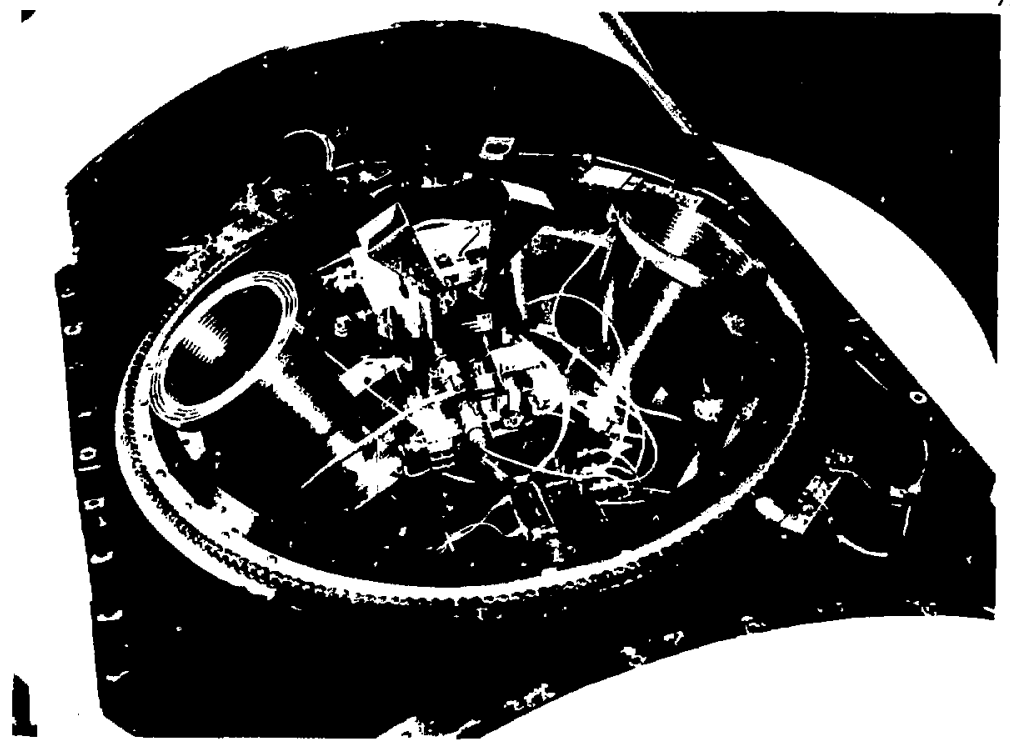

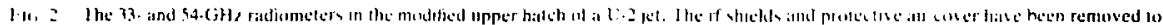

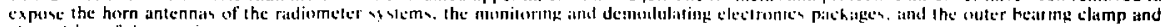
chats srive of the retation vyvem.

halances. This "roll moniker" is tuncel to $54 \mathrm{GH} \%$, in at region near strong oxygen ensision lines.

Two switching techniques cancel and delecl equipinent-based imbalances. Periodic inlerchange of the antennias canceds insertion lom differences between the radiometer arm. The ys $4 \mathrm{em}$ is mounted in at bearing that rotates the radiomsters ino every $64 \mathrm{~s}$. Periodic reversal of the aircraft n:ght path (about once per $20 \mathrm{~min}$ )

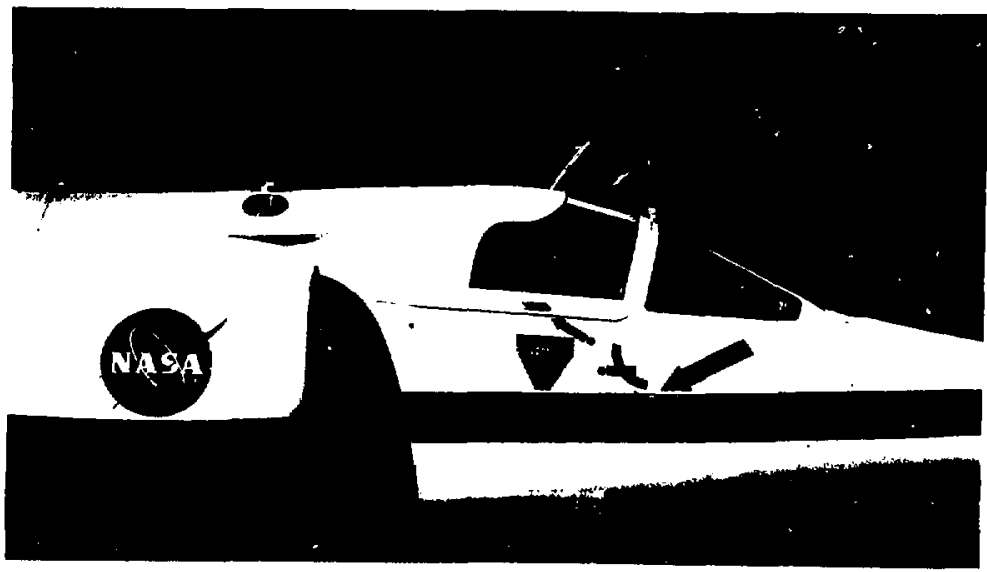

Fk. 3. The forward section of U.2 jel with a 33 -GHz antenns mouth and a S4-tiHz Jeflon window visible. The modified upper hatch, situated just af of the pilot's canopy, is easily remuved from the U.2 equipment bay with the equipment installed, for sheskout and testing. The lup surfaces of the airscoops are $72^{4}$ fron the $33-\mathrm{GHz}$ antenna beam ixis. 
detects asymmetries in the equipment correlated with rotation state.

The system incorporates thermal controls that regulate and monitor the temperatures of crucial components. All anisotropy, roll, and housekeeping data are ricorded in flight on a magnetic tape cassette for later processing. The data collection is fully automated. Except for turning the equipment on, and initiating the rotation sequence at altitude, the pilot's primary reuponsibility is to orient the airplane according to the Right plan.

\section{l. CHOICE OF FREQUENCY AND OBSERVIIIG PLATFORM}

In chowsing a receiver frequency one must consider astrophysical backgrounds, emission from the atmo:phere, and receiver sensitivity. Synchrotron radiation from the Milky-Way Galaxy places a fundamental limit on the sensitivity of any experiment which measures the ithisutropy of the :osmic background radiation. At about $1 \mathrm{GHz}$ the intensitics of galactic synchrot ton emission and the cosmic hackground are comparable. Forturatels, compared to the cosmic background, galactic ynchr:ian radialion falls off rapidly with frequency.

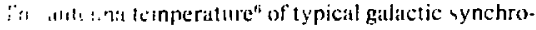
iron eniwionn is plotted as a function of frequency in Fig. 4. This plot shows that by $20 \mathrm{GHz}$ the magnitude of the earapolated galactic hackground falls below $1 \mathrm{mK}$. The thermal spectla of ionized hydrogen $(H$ II) regions and dusi clouds, which are mainly localized near the galiactic plane are atso shown.

Also plotted in Fig. 4 is our estimale of state-ol-the-

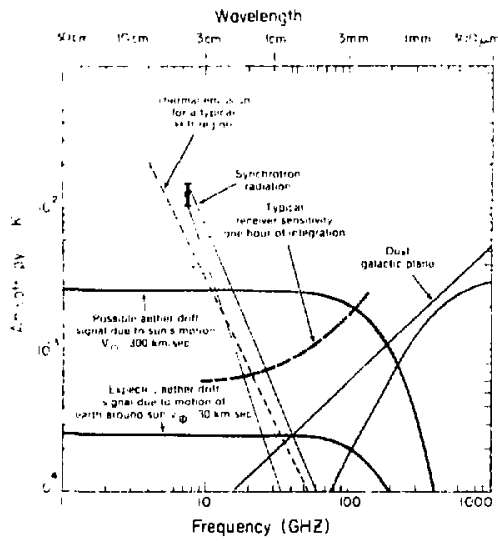

Fit. 4. Estimates of galactic radiation backgrounds as a function of Ireyuency compared to u possible "Aether Drift" signal. The large reale intsotropy of galuctic microwave radiation is comparabl. to the ahwoter intensity of the suurces. The Just and HII regions ate concentrited in the galactic plane and tend to be greatest near the galactic center. An ehtimate of receiver sensilivity for $J \mathrm{~h}$ of integiation is in:lieved.

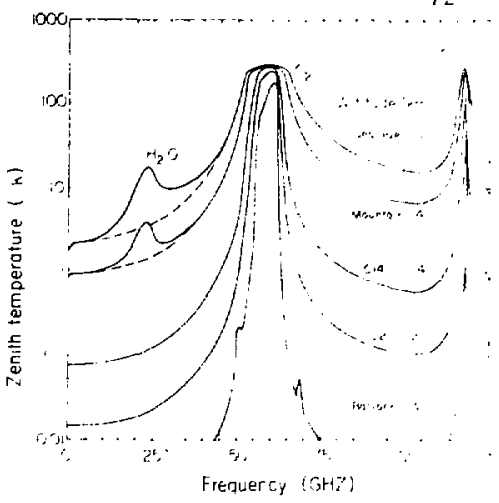

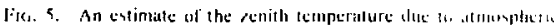

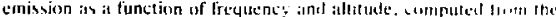

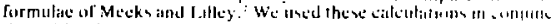

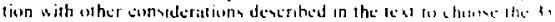

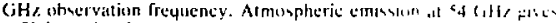

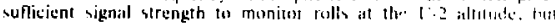
is sufficientily ansiturated on the ground to per nut wedtication on the predicled emissien.

art room-temperalure receiver ensitivity at a lianction of frequency for I h of integration. I he need lo delest anisotepies on limited time scilles constrains the chuice of receiver frequency to frequencies where the expected ininotropy is on the order of it millikediul more.

Thermal microwave emission from the warth" atmon phere is an important batckeround. Figure: is a plat ol the expected zenith temperature dac lo atmonpheric emission as a function of frequency and altitude. The oxygen spectrum is calculated using a itandard model ot the carth's atmosphere iagether with formulate that the scribe the microwave spectrum of $O_{2}$ as a function of temperature and pressure. This plot shows that therr are preferred windows - below $20 \mathrm{GHz}$, around 35 ( $\mathrm{iH} z$. and atround $90 \mathrm{Ghz}$ - in which atmospheric effect atc greatly reduced relative to the peaks. The choice of the 33-GHzreceiver frequency wits hased on the athowe considelations. This is a frequency where the effects of gatlactic barkground and atmospheric emissiun are minimized, and where receiver performance and sigita! strength are adequatc.

A high-altitude platform is required for this measture ment beeause fluctuations of precipitable watter bipor do not allow a sensitive experimen! to be June on the ground. Even at mountinin-top altitude fluctuations of 2u...K are common. "The experiment must be conducted at altitudes above $14 \mathrm{~km}$, where all significant walct vapor has been frozen out." Pointing the antennis at nearly the same zenith angi can cancel the residual thermal radiation from the oxygen above this allitude.

There are several vehicle, which could he used for altitudes of $14 \mathrm{~km}$ and above: salellites. ballowm. 


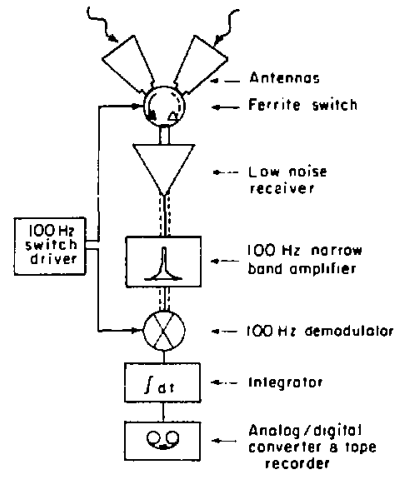

1. 16. h. Components of the 3,- and $54-\mathrm{GH} 2$ radiomelers. The individual cumpunents making up the receiver section are shus'n in Fig. 8.

and aircraft. Although a satellite experiment is potentially the most sensitive. having no atmospheric background and long integration times, it is also the most expenaive. Such an experiment the Cosmic Background 1:xploren is now being planned. but it will not be flown for several years. The results from an airplane experiment will aid in the design and planning of the satellite experiment. (Jher anisotropy experiments sensitive to the inillikelvin range are currently being flown, ${ }^{4.11}$ and use hallows 10 reach the necessary altitudes. The U-2 is a particularly good vehicle for this experiment because of its high-altitude (20 $\mathrm{km}$ ), excellent roll stability, and quiet electrical and mechanical environment. The U-2 hus the advantuge over balloons of being piloted and less at the mercy of weather. Recovery of the instrument ifter a flight is straighforward.

\section{RADIOMETER}

Figure 6 shows a schematic drawing of the 33- and $54 . \mathrm{GHz}$ radiometers. Rapiu switching between a source and a reference load is a standard technique used to reduce the effect of receiver gain fluctuations $(1 / f$ noise $)$ in a microwave radiometer. We use a dual antenna configuration where the sky is both the source and the reftrence. Thus difficulties in monitoring the temperature of a reference load within a few tenths of a millikelvin are eliminated. Radiation from the atmosphere is canceled by pointing the antennas at the same zenith angle. The primary components of the radiometers are the antennas, the ferrite ("Dicke") switch, the receiver, and the downstream electronics. A discussion of each of these components for the $33-\mathrm{GHz}$ radiometer follows.

\section{A. Antennas}

The anisotropy in the blackbody radiation is minute compared to anisotropies in the radiation from the earth and aircraft. Thus a first requirement of the antenna system is that its side-Jobe response reduce the differential emission from the earth and aircraft below the design sensitivity, about $0.2 \mathrm{mK}$. Thus the integrated 300-K signal from the earth must be reduced by a factor of about $10^{-3}$ compared to the main beam. Secondly, this performance must be achieved with a compact design. Mechanical and aerodynamic considerations make installation of antennas w/th large apertures or ground shields impractical in the. U-2. Thirdly a beam width of more than $1^{\circ}$ is needed. A small beamwidth would make the measurement susceptible to spurious signals from pointlike astrophysical sources of radiation. Finally to efiminate potential systematic erross, the insertion loss of the antennas must be small, or comparable to losses of other components upstream of the receiver.

These criteriat were met by corrugated horn antennas based on the work of Simmons and Kay. "A matched pair of antennis with a beam width of $7^{\circ}$ FWHM were built by TRG Division of Alpha Industries for this experiment. Each antenna is an aluminum cone with concentric grooves mathined down the full length of the inside surface. The grooves force the electric field at the edges to zero, effectively apodizing the aperture. This effect is enhanced by the excitation of two modes in the antenna throat phased to cancel at the mouth of the antenna. At the throat end of the antenna a transition is made from circular to rectangular waveguide.

A sensitive measurement of the antenna beam patterns was mate at the JPL-NASA test range of the Jet Propulsion Laboratory in Pasadena, CA. Figure 7 shows the results of the experimental measurement along with the theoretical predictions of antenna patterns. ${ }^{12}$ These re-

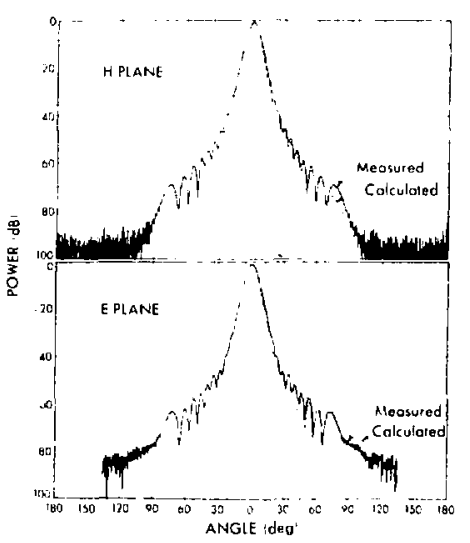

Fig. 7. The $\boldsymbol{E}$ und $\boldsymbol{H}$ plane one-way power pattern of the 33-GHz corrugated horn antennas used in this experiment, as measured at the JPL test range. Low side-lobes are necessary to reduce anjsotropic radjation from the earth and aircraft. The integrated power received from the earth is reduced by over $10^{-3}$ compared to the main 
sults imply that the earth should contribute a tolal antenna temperature of no more than $2 \mathrm{mK}$. and the airplanc no more than 2 . I $\mathrm{mK}$ into cither antennil during level flight. Radiation from terrestrial surface features with different emissivily illuminating the side-lohes should result in differential reception between the lus antennas of no more that $0.2 \mathrm{mK}$.

The aircraft made 20 banks over the Califarnit coast (s) theck the calculations. Juring the hanks. terrestrial latdation illuminated the side-lohes of the loucred anIenna to within 4$)^{\prime}$ of the central hearn axis. Syblematle differences of $4 \mathrm{mK}$ cut of the 22 - $\mathrm{mK}$ hitnk signal uele "hacerved is the lawered antennit swept over territe af rarying cmestity. The limit is in agrecoment with the pecteled walue calculated from convolving the antemuit he:im pallery with the valy ing thermal emission from the cimlh al 33 cilts.

\section{B. Ferrite switch}

A bitching ferrite circulitor swilches the input of the

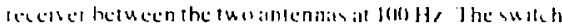

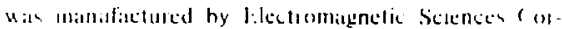

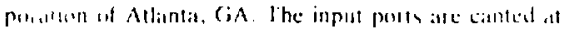

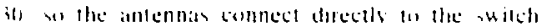

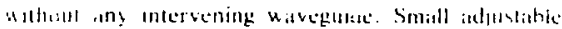

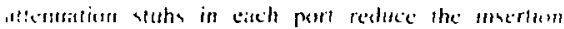

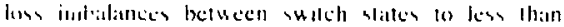
(1) IIK

The us iteheng is alcomplished hy reversing the mage nets lest of at ferrile emberded in the circulator. If an inteldellon helween the eisth's mangetic field alld the in ith has is significant orientution dependence, then । sgnal i, nchronous with the anlennat rotition maty result:

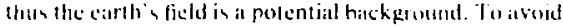

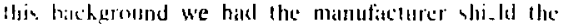

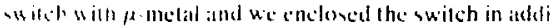
liunal mighetic shielding. We tested the shichling hy

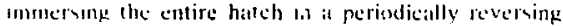

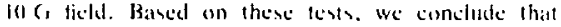

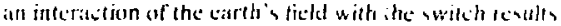
III it spuikus signal of less that $0.1 \mathrm{mk}$.

\section{Receiver}

A promiry limination in the measurement of dilleren.

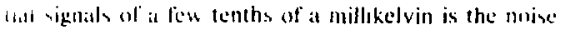
added to the uignat by the receiver. The serrsitivity of it rationetric system is defined as the rout-mean-square (rems) noise fluctestion in the powti outpis of the reLeiver (referenced to the input port) : and in given hy the fais inuli: is

$$
\Delta 7_{\text {rets }}=\kappa \frac{\left(T_{H}+T_{.1}\right)}{\sqrt{B T}} .
$$

$T_{\text {I }}$ is the receiver noise temperature in kelvins, $T_{A}$ is the anlenna temperature for this measurement. $B$ is the i.f. hindwidth, $\tau$ is the integratiun time, and $K$ is a constant depending on radiometer design (1 for a total power radioneter, 2.2 for this configuration).

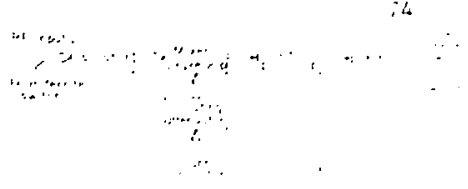

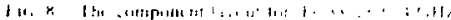

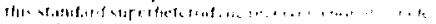

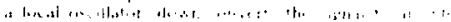

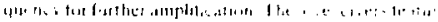

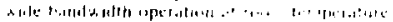

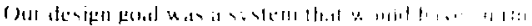

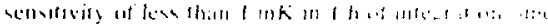

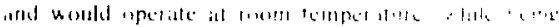

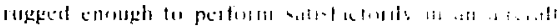

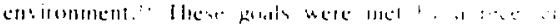

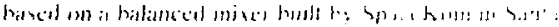

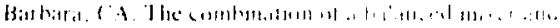

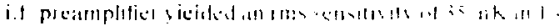

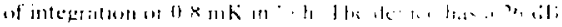

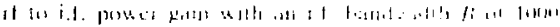

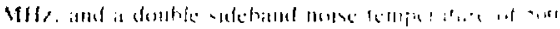

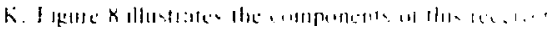

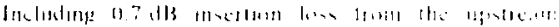

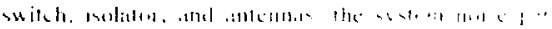

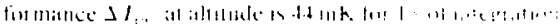

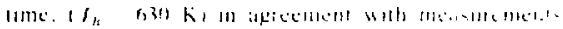

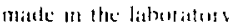

\section{Downstream electronics}

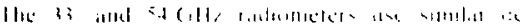

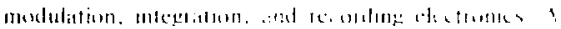

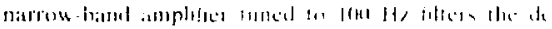

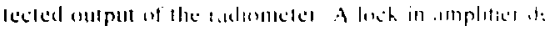

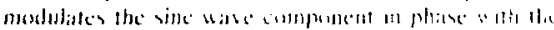

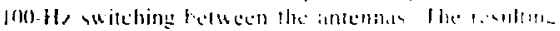

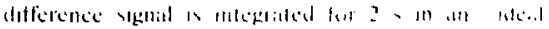

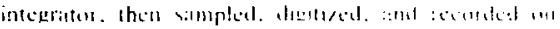

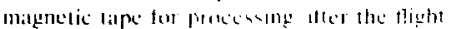

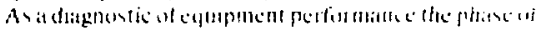

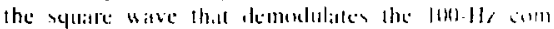

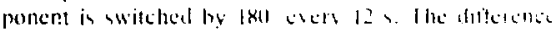

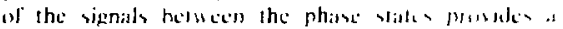

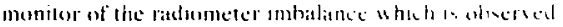
to be aboul so $\mathrm{mk}$ fir the 33 (ill/ lidsumeter. Ithe

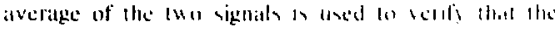
de level of the shtem after demodubstums in collotiant

\section{MONITOR FOR ATMOSPHERIC ANISOTROPY}

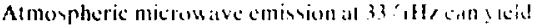

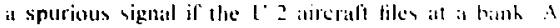

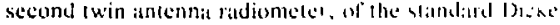
design, operaling at 54 (ith momilors the poremtal

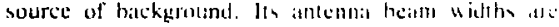

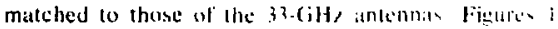
and 2 show the pesition ol the restiometer in the atiplans hatch. The 54-GH/ radiometer has at double-sulebind

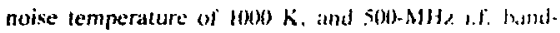




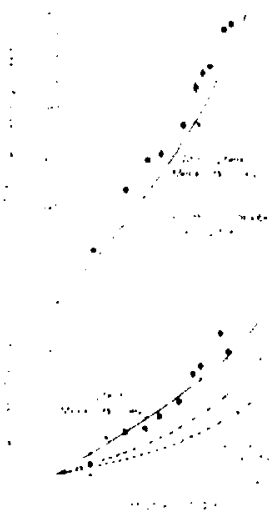

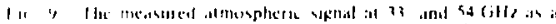

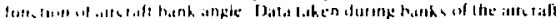

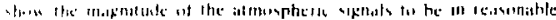

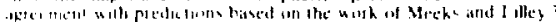

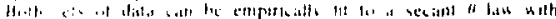

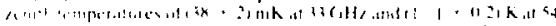

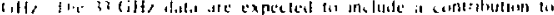

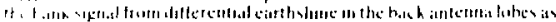
$1+1, \mid 1,110.1$

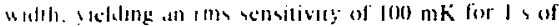

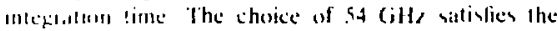
recumements that the oxygen signal das fo airstatt moll we vanne and casily monitored at the $20-\mathrm{km}$

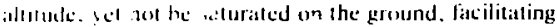
shesh wat.

In acvelat flighes the U-I petioned a series of hanks

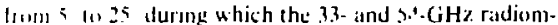

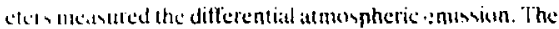
revale of these runs are shown in Fig. 9 along with the prodictions hatsed on our talculations of atnospherke enith temperature (Fig. S). Dus fo the small uplical depth. atmospheric emission at thes alutude vare approximately as the secam of the zessith angle. A 0.25 bank results in a differential signal of $0.2+0.03$

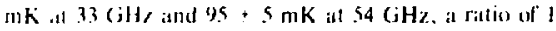
(11) 42(1. Thus in ; of integration the 54- $\mathrm{GHz}$ radiometer cian measure the atmaspheric contrihulion to tha 3.3-GiHe. signal la $+0.2 \mathrm{mK} \mathrm{rms}$.

In level fight the $54-\mathrm{GHz}$ roll monitor indicates that the U. 2 autopilot, a Lear 201 automatic flight control syntem, maintains the aircraft at constant average bank angles of less than $0.25^{\circ}$ for periods up to an hour. For departures from level flight of a few uggiees or less, the a verage roll monitor sign .J is proportional to the average atmospheric signal al $33 \mathrm{GHz}$. Since a $0.25^{\circ}$ roll yields a signat of only $0.2 \mathrm{mK}$ at $.33 \mathrm{GHz}$, the substquent corrections (t) the anjsoiropy dala during post-flight analysis are small. As with the $33-\mathrm{GHz}$ signal, the $54-\mathrm{GHz}$ signal is integrated and recorded every $2 \mathrm{~s}$. On this time siale the rms fuctuations about the mean bank in level flight are less than $1^{\circ}$ in roll angle. The output of the roll monitor is displayed to the pilot, but the average bank is so imall that there has heen no n.ed fu make torrections (1) the ittitude of the aircraft in fleght.

\section{U-2 AIRCRAFT AND ENVIRONMENT}

The NASA-Ames lath Survey Aircraft (U-2) is a single-seat aticraft slesigned as a high-altitude $120 \mathrm{~km})$, long-range $12500 \mathrm{~km}$ ). recomnaissance jet by (Carenet "kell!" Johnson of lockheed Aircraft Company of (alifornia. In appearance the U. $\mathrm{J}$ is like a glider with a single powetful jet engine. ()ur annatalus fits in al modified uppes bach replacing the standard access hatch above the equipmen: hay. It is located just alt of the cockpit and fourard of the wings, Fig. 3. The (wo radjuncters and nose of the aceompanying toctronics atre sealed off from helow hy a pressure can which maintains

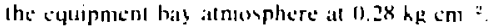

Tuenty-exight volle de aupplied hy the aireraft poswers the cyuipment. The voltage is filtered agitinut of interfeocese and regulated at $24 \mathrm{~V}$. All dista are recorded on hoird: no telemetry is aned. The pilot flies the atroraft on at predetermined path. Normally there is no compunication to the ground during clat it laking.

The equifment is operates in a carcfully regulated the:mal envirunment. Due to the tinile temissivily of the horn antennats, a 0.05 ( physical ternjerature difference betueen the 3.3. (iHs antennas would produce a l $\mathrm{mK}$ signal. However the re is considerable variation in the lis ner unit length along the horn. In flared smooth. walle 1 ." tennils eatch transverse section radiate power approximately in inverse proportion to its diameder. But in the dual-mude corrugated design, the greativ reduced lields at the surface of the antenna mouth resalt in correspondingly lower loss per unit length. In the 3.3-6 $\mathrm{Hz}$ antennas the nower per unit length contribuid by th: mouths is only $1 / 3$ so that of the Ihroats.

A 20-ky aiuminum block thermally shorts the throats iogether, and an aluminum bar shorts the midpoints of the antennas together. The temperature of the block. containing the antenna throats and the ferrite swich, is regulated at $26^{\circ} \mathrm{C}$ by embedded resistive heaters. The antenna mouths cool in the air-stream where they reach $-35^{\circ} \mathrm{C}$ during the flight.

Silicon diodes used as temperature sensors monitor the absolute and differential temperatures of the antenna mouths ard midpoints. Measutements made during the flight show the differential temperatures to be less than $0.05^{\circ} \mathrm{C}$. Additional heaters maintain the $54-\mathrm{GHz}$ ferrite switch at $35^{\circ} \mathrm{C}$ and regulate the digitizing and sequencing clectronics at $25^{\circ} \mathrm{C}$. Total heat dissipation through the antennas is about $70 \mathrm{~W}$ from the electronics and $50 \mathrm{~W}$ from the heaters. 'The equipment cools for $20 \mathrm{~min}$ after the rotation sequence is initiated at altitude, allowing the sustem to reach therinal stability. The aluminum bloc.. gradually cools an additional $1.6^{\circ} \mathrm{C}$ during the remainder of the flight.

Tefon windows protect the mouths of the $54-\mathrm{GHz}$ antennas. The windows ate $1.9 \mathrm{~mm}$ thick, or $1 / 2$ wave- 
length at $54 \mathrm{GHz}$, therehy minimizing reficctions of an incoming signal. The emissivity of the windows is less than $1 \%$. A physical temperature difference between the windows of a few kelvins results in a thermal signal of a few hundredths of a kelvin. This is negligible compared to the $8.5-\mathrm{mK}$ sigral generated at $\$ 4 \mathrm{GHz}$ hu the minimal roll to be detected, $0.2^{2}$. In contrast, at $33 \mathrm{GHz}$, windows with sufficient mechanical strength to withstand aero. dynamic stress cannot be used. Differences in physical tcmperature of a few kelvins would produce spurious signals large compared to a few tenthe of a milikelvin (1) he delected with this radiometer.

The entire assemblage is mounted on three vibration dampers that reduce potential microphonics due lo aircraft vihration. The electronic components are packaged in modules that are shielded against radio-frequency interference and a double-shielded container encloses the entire assembly except for the actual anternit moulhs.

\section{A. Rotalion system}

As with previous anisotropy experiments, it is es. sentail that the postion of the antennas he periodically interchanged to cancel anisotropy inherent is the instrument. The main portion of the equipment is sw. pended on a $56 . \mathrm{cm}$-diam b. -ing mounted in the 1.2 hat ${ }^{\prime} h$. $A$ motor drives the hearing through a worm gear. it cluteh. and at stainless stcel chaisi. This system rotittes the instrument $180^{\circ}$ every 54 s to the alternate uherving position.

A iolation takes 5 to $6 \mathrm{~s}$ during which the instrument is accelerated through a $90^{\circ}$ turn and then deiccelerated until il corast s lo rest against a positioning stop. The motor is shut off with a sensing microswitch. The design of the system insures proper alignment of the antennats in the observing positions to within $0.1^{\prime \prime}$. A ten-turn putentiometer and four microswitches measure the rotation angle to within 0.5 . Their outputs a c recorded, ant? the analog rotation angle signal is displayed on the pilut's instrument panel.

During ascent and descent the equipment is rotated y1) atway from the observing positions to protect the 3.7. $\mathrm{GH} x$ antennas from the external environ ment. In this 'stored position. the 33-GHzantennas are positioned inside the hatch, and plugs, lined by brushes, seal the open ports.

\section{B. Alrcraft reversals}

A spurious anisotropy signal would appcar if the output depended on rotation state or if the apparatus were not located symmetrically in the U-2 aircrafi. We detect and cancel any such signal by taking data in pairs of "legs" flown in opposite directions with respect to the ground and sky. During each leg the pilot flies the aircraft straight and level for $\mathbf{2 0} \mathrm{min}$. Six pairs of legs are fown in a typical flight. The final three pairs are usually flown in directions perpendicular to the first three.

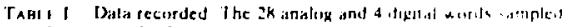

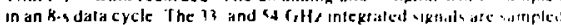

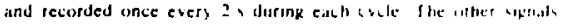

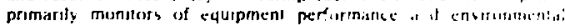

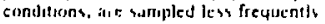

\begin{tabular}{|c|c|c|}
\hline & $\because \quad-\ldots-===\div$ & 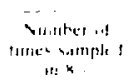 \\
\hline 1 & 33. (iH) falfumetes verial & .1 \\
\hline 2. & 33 ciste noulse monilot & $\therefore$ \\
\hline 3 & 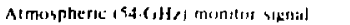 & 4 \\
\hline 4 & Almosphesic nutse monilos & ? \\
\hline 9 & Heidtet corcull current & $\therefore$ \\
\hline b & Anlennis uremtalionn & 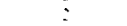 \\
\hline 7 & 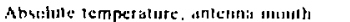 & 1 \\
\hline g & $\begin{array}{l}\text { Differential temperatiore hetucen mentennil } \\
\text { mesulbs }\end{array}$ & $!$ \\
\hline ני & 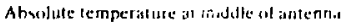 & 1 \\
\hline 10 & $\begin{array}{l}\text { Dofferental leamperature aterise mudille of } \\
\text { antennass }\end{array}$ & 1 \\
\hline 11 & 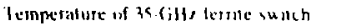 & $i$ \\
\hline 12 & $\begin{array}{l}\text { Five temperatures of it and a } 4 \text { cill, } \\
\text { ritdumeters }\end{array}$ & $\therefore 1$ \\
\hline 13. & ALcelestometer uisput & ! \\
\hline 14 & Puner suppla voltiale & $i$ \\
\hline \multicolumn{3}{|c|}{$D_{t h u l a l}$} \\
\hline & I'niversal dime & $\therefore$ \\
\hline & Antenna movilun. valus bass & ; \\
\hline
\end{tabular}

$\because$ wotil

\section{DATA RECORDING AND ANALYSIS SYSTEM}

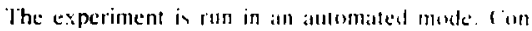
trolling electronics, activited hy the pilat al take-aft. provide the necessary timing and ecolenemg signials lo

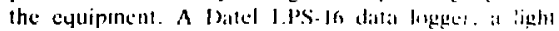
weight low-power incrementill tape recorder, dipitises and records four words of ditat per secound on . Imatg-

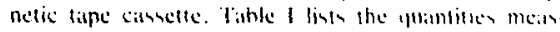
ured and recorded in an $8 .>$ datit eycic

During post-llight anclyois we llse compulas pro grams to display. edit. and average the meisurements. The bulk of the editing consist of deleinne dalat laken during banks and antenna rotations. The saltter of the edited dala is generally consistem with at gitl. niatl distribution, as expected for signals from a moixe-limiled radiometer. On two occasions during dattatiaking flights transients oecurred that were inconsislent with itativtical fluctuations about the meatl. These poinl were removed, resulting in a loss of 20 , of datia. Datta taken during course corrections made by the plot are deleted if the 54-GHz roll monitor indicates it hank of more thall $1^{\circ}$. The cuts due to rolls and transients amount to bers tran 6 min out of $32 \mathrm{~h}$ of data taken over nine flights.

the remaining data are grouped by "legs" and averaged. The anisotropy is found in cach leg by suhtracting the averages of data taken in one antenna urientation from the averuge of data lake $n$ in the other orienlittion. Corrections are applied to these averiges fin istrophysicul, local, and equipment-halsed buckgrounds. I:ablo II lists these corrections, and tabulates the $(x)$ percentile limits on the magnitudes of the corrections that alc ap. 
TaHt \& II Residual systemate eflects The 90 percentile limits on the magnitude of the corrections applied in data averaged aver a leg Most systematic correcitons applied in the data are small compated to the integrated sensitivity of a flight. ahout $0.5 \mathrm{mK}$.

\begin{tabular}{|c|c|}
\hline bflest & $\begin{array}{c}\text { Yori of the corrections if each } \\
\text { talegony reyult in thange of } \\
\text { lew than imki }\end{array}$ \\
\hline \multicolumn{2}{|l|}{ Gialacllc hath hefunnds } \\
\hline Syncherflom tiathalion & $11 x_{2}$ \\
\hline lonised hi drupen iff If regum & (1) 011 \\
\hline Rddan sintsise & (1) (ik \\
\hline Duvi & (1)। \\
\hline 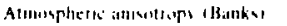 & 1115 \\
\hline Antenna wede whes & " 21 \\
\hline Antentas teriperiture delterente & $112^{-}$ \\
\hline 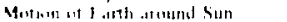 & 1121 \\
\hline Junit:a & $11: 1$ \\
\hline ( nfmlinel & $\because c_{k_{n}}$ \\
\hline
\end{tabular}

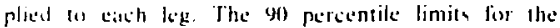

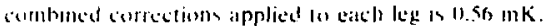

\section{RESULTS OF ENGINEERING AND DATA FLIGHTS}

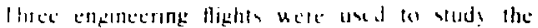

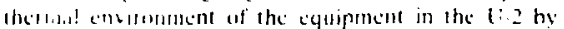

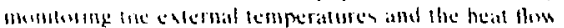

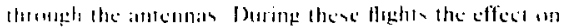

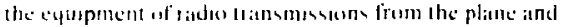
cngenc testart were thecked and loumd not to callse sigmolisate interference.

The statesteal and sybematic propertes ot the .3 .3 .

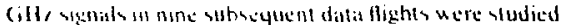
by at birled of methods. The datia were atute corretated,

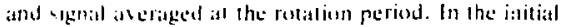
fince dattit flighes conselations uere seen with lime perreds af 41) to I I 4 a and amplitules that varied from $10104^{6} \mathrm{mk}$. Alfer these theht, were midde a number of changer and insporements indeding the following: A parametric anteplifier" ' was replaced w ith the Spacekom mixer. atul regulation of the lemperitures of the aluminum block and the controlling electronics was ionproved. In the final six datit llights in correlatio ; were "heserved, nor inomaloun effects in the hignal-averaged

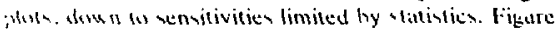
(1) vhus as segmenl of diatat taken with the 33- and 54(ille rediuncters from the fifth dialia flight.

A spurious signal of aboul $2 \mathrm{mK}$. of yel unexplained orign, is associated with the rotation talle of the system. Reversing the heading of the ircraft measure this effert. and bows it is constan Juring a thight. This offset is iuhtracted from the data for litter analysis. It may be inherent in the system, or due to an asymenetry in the way the equipenent is mounted in the plane. This prob. lem is being investigated.

Miciowave iharbers inilintained at room temperature und at liquid nitrogen icinperature are used in the laboratory as the primary cillibrators of the 33- and 54 Glt< radiometers. The equipment was also calibrated Juring pre- ind post-flight theckoul with a secondary calibrator. In several flights the moon provided a theek of the calibration. The U-2 flew the equipment _ crapre. determined localion at the proper lime and heading so that one of the antennas pointed at the moon to within $0.5^{\circ}$. The obseryed signals of $(67.5 \div 25) \mathrm{mK}$ imply at surface temperatiare of $122 \mathrm{H}$ - 121 K consictent with meatsurements made on ine ground by us and otherst: at similar wavelengths.

During the flight the ant pited thermal, terrestrial, and atmospheric backgrusti, is were at the expected level. Data were accumulated for directions distributed over the northern hemisphere. A nisutrops in the eosmic bilckground radiatson has boen detected in these data with in overall sensitivity of $\cdot 0.6 \mathrm{mK}$. Details itle publinhed elsetw here. ".

\section{ACKNOWLEDGMENTS}

Thin work uan supporled by the Department of l:neygy and the National Aeronatutic and Space Admunistration. We gratefully atcknowledge contrihution: to the design of the experiment hy 1 .. W. Alvares. I. S. M:ıt, H. H. Dougherty, J. H. (ihsoun. J. S. Aymong. R. lance, W. Ferguson. and R. (i. Smits. and participation in the experiment by $S$. Pollaine and $P$.

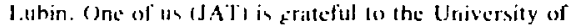
Califormial Physic Department at Berkeley, the Spate Stiences Labolatory. and the lawrence Berkeley

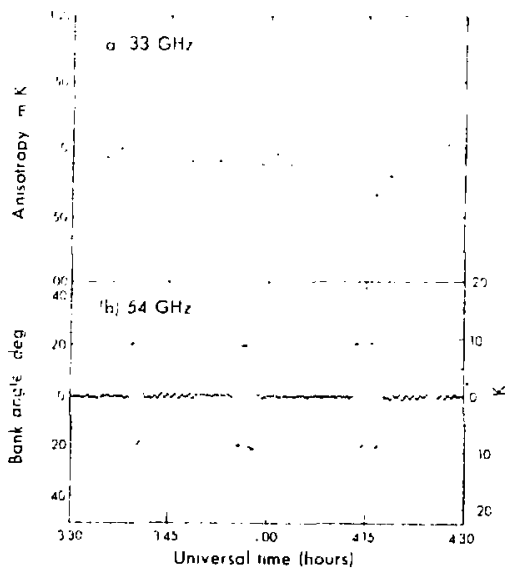

Fit, 11. The 3.3- and S4-GiHe data fr. m the finh data flight. (it)-liath point in the moas'sed anisotropy at $3.3 \mathrm{GHz}$ averaged for So, during sutsessive alllenna arientations. 'The dala are combined from hoth phase stiates of the 100 . Hy demedulating wave form. The error hats are the computed rms fuclualions of the 2 , data divided by the hyuare rout of the number of measurements. (b) - The corresponding 54-GH2 dita. where no averuging hats heen dont, show the scalter lor ? of integralion, and the roll signal during $20^{\circ}$ banks of aircrat $\mathrm{f}$.

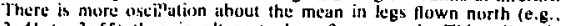
3:4l to 3:55) than in allernate legs flown south. This effect is produced by an interation helween the afrerafl's magnetic heading vensor und the allopilot. Averaging the Jala shows thit only the implilude. not the mean. of the roll uncillation is affecled. 
laboratory for their hospitality during a sabbitucal year. The experiment was made possible by the support and encourage'nent of Dr. H. Mark, Dr. A. Sessler. Dr. K Hirge, Dr. R. Cameron, Dr. N. Boggess, and Dr. $N$ I iman. Imourtant contributions and suggestions were made by $A$. Buffington, $(', 1)$. Orth, A Webster. W. J. Welch. D. D, Thorton, and B. Leskovar, and by the members of the Earth Survey Aireraft facility at WASA-Ames including $M$. Knutern, J. Barmes. (C. Webster. R. Williams, R. Frickson, and S. Norman.

This uork was supported by NASA Giant $2 / 2.5$ and I:ROA C untract \&W-7405-ENG.48.

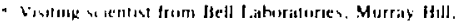
40.94

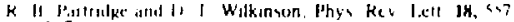
$1, m_{1} \rightarrow$

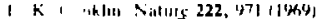

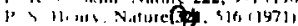

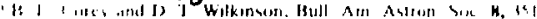
$1,1,1,$.

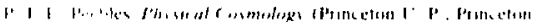
il roil, bil, 14?

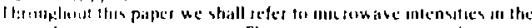

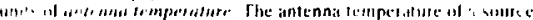

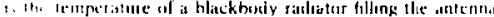

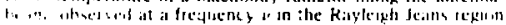

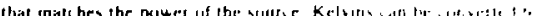

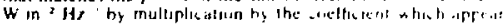

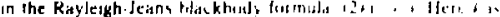

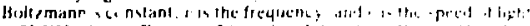

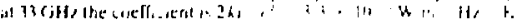

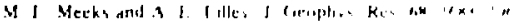

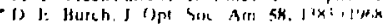

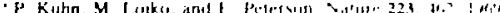

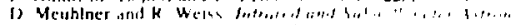

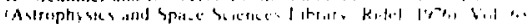

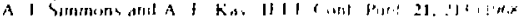

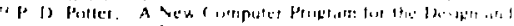

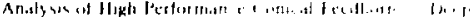

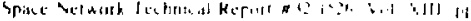

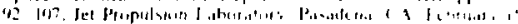
Jiग?

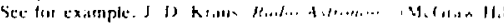

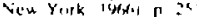

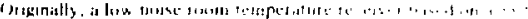

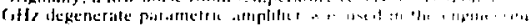

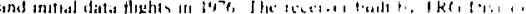

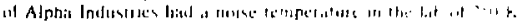

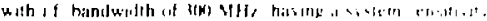

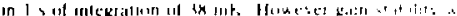

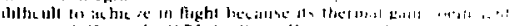

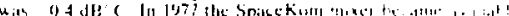

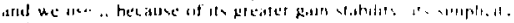

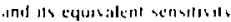

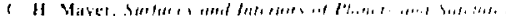

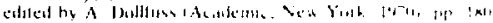

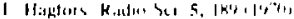

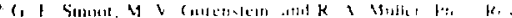
I 411 s. $x+1,1, ?=$ 


\section{Appendix C - The Ferrite Switch and Radiometer-arm-offset}

\section{C.I Introduction}

In an ideal radiomeler. ballance, sgnals appled to each of the two anlenna inputs should bield a null output In praclice inymmeld:"s belween the two antennas and between the iwa circulation states of the ferrite switch result in a spurious nutpul called the radioneter-arm-offset. The prinary source of thes offect in inserturn lass imbalance in the lerrite switch. Interchange of the rademeter arns was, of course. expressly incrifporated into the equipment design to cancel such imbatance. Howe er, in the second order, the offiset must be stable within $0.2 \mathrm{~m} \mathrm{~K}$ dursng

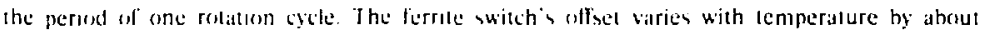
$17 \mathrm{~m} \% / \mathrm{K}$ requiring thermal regulatuon on withon a few tenths of a degree Kelvin. The offset must also be of small enrugh magnilude thal small variations an receiver gain throughout a rolatoon cycie wall yleld atcentahly small vatration in signal strength. Variatoons in receiver gatun of about $0.3 \mathrm{dh} / \mathrm{h}$ rus equate that the radioneter-ilrm-otlset be less than about $100 \mathrm{~m} \mathrm{~K}$, in order that signat dritt be kess than $0.2 \mathrm{mi}$ K in the 128 second antenna cycle.

This Append. writhes our experience with the ferrite swilch. Section $4: 2$ describes the saileh and the cold-load iddjustment technique that nulls, or balances, its insertion loss. Secflom ( 3 describes the phase suilching technique that measures the radiometer-arn-offset in night. The ground based lest that demonstrates the negligibie interaction of the switch wath the earth's magnetic field, is descrsbed in Section C.4

\section{C.2 The Ferrite Switch Ofset}

The ferrite switch reduces the effect of gain fluctuations $(1 / f$ noise $)$ in the receiver, by swilthing the receiver between the two antennas at $100 \mathrm{~Hz}$. The switch is a symmetric three port circulator. Upon application of a current pulse, of the appropriate sign, it latches into a clockwise, or counterclockwist curculation slate. The switch was manufactured by Electromag. netic Sciences Corporstion of Allanta. Georgia to our specifications. Its input ports are canted $\pm 30^{\circ}$ so the antennas connecl directly to the switch without any intervening waveguide. A patir of adjustable insertion loss stubs project from the broad wall of each input port. These stubs are iunctionaly identical to slandard micsowave attentutors, though they can modify the insertion lo:s with a resolution of $10 \mathrm{~m} \%$ out of $290 \%$, or about $10^{-4} \mathrm{db}$. 
The insertion loss of the ferrite switch is about $0.35 \mathrm{db}$, or $8 \%$. Wilh the waveguide os the switch at $290 \%$, the thermal signal injected into the receiver due to this insertirn lest is thon $24 \%$. With no adjustment, there is a $4 \%$ difference in the insertion losi beiween the two curcu. Jation state, yielding a contribution to the radiomeler-arm-offset of about $1 \mathrm{~K}$. We adjust the offset in the laboratory by replacing the antennas with a pair of identical terminations ceroled in a bath of liquid nitrogen to $77 \%$. adequately simulating the signal from the cold sky The terminations are thermally isolated from the switch with onc inch lengths of thrn-walled slanlush stecl waveguide. The loads are periodically interchanged, sanceling their intrinstc imbalince al about $50 \mathrm{~m}$ "K. The in ertion lass of the "croler" input port is increased hy inserting the adjustable stub until an ads quate balance is acheved. In flight the radiomeler-arm-otfset wirs usually below about $50 \mathrm{~m} \mathrm{~K}$, Figire III.1.

The difficulles w.th this procedure center on maintaining a stable stenal ditlerence

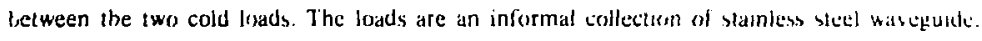

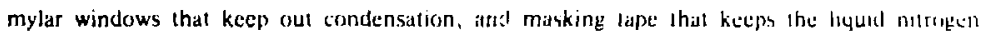
fiom filling the immersed terminatem. However. the masking tape stal is unrelathle With some care and patience the system does yold reproutuble measurements. and the adfusinient al itio insertion loss can be made to about $\pm 10 \mathrm{~m} K$.

In fights 8.11 the offsel was below $50 \mathrm{~m}$ K but increased to about $142 \mathrm{~m} \mathrm{~K}$ in $\mathrm{h}$ hbl 12. requiring additional adjustment to the swilch. In the pre-flegh lests fror llight 13 and 14 the oftsel as measured and adjusted with the cold kad echnigue was datlerent from the affect in measured in the pre-flight contiguration by some $100 \mathrm{n}$ ' $\mathrm{K}$.

\section{C.3 Phase Swilching}

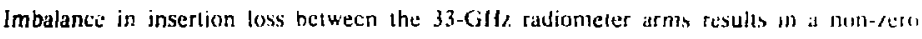

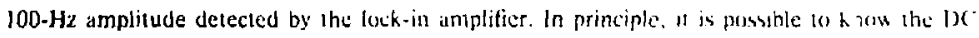
level sufficiently well that the offet can be determined from the recorded output alone. But, m praclice, reversing the sign of the 100-Hz demodulation waveform in the lock-in amplitier determines the radiometer-arm-offset more accuralely. Since this is equivalent to thanging the demodulation phase by $180^{\circ}$, we call this feature the $180^{\circ}$ phase-switch. Thus in the $0^{\circ}$ phat state,

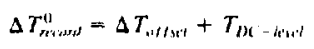

where

$\Delta T_{\text {recurd }}^{0}$ is the digitized signal recorded in the $0^{\circ}$ phase state. 
$\Delta T_{\text {a } / \text { ses }}$ is the radiometer-arm-offset, appearing as a $100 \cdot \mathrm{Hz}$ amplitude. delected by lhe lock-in amplifier.

$T_{D C \text {-wei }}$ is the arbitrary voltage level that the recording sysiem adds to the signat.

We assume that the signals injected into the 33-GHr horn antennas are equal and independent of the rotation orsentation of the antennas. Changing the demodulation phase by $180^{\circ}$ gives

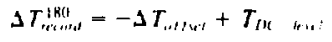

whence

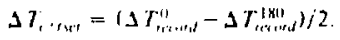

The phase-switch is implemented in the demodulation electronics of the 33-G11/ and $54-$ (illy lock-in anplifiers. The switch is cither set manually 10 one phase state, or is operated in the autonatic mode, switshing phase state afler every $6^{\text {th }}$ recording of a 33 -Cillz dital word. The data-recording system tags each 2-second inlegration with a status bil alcordini" to the phase btate. Signal averaging the data recerded in-flight at the 24 second phase period verities proper operation of the switch. The algebra that cxtracts anisolsopy measurements and $\$ T_{\text {urw }}$ is described in Section IV.2.

\section{C.4 Limits on Switch Interaction with the Earth's Magnetic Field}

The alternation of the circulation state is accomplished by reversing the magnetic ficld of a firrite embedded in the circulator. If an interaction between the earth's magnetic field and the switch has a significant orıentation dependence then a signal synchronous with antenna rotation may result: thus the earth : field is a potential background. To avoid this background we had the manufacurer shield the switch with mu-metal and we enclosed the switch in additional magnetic shit ding. We tesi the shielding by immersing the entire hatch in a periodically reversing magnetic fjeld. The tests are carried out with the hatch in its usual flight configuration. Measuremen s show no effect at the level of $\pm 0.9 \mathrm{~m} \mathrm{~K}$ in fields, up to 10.8 gauss. This puts a limit of $0.06 \mathrm{~m} \mathrm{~K}$ at the two sigma level on the size of a magnetically induced background. The magnetic field is produced by 1 wo coils, about $80 \mathrm{~cm}$ in diameter with field lines directed across the narrow dimension of the hatch. The antenna's are positioned so the field is either oriented perpendicular or parallel to the plane containing the two antennas. 


\section{Appendix D - Flight Profile and Preparation}

This section describes the procedures that have cvolved in executing a data flight. Prufight preparations begin with a ground test conducled outdoors that measures the radiometerarm-offset. Two atuminum reflectors re-direct bolh anterina beams so they point towates the renith insuring that both inputs to the radiometer see balanced low level signals. Perindic reversal of the 100-Hz demodulation phase, and interchange of the reflectors ahrout the antennils. measures the offset of the ;adiometer arms to a few nilli-degrees Kelvin.

If the offset is above $100 \mathrm{~m} \mathrm{~K}$, addilional tuning of the ferrite switch is necoded 1 his as a laborious procedure. The equipment must be disassembled so that the adjustment screus on the switch are exposed, and so the horn antennas can be replaced with liquid nitrogen cold loath Wher. the ground test shows that the offect in redured sufficiently and all signals recorded on a lest cassette appear normal. the equipment in ready to be taken to Ames Research (enter ill Moffelt Fiels, California.

The night crew is generally aviliable only for sunsel launches, although flights all later limes in the right would sometumes be more convenient for us. The tlight lime is limiled b; the fuel load of the U.2 lo about 5 heiurs. Ihere are generally more flight opportunitus in the fill and winles montbs. Durang the summer the U-2's are needed lor agricullural pholography and forest fire monitoring. limuting their avillability for astrophysical rescarch.

The pre-launch check-out commences about 3 hours betare lake-sif and lasts 45 minutes. The main purpose of the check-out is the veritication of proper oneralon of the equiprent in the aircraft. A series of calibration runs, recesded on the installed llight caisente. documents the radiometer performance. This period is the last experimenter access to the eyupmen. until affer the night.

The take-off of the U-2 is spectacular and olten brings out it crowd ol fritends and $x$ cltwishers to watch. Always on schedule, the simgle engine pushes the aircraft along the ranuay into the air after a short 100 meter roll. The pilot quickly takes advantage of the $1:-2 ; 26$ meter wing-span as he rotates the dircraft to its $40^{\circ}$ climb angle. Walching the $U-2$ race 10 uards 20$) \cdot \mathrm{km}$ altitude we understand why Moffett lield air controllers are carcful to clear air iratlic from औs steep ascent path.

Figure III. 2 shows, as an example, the geographical night plan for flight 9 . A llight plan optimizes the following considerations, ordered roughly from most important to least inportant: (1) Flight lime and date are chosen to maximize new sky coverage.

(2) Legs are flown by the pilut in pairs of opposing headings. 
(3) Headings are chosen that avoid the galactic plane and the moun during datia laking

(4) Flight dates and night plans are chosen that allow a calibration leg that points one anteunat al the moon.

Pointing one amtenna at the moon during a llight provides a check on equipment nerformance and gives and in-flight calibration of the radiometers good 10 ahoul $\pm 5 \%$. A moon run. usually 20 minutes in duration, has a considerable impact on the flight plan. Not only must the pilot orient the aircraft properly at the correst tims, but, for the rest of the theint. the data legs must he flown so the antenna heams noint away from the moon by more than $20^{\circ}$ reducing the moen slgnal to less than $0.1 \mathrm{~m} \%$ in the sidelobes of the horn antennits. Moon calihrations werc performed at least ance with each recesser conliguration.

The pilot's main responsibility is orierang the aircraft according to the fligts: platr and mauntaning level flight during dala legs. T ahle b.1 lists the pilot's responsthilities during a dala night. The operatuon of the radioneter system normally makes minini..l demands on the pilot. However during the engnecring llights. the pilots made significant unplanned contributions in the dala laking. In the second thight the rotation system jamned during most rotations as it attempted in interchange the rademeter arms. The pilot. realising the problem. togeted the unlennat Operate/Store istch working the rotation bearing loose e teh lime the monitoring meter indicated trouhle. On the therd llight, the rolation system faile.d al ahlitude, learing tho amennas stuck in the C' $C$ 'position Although the aircraft wats cout of radio range at that time. the pilot, aware of the prohlem. left the power on the equipmeni hroughout the renatinder of the night. Thus the initative of the pilots was responsible for acquisition of much of the valuable enginecring dala.

The post-flight instrument check-out conmences after the ground crew releases the plane Io the experimenters some 15 minutes after landing. The tompletion of equipment checks and the pilot's debriefing requiren an additional 45 minutes. The radiometer and hatch are then lified from the U-2. and we drive the equipment back to the Lawrence Berkeley Laboratory. P'ost-1light data analysis comnences with the transfer of the data from the thight cassette to a stanclard computer tape in the carly morning after the fight. 


\begin{tabular}{|c|c|c|}
\hline \multicolumn{3}{|c|}{ Table D.1 - Pilat's Flight Operations Profile } \\
\hline $\begin{array}{c}\text { Time } \\
\text { (hours) }\end{array}$ & Pilot operaliss & Flight operatusn \\
\hline-0.10 & $\begin{array}{l}\text { POWER ON } \\
\text { DATA RECORD }\end{array}$ & $\begin{array}{l}\text { Preflight varm-up. } \\
\text { Starl lape recorder. } \\
\text { Data acquisition. }\end{array}$ \\
\hline 0.00 & Take-ofT & \\
\hline $0^{16}$ & $\begin{array}{l}\text { ANTENNA OPERATE: } \\
\text { all switches up }\end{array}$ & $\begin{array}{l}\text { Initiate antenna roation } \\
\text { sequence at } 15.2 \mathrm{~km} \text { altutude. }\end{array}$ \\
\hline $0^{30}$ & $\begin{array}{l}\text { Reach } 19.8 \mathrm{~km} \\
\text { altitude }\end{array}$ & $\begin{array}{l}\text { Equipment approaches thermat } \\
\text { stahility at altitude. }\end{array}$ \\
\hline 0.60 & Level filighı. & Slart dala luking legs. \\
\hline$"$ & $"$ & $"$ \\
\hline$"$ & $"$ & $"$ \\
\hline$"$ & $"$ & $"$ \\
\hline$"$ & $"$ & $"$ \\
\hline$"$ & $"$ & $"$ \\
\hline 4.25 & ANTENNA STORE: & $\begin{array}{l}\text { Jind dala laking legs. } \\
\text { Store antennas. } \\
\text { Begin descent. }\end{array}$ \\
\hline 4.40 & $\begin{array}{l}\text { DATA STANDBY } \\
\text { POWER OFF } \\
\text { All switches down }\end{array}$ & Shut down for landing. \\
\hline 4.50 & Land Aircraft. & \\
\hline
\end{tabular}

\section{Appendix E - Radiometer Gain and Calibration}

\section{E.1 Introduction}

The cramped quarters in the equipment bay of the U-2 make inclusion of an accurate inflight calibrator difficult. However because of the stability of the mixer-based receiver we art able to calibrate the system within an error of $\pm 3 \%$ on the ground and demonstrate the relative gain stability to $\pm 1 \%$ with in - Bight monitors.

The voltage after the detector diode and the rms fluctuations of the recorded 33-GHz signals measures the product of system noise temperature times receiver gain; these quantities are monitored throughout each flight. These two techniques, described in section E.2, demonstrate 
that the product of receiver noise limes system gain is stable to heller than $\pm f^{\text {y. }}$. Arrcraft tanks performed periodically tr-oughout ach flight inject unequal signals inlo the antennas providing a standard signal source external to the radsometer and show that the ystem gains is stable to within the 10\% malsurement error.

Converting the empiricil units recorded on the Right cassette 10 units of antenna lemperature is the subject of Section E.2. Ground hased measurements using targets of ficosorb. at commercially made micsowave "hlackbody". provides the values of the converuton comblant $C$. used in eq. IV.5. The atcuracy of these measuremenls seems limited by sight varlations in lechnique employed throughout the serese of ealihrallons from llight 8 to fligh 14.

The 33-GHz radiometer neitsured the antennis temperature af the moon in flehl 4.6.8. and 14. The main syblematic uncertainty is determining the actlall brightness temperature of the lunar surface. According to published measurements this error is small enough that we could

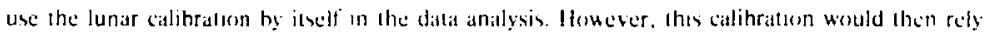
on wher measurenents that are outside of eur direcel experience.

\section{F.2 Stability of the 33-f;, Radiometer Gain and Noise Temperature}

Three in-flight indicators monitor the slahility of the system noise temperalure and the system gain of the 33-6it/ radionmeter. Firslly, a noise-monitor circuit mealsures and records the voll uge level at the outpul rif the detector diode. Al allitude, the total noise temperature af the system, nominally $650 \mathrm{~K}$, is duminaled by the noise generaled it: the mixer. Contributions to the noise temperature external to the radiometer systen are minimal: the cosmis background adds a few degrees Kelvin, and the atmospheric signal adds only $34 \mathrm{~m}$ K. Thus the noise monifor measures a signal proportional to the product of the noise power of the radiometer and the system gain up-strean of the detector diode. In flighl 8 -14 the noise-monitor signul dropped $2^{1 / 4}$ during the initial cooldown leg, then drifted downward an additional $2 \%$ during the remainder of the nizhl. The rms fluctuations between the mean noise monitor rignals for hights $8-14$ was $\pm 0.3 \%$

A second monitor of relative system guin is the magnitude of the rms nuctuations of the 33- $\mathrm{GH}$ data words recorded every 2 seconds. The $\mathrm{rms}$ fluctualions are proportional to the system noise temperature. The Arerage "rograms compute the rns lluctuations of some 5000 edited 33-GHz dala words recorded in a typical night. Data from each flight flown with the SpaceKom mixer yields a measuremont of rms fuctuations that varies belween hights by $\pm 0.75 \%$. Receiver noise alone accounts for this variation: Wilh 5000 words recorded in a Might we expect

the rms fuctuations to be measured with an error of $\pm \frac{\sqrt{5000}}{2}= \pm 0.0071$, ar $0.71 \mathrm{~m} \%$. 
Lastly, aircraft banks inject a $24 \mathrm{~m} \mathrm{~K}$ signal into the $33-\mathrm{GHz}$ radiometer and provide a final indicator of system gain. In a typical flight the U-2 changes headings between data legs by banking at a nominal roll angle of $21^{\circ}$. During a bank each antenna receives unbalanced contributions of atmospheric thermal radiation yielding the $24 \mathrm{~m}$ K signal. The atmospheric thermal radiation then provides a test signal which we use to compare system gain between flights. There are three sources of error in the measurement of this bank signai yielding a net uncertainty of $\pm 2.4 \mathrm{mK}$, or $\pm 10 \%$ of the total signal. Within these errors, the bank data from flights 8-14 are consistent with the hypothesis of constant system gain.

The sources of the error are the following:

(1) The $33-\mathrm{GHz}$ receiver noise, $46 \mathrm{~m} \mathrm{~K} / \sqrt{\mathrm{Hz}}$, contributes a $\pm 1 \mathrm{~m} \mathrm{~K}$ error due to the limited integration time during the twelve 3 minute banks in each flight.

(2) During a $21^{\circ}$ bank the sidelobes of the lowered $33-\mathrm{GHz}$ antenna receive a $3 \mathrm{~m}$ K signal from terrestrial microwave emission. The signal varies by $\pm 1 \mathrm{~m} \mathrm{~K}$ depending on the terrain swept over by the lowered antenna.

(3) Correction of $8 \mathrm{~m} \mathrm{~K}$ variations in the $33-\mathrm{GHz}$ signal due tc deviation from $21^{\circ}$ bank angle, using the $54-\mathrm{GHz}$ roll monitor signal, introduces a $\pm 2 \mathrm{~m}$ K error. During the banks the earth-directed sidelobes of the $54-\mathrm{GHz}$ horn antennas receive atmospheric emission whose intensity varies depending on the surface weather.

Although we would prefer independent measurements of both receiver gain and system sensitivity to $\pm 2 \%$ or better, we feel that the various limits described here, taken together. justify using a single calibration constant for the data in flights 8-14. As is descrioed in the following section, the error in this conversion constant is limited by the uncertainty of the absolute receiver calibration to about $\pm 3 \%$.

\section{E.3 Absolute Ratiometer Calibration}

Blackbody targets of Eccosorb AN 72 placed over the mouths of the horn antennas are used to calibrate the $33-\mathrm{GHz}$ radiometer in the laboratory. Eccososb AN 72 is a commercial microwave absorber made of urethane foam jmpregnated with graphite. The radiometer is calibrated by covering one horn mouth with a room-temperature target at $300 \%$ and the other with a target soaked in liquid nitrogen ( $\mathrm{LN}$ ) at $77^{\circ} \mathrm{K}$. Tlis fills both antenna beam patterns with uniform temperature blackbodies and establishes a nominal $223 \mathrm{~K}$ signal difference between the arms of the radiometer. The recorded digitized signal difference yields the desired calibration. Several repetitions of the procedure, with the loads interchanged over the an:anna mouths, check the consistency of the measurements.

The AN 72 is porous; a target withdrawn from a bath of LN maintains a stable temperature within a degree Kelvin for more than 30 seconds while the $L N$ boils off. The measured difference in signal strength between a target immersed in LN and one withdrawn from a bath is less than a degree Kelvin. The withdrawn target, although prone to drip liquid nitrogen over 
the equipment, is more convenient to use in practice. In light, the fulf scale output of the iock-in amplifier corresponds to an amplitude of $\pm 20 \mu$ Volts at the $33-\mathrm{GHz}$ detector diode. The Datel recorder digitizcs the integrated output of the lock-in amplifier with 12 bit resolution. Thus the digitized voltage resolution is $9.8 \mathrm{nV} / \mathrm{least}$ coun , referenced to the $33-\mathrm{GHz}$ delector diode.

The LN calibration procedure was performed before the fights 4,6, and 7 in the initial series of data flights, and before nights 8,13 and 14 in the final series of data flights, and several times since Oight 14. The empirical rms variation between these calibrations is $\pm 2.1 \%$ The contribution of receiver noise to this error is negligible. The uncertainty in physical temperature difference between the two foads for any one measurement is about $\pm 0.5 \%$. The probable origin of the $2 \%$ fluctuation is a combination of receiver temperature variation between the calibrations, and variations in the exact way the cold target is held over the antenna mouths. If the cold target is held exactly perpendicular to the antenna beam axis then dielectric reflection from the LN decreases the signal difference hetween the calibrators. After flight 14 we measured this reflection to be about $1 \%$ and found that tilting the surface of the cold Eccosorb about $10^{\circ} \mathrm{from}$ the beam axis reduces the reflection below $0.1 \% \%$

There are two additional systematic corrections. The first is correction for the saturation of the detector dioda during the LN calibration procedure. Two different operating points of the diode are used for the room-lemperature versus LN calibration. Ideally the detector diode is a square law device whose voltage output is proportional to the IF input power. However, we try to get the maxinum signal out without badly saturating the diode, an HP 8472 B negative. Putling various attenuators before the detector diode measures the diode response and shows that the larget signal of $290 \%$ slightly saturates the delector diode, reducing the system gain by $5 \%$ compared to the case when both antennas see cold signals.

The second systematic correction, discovered after flight 14 , is the variation in the lock-in amplifier gain belween the setting used for the low-level signals in fighı, and the coarser setting used for calibrations. Nominally there is a factor of 250 gain change belween the two settings. but it was discovered that the gain in fact changes by an additional $2 \%$ requiring a correspanding adjustment to the calibration constant. In the previous publication (Smoot. Gorenstem \& Muller, 1977) diode saturation and the rellectivity of the Eccosorb were not corrected for, and the small deviation in nominal gain between lock-in amplifiers setting was not known. The inclusion of these additional corrections changes the nel calibration by less than 5 lit. 


\section{E.4 Moon Calibration}

The moon calibrations, performed in-flight, cross-check the ground based measurements. Each receiver configuration has been calibrated at least once by pointing an antenna at the moon during a flight. The calibration constant determined from moon runs in flights 8 and 14 is within $5.4 \%$ of the ground based results, consistent with the $6 \%$ uncertainty of the moon calibrations.

The moon fills a small fraction of the solid angle subtended by the antenna beam, thus the antenna temperature of the moon $T_{m m}$, is given by

$$
T_{\text {ant }}=T_{\text {lumar disk }} \frac{\Omega_{\text {moon }}}{\Omega_{\text {anteang }}}
$$

where

$T_{\text {lunar disk }}$ is the mean antenna temperature of the lunar disk, used to calibrate the radiometer.

$\Omega_{\text {moon }}$ is the solid angle subtended by the moon. The mean solid angle is 0.211 squarc degrees, and varies by $\pm 15 \%$ during the lunar orbit. The apparent diameter of the moon is tabulated in the American Ephemeris and Nautical Alamanc with an error that is negligible for our purposes.

$\Omega_{a m}$ is the antenna beam width which spans a solid angle of $69.3 \pm 0.7$ square degrees.

The temperature of aise lunar disk is the main uncertainty in this calibration procedure. The radiation temperature at the center of the lunar disk has been measured (Hakfors, 1970; Mayer, 1970; Linsky, 1973) to be

$$
(215 \pm 4) \mathrm{K}+(34 \pm 3) \cos (\phi-41 \pm 39 \mathrm{~K}
$$

where

$\phi$ is the phase of the moon after the new moon.

But our measurement includes the whole lunar disk. This has the advantage that the variations in antenna temperature due to the lunar phase are reduced, but adds additional uncertainty as now we must include an estimate of variations of temperature and emissivity over the lunar disk. According to Hagfors, the emissivity of the center of the lunar disk is 0.97 due to dielectric reflection. And greater reflection near the edges reduces the net thermal signal by an additional $6 \%$ compared to the center. The result is

$$
\Gamma_{\text {lunar dusk }}=(202 \pm 7.5) \mathrm{K}+\left(27_{-2.5}^{+5}\right) \cos \left(\phi-41 \pm 3^{9}\right)
$$

A final correction to the lunar antenna temperature is due to navigational errors that misdirect the antenna slightly during a moon rur. The pilots check the altitude of the moon during 
the run, and the resulting corrections have amounted to a few percent at most, with less than a percent increase in error in the final calibration constant. 


\section{Appendix F - Astrophysical and Atmospheric Corrections to the Leg-measurements}

\section{F.1 Galactic Synchrotron Radiation}

The primary astrophysical background in this experiment is microwave emission from relativistic electrons spiraling in the weak magnetic field of our Galaxy. This "synchrotron" radiation is highly anisotropic: the radiation is most intense towards the galactic center and is about a factor of 10 lower towards the anti-center and the galactic poles. Moreover the radiation is intense: at $1 \mathrm{GHz}$ its flux is comparable to the $3 \mathrm{~K}$ background whose angular properties we wish to study. Fortunately the intensity of synchrotron radiation decruases above $1 \mathrm{GHz}$ while the intensity of the $3 \%$ radiation increases. At sufficiently high frequencies the synchrotron background is a relatively minor correction to the microwave background anisotropy for most directions in the celestial sphcre.

Measurements show that the spectral intensity of synchrotron radiation obeys a power law given by

$$
\frac{d I_{11 m \text { hitroutum }}}{d \nu} \propto \nu^{-n}
$$

where the spectral index, $n$, clusters around 0.8 (Kellerman, $/ 964)$. The spectral intensity of the $3 \mathrm{~K}$ radiation increases as the square of the frequency in the Rayleigh-Jeans region, below 100 $\mathrm{GHz}$ :

$$
\frac{d I_{\text {hiackinuts }}}{d \nu} \propto T \nu^{2}
$$

Thus the intensity of synchrotron radiation relative to the blackbody radiation, i.e. the antenna temperature of the synchrotron radiation, falls with increasing frequency according to the formula,

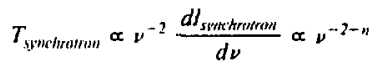

The frequency at which the antenni temperature of galactic synchrotron radiation is below $0.2 \mathrm{~m} \mathrm{~K}$ is then estimated by

$$
(1 \mathrm{GHz}) \times\left[\frac{2 \times 10^{-4} \mathrm{~K}}{3 \mathrm{~K}}\right]^{-1 / 2.8}=31 \mathrm{GHz}
$$

Figure 4 in Appendix B illustrates this frequency dependence of the antenna temperature of galactic synchrotron emission. 
The corrections to the $33-\mathrm{GHz}$ data are based on a map of galactic synchrotron emission at $400 \mathrm{MHz}$, compiled by R.E. Taylor (Taylor, 1973). We use this map, scaled to antenna temperature at $33 \mathrm{GHz}$, to generate corrections to the data. A single scale factor carries out this extrapolation:

$$
T_{33 G H z}=T_{0.4 G H:}\left[\left(\frac{33 G H z}{8 G H z}\right)^{-2.9}\left(\frac{8 G H z}{4 G H z}\right)^{-2.8}\right]
$$

These two values of spectral indices account for the apparent steepening of synchrotron emission above $8 \mathrm{GHz}$ (Hirabayashi, 1974; Webster,1974; Penzias \& Wilson, 1966; Conklin, 1969). This data, folded with the antenna beam pattern, corrects the measurements for each leg. Figure F.1 is a three dimensional projection of the sum of the contributions of diffuse galactic synchrotron emission with point like emission from HIl sources along the galactic plane.

\section{F.2 HII Regions}

The second major source of radio interference from the galaxy is thermal enission from clouds of hydrogen gas that are ionized and heated by ultra-violet radiation from nearby stars. The Orion nebula is one classic example. For wavelengths shorter than $30 \mathrm{~cm}$, the Hll regions are optically thin and the power specirum is nearly flat (Kraus, 1966, pg. SII)

$$
\frac{d I_{M I I}}{d \nu} \propto \nu^{0}
$$

Thus the antenna temperature drops with increasing frequency,

$$
T_{I I I I} \propto \nu^{-2}
$$

The sources thus have approximately the same power spectrum as synchrotron radiation, and in fact have similar intensily. Figure 4 in Appendix $B$ shows the antenna temperature spectrum of a typical HIl region. Unlike synchrotron emission, which is diffuse throughout the celesifai sphere, most HII regions are localized within $2^{\circ}$ of the galactic plane, and appear as the point-like structures in Figure F.1. We obtained a list of sources fron a compilation by Lang and Kraus (Lang, 1974, pg. 121-127; Kraus, 1966, pg. 246-248). The sky coverage avoids mosl of these sources and the contamination of the data by HIl eraission is slight: two legmeasurements in the data from flights 8-14 required corrections between 0.1 and $0.2 \mathrm{~m} \mathrm{~K}$, with errors of $\pm 15 \%$. All other corrections were less than $0.05 \mathrm{~m} \mathrm{~K}$. 


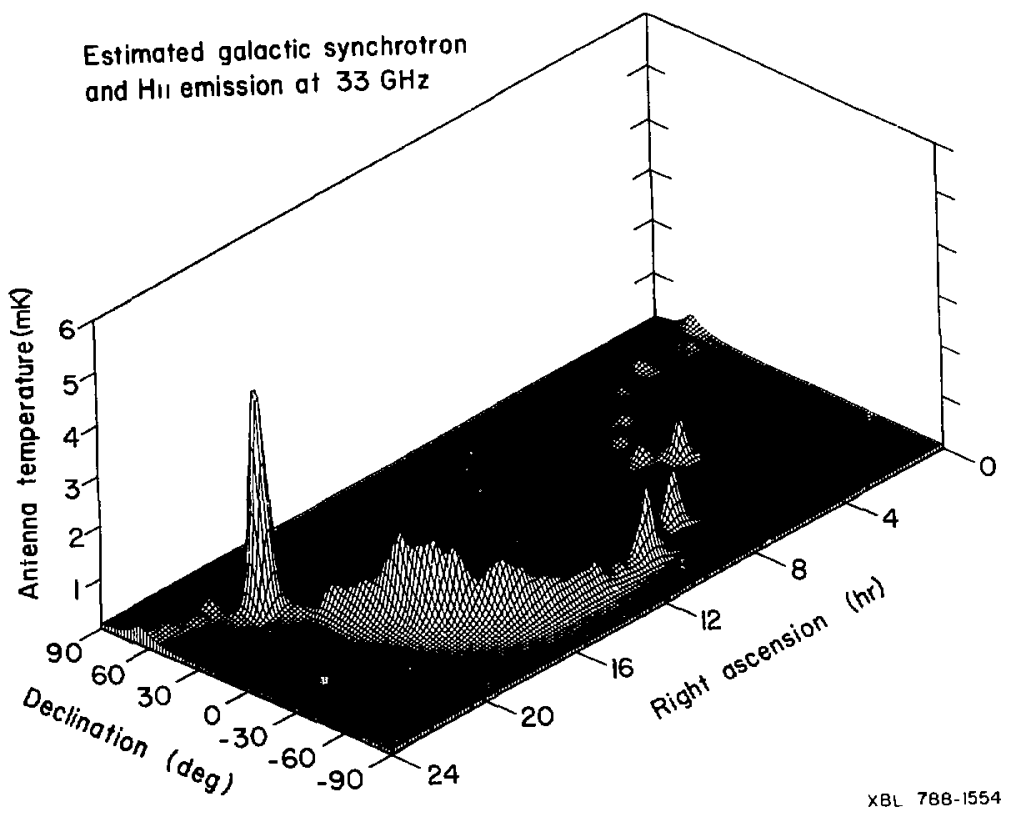

F1gure F.1 - Galactic Synchrotron and HII Emisston Extrapolated to $33 \mathrm{GHz}$ 


\section{F.3 Corrections for Aircraft Roll}

The aircraft roll generates an almost negligible background for the anisutropy measurement. The $\mathrm{L}-2$ roll-attitude is quite stable; deviations from the mean roll for a leg were typically less than $0.3^{\circ}$, requiring corrections to the leg-measurements of no more than $0.4 \mathrm{~m} \%$. A series of airufaft banks from $5^{\circ}$ to $20^{\circ}$, performed over several flights, determined the ratio of atmospheric imbalance signal to bank angle,

$$
\begin{aligned}
& \frac{\Delta T_{33-\mathrm{GHz}}}{\text { 9oll }}=1.22 \pm 0.12 \mathrm{~m} \mathrm{~K} /{ }^{\circ} \mathrm{roll} \\
& \frac{\Delta T_{54-G H z}}{\text { 9oll }}=220 \pm 10 \mathrm{~m} \mathrm{~K} / \text { Toll }
\end{aligned}
$$

Since the rmıs receiver sensitivity at $54 \mathrm{GHz}$ is $100 \mathrm{~m} \times / \sqrt{\mathrm{Hz}}$, an integration for two seconds measures a roll to an accuracy of $\pm 0.32^{\circ}$ in angle. This in turn corresponds to a measurement of atmospheric imbalance at $33 \mathrm{GHz}$ with an error of $\pm 0.4 \mathrm{~m}$ K .

The 3\% error in eq. F.8 is statistical only; the precision of the measurement is limited by the $33-\mathrm{GHz}$ receiver noise for the short time of the aircraft banks. The $5 \%$ error in eq. F.9 is considerably larger than the fluctuations due to radiometer noise alone. The error is likely due to deviations from the mean roll during an aircraft bank, and variations in the atmospheric temperalure.

The correction to the 33-GHz signal for roll is straight-forward. The mean roll sigral, $\Delta T_{54 G / z}$, is computed for each leg in a manner which is exactly analogous to the computation of the mean $33-\mathrm{GHz}$ anisotropy signal. The mean roll signal over the flight is computed in analogy with the rotation offset of the $33-\mathrm{r}$ idz signa!* The correction to the $33-\mathrm{GHz}$ signal is then in propurtion to the deviation of the $5.4-\mathrm{GHz}$ signal from iss mean value.

\section{F.d The Motion of the Earth about the Sun}

The motion of the earth aboul the sun produces an anisolropy of $0.3 \pm 0.03 \mathrm{~m}$ \% magnitude; the $10 \%$. Lineertainty is in the measured temperature of the $3 \%$ background radiation. The $0.3 \mathrm{~m} \mathrm{~K}$ signal is not a correction in the usual sense, but it must be removed from the data to compute the anisotropy in a barycentric coordinate system. The value subtracted from each leg-measurement is proportional to the component of the eath's motion along the difference vector of the antenna directions,

\footnotetext{
- The rolation offsit at $54 \mathrm{GH} / \mathrm{z}$ is an more than $50 \mathrm{~m} \mathrm{~K}$ in cath flight, cquivalent to a $0.25^{\circ}$ roil. Assuming such a signal is due to a roll, then it would contribute $0.3 \mathrm{~m}{ }^{\circ}$ to the rolation offsel at $33 \mathrm{GHz}$, which eannot account for the observed $2 \mathrm{~m}$ K rotation offsel.
} 


$$
\Delta T_{3 \xi_{G H z}}^{\mathrm{seg}}=3 \mathrm{~K} \cdot \frac{\vec{v}_{\text {earh }}}{30 \times 10^{5} \mathrm{~km} / \mathrm{sec}} \cdot\left(\hat{n}_{1}-\hat{n}_{2}\right)
$$

where

$\hat{n}_{1}, \hat{n}_{2}$ are the direction vectors of antenna 1 and 2 for the leg-measurement

$\vec{v}_{\text {earth }}$ is the velocity of the earth about the sun for the epoch of the leg-measurement.

$\left|\vec{v}_{\text {earnh }}\right|$ is $30 \mathrm{~km} / \mathrm{sec}$

The uncerlainty of this correction is negligible compared to the statistical uncertainty of the leg-measurement.

With data of sufficient sensitivity we could detect the earth's orbital motion about the sun. This would be an important cross-check of the experiment, but unfortunately, the noise in our data does not allow a significant measurement. Nevertheless it is worth going through the exercise. We do a four parameter fit to the data from lights 8-14, uncorrected for the earth's motion. Three parameters are the usual cosine anisotropy, and the fourth is the magnitude of the expected signal; i.e. we use the known motion of the earth about the sun to determine the relative amplitude and sign of the effect in each leg-measurement, and we fit only for the overall magnitude - the speed of the annual motion. The result of the fit is $-0.2 \pm 0.4 \mathrm{~m} \mathrm{~K}$, the minus sign meaning the fit gives a speed opposite the expected direction. 


\section{Appendix G - The Rotation Offset}

The rotation offset is an oscillation in the 33-GHz signal that changes in synchrony with the antenna rotation. Plots of the $33-\mathrm{GHz}$ data words, signal-averaged at the rotation period, show that the change in signal level between the two antenna orientations is consistent with a square wave shape. There is no evidence for a slope or spurious flurtilation during the 64 second period belween antenna interchanges. Dividing the flight data into segments gives consistent values of the offset. Flying data legs in opposing headings along the ground detects and cancels the rotation offset. Thus the mean difference between sequential pairs of legmeasurements is the celestial anisotropy, while the mean sum is the rotation offset. The offset is measured in a flight with an uncertainty of $\pm 0.5 \mathrm{~m} \%$. Its value for each flight is shown in Figure IV.3. In the final seven flights the value has been the smallest and most stable. Comparable values have occured in fights nown in holh $3-2$ aircraft based at Moffelt Field. The rolation offset is a concern because its origin is uncertain.

The data in Figure IV.3 suggest that a major component of the effect is internal to the apparatus simply because the rolation offset changes so mich between the early flights as the equipment was being modified. However, Lare was taken to minimize or eliminate electrical interaction between the rotation system and the 33-GHz radiometer. The rolation electronics is isolaled from the 33-(3Hz radioneter by employing different grounds and power feeds, and resistors isolate the monitoring limit-switches from the dalat recording system. A mechanical relay shuts off the power to the rolition system during periods of data taking. After flight 12, a five hour ground test. in which care was taken to insure equal signials in each antenna, atlempted to meisure the offset. It gave an incolaclusive result of $1.1 \pm 0.5 \mathrm{~m} \mathrm{~K}$.

Two olher possible origins for the rotation offset that have been investigated are asymmetric radiation into the antenna sidelobes from the aireraft wings and asymmetric cooling of the antennas by the airstream. This latter effect would arise if an antenna is cooled by the airstream differently depending on whether it is on the pilot's left or right. Integration of the ante.na sidelobe pattern over the airplane wings gives a signal for eath antenna of about $0.5 \mathrm{~m} \%$. And since the equipment is mounted symmetrically in the equipment bay of the U-2, this signal should cancel to below this level. Asymmetric socling of the antennas by the dirstream is a possible origin of the offset because the cold airstream. rapidly llowing along the aircraft, mainains a large, $1 \mathrm{~K} / \mathrm{cn}$, gradient along the horn bodics. Presumably minor asymmetries in either rolation angle of the antennas, or in the surface geomelly of the aircraft and hatch, could result in differential cooling, causing a few degress temperature difference between the antennas.

By estimating :the insertion loss for the mid-section of a horn antenna we can calculate the physical temperature change on the inner surface that yieids a $2 \mathrm{~m}$ K offsel. The insertion loss 
per unit Jength is about $0.02 \% / \mathrm{cm}$ at the mid-point, or about $0.2 \%$ for a $10 \mathrm{~cm}$ length. A $2 \mathrm{~m} \mathrm{~K}$ variation then results from a $2 \mathrm{~m} \% / 0.002=1 \%$ variation in the temperature of the aluminum surface.

A pair of temperature sensors, one at each mid-point, measured the temperature difference in flight. The sensors were placed along a flange $4 \mathrm{~cm}$ from the horn surface to avoid drilling into the horn body. Therefore it is difficult extrapolating from this datia the temperature variations within the 1 micron skin depth at the horn surface. However, the sensor signals did have one striking property in common: in al! flights the signal showed clear triangular or quasi-sinusoidal oscillations synchronized with the rotation period. This is evidence that the mid-point temperatures are in fact driven up and down by the wind as the antennas rotate. Moreover the amplitude and shape of the signal was stable throughout a flight. However, the amplitude of the effect is smail, between 40 and $100 \mathrm{~m} \%$ between the different flights, and the flight where the amplitude was highest, $100 \mathrm{~m} \%$ in flight 12, the rotation offset was the smallest, about $0.3 \mathrm{~m} \%$.

Although the behavior of the lemperature sensor signals ooes nol correlate well with the behavior of the rotation offset, we can use the magnitude of the rotation offset to place a limil on the size of spurious anisotropy that results from variations in the physical temperature of the antentas. The amplitude of the mid-point temperature sensor oscillation is stable within 19 \% from leg to l.eg within a single flight. Residual difference in the spurious signal between legmeasurements should be at most $10 \%$ of $2 \mathrm{~m} \%$ or $0.2 \mathrm{~m} \%$. In aduition, the amplitude of oscillation changes smoothly between legs so differences cancel even below $0.2 \mathrm{~m}$ K. Finally, the residual differences between pairs of legs are uncorrelated with antenna Jirections in the sky, and the net change in the parameters of cosine anisolropy is negligible compared to the statistical errors.

Thus the origin of the rotation offset is not known. However, since it appears constant and stable throughout a flight, we believe that it cancels to a low level as the aircraft heading is periodically reversed. 


\section{Appendix H - Fitting Procedures}

\section{H.I Linear Least-squares-fit to $\cos \theta$ Hypothesis}

The leg-measurements are fit to the following hypothesis that describes a $\cos \theta$ (dipale) modulation of the $3^{\circ} \mathrm{K}$ background radiation:

$$
T(\hat{n})=T_{:}+\vec{T} \cdot \hat{n}
$$

where

$T(i)$ is the radiation temperature in the direction $\hat{n}$.

$T_{\text {n }}$ is the mean temperature of the background, not measured in this experiment.

$\vec{T}$ is the vector describing the direction and amplitude of $\cos \theta$ anisotropy.

The 33-GHz radic ater measures the difference temperalure between two antenna directions $i_{k}^{1}$ and $i_{h}^{2}$ for the $k^{\text {th }}$ datum. Define

$$
\overrightarrow{d_{k}}=\hat{n}_{l}^{\prime}-\vec{n}_{k}^{2}
$$

Then from eq. H. 1 and $\$ 1.2$.

$$
\vec{T} \cdot \vec{d}_{h}=T\left(\hat{n}_{h}{ }^{1}\right)-T\left(\hat{n}_{h}^{2}\right)
$$

We wish to find the value of $\ddot{T}$ that besi fits the data. We generally use rectangular celestial coordinates, defined in Table IV.2. In this coordinate system we express $\vec{T}_{\vec{l}_{h}}$ as

$$
\vec{T} \cdot \vec{d}_{h}=T^{\prime} d_{h}^{\prime}+T^{\prime} d_{h}^{\prime}+T^{\prime} d_{h}^{2}
$$

Given a sel of anisotrojy measurements $A T_{h}$, each with variance $\sigma_{h}^{2}$. then the best estimate of $\widetilde{T}$ is the one that minimizes the following expression for $S$.

$$
S(\vec{T})=\sum_{k=1}^{M} \frac{\left|\Delta T_{k}-\vec{T} \cdot \vec{r}_{k}\right|^{2}}{\sigma_{h}^{2}}
$$

where

$M$ is the number of measurements.

Let $\vec{T}$ now be understood as hat vector which uniquely minimizes $S$. Minimizing $S$ maximizes the a posteriori probability that given $\vec{T}$ we arrive at the set of measurements $\Delta T_{A}$. T.le delails and justification of least-squares-fiting for data corrupted by Gaussian noise ara covered in muny texts (see for example Martin, 1971; Sulnit:, 1964).

Setting the partial derivatives of $S(\vec{T})$ in eq. H.5 to zero with respect $10 T, T$, and $T$ : gives three equations for the minimum of $S(\vec{T})$. After some algebra these become, 


$$
\text { [H] } \vec{T}=\vec{T}_{m}
$$

where

$$
[\mathbf{H}]_{i j}=\sum_{k=1}^{M} \frac{d_{k}^{\prime} d k}{\sigma_{k}^{2}}
$$

and

$$
\left[\vec{T}_{m}\right]_{1}=\sum_{k=1}^{M} \frac{d_{k}^{\prime} \Delta T_{k}}{\sigma_{k}^{2}}
$$

The indicies $i$, and $j$, take on the component indices $x, y$, and $z$.

Inverting the matrix [ $\left[{ }^{\prime}\right]$ finds the solution we seek,

$$
\vec{T}=[H]^{-1} \vec{T}_{m} .
$$

Note that $[H]$, and $[H]^{-1}$, contain only the variances $\sigma_{k}^{2}$ and the difference of the antenna directions $\vec{d}_{k}$; all reference to the measured anisotropy is compressed in the 3-vector $\vec{T}_{m \text {. }}$. This fact will have some significance later.

We now wish to find the error in each component of $\vec{T}$ and the correlated error between components of $\vec{T}$. Uncertainties in components of $\vec{T}$ result from uncorrelated fluctuations present in the input data. Let $\delta T_{k}$ be an independent fluctuation about $\Delta T_{k}$ that induces a corresponding variation, $\delta \bar{T}$ in the solution vector, $\vec{T}$. Then the variation in $\vec{T}$ is given by

$$
\delta \vec{T}=[\mathbf{H}]^{-1} \delta \vec{T}_{m}
$$

where

$$
\left[\delta \vec{T}_{m}\right]_{i}=\sum_{k=1}^{M f} \frac{d_{k}^{\prime} \delta T_{k}}{\sigma_{k}^{2}}
$$

from eq. H.8 and H.9. The correlated error between components of $\vec{T}$ is expressed by

$$
\begin{aligned}
\left\langle\delta \vec{T} \delta \vec{T}^{\dagger}\right\rangle & =\left\langle\left([\mathbf{H}]^{-1} \delta \vec{T}_{m}\right)\left([\mathbf{H}]^{-1} \delta \vec{T}_{m}\right)^{\dagger}\right\rangle \\
& =[\mathbf{H}]^{-1}<\delta \vec{T}_{m} \delta \vec{T}_{m}^{\dagger}>[\mathbf{H}]^{-1 \dagger}
\end{aligned}
$$

where the brackets indicate an ensemble average. It is straightforward to show from eq. H.7, 11 , and 12 that

$$
<\delta \vec{T}_{m} \delta \vec{T}_{m}^{\dagger}>=[H]^{\dagger}
$$

whence 


$$
\left\langle\delta \vec{T} \delta \vec{T}^{\dagger}\right\rangle=[\mathbf{H}]^{-1} .
$$

Thus the errors on the components of $\vec{T}$ are weighted averages of the errors $\sigma_{k}$, and are independent of the measurements $\delta \bar{T}_{k}$. This is in contrast to the expression of the dipole anisotropy in polar coordinales in which $\vec{T} \cdot \vec{d}_{k}$ would be a non-linear expression in polar parameters, and the errors would depend on the best fit values of $\bar{T}$.

The diagonal elements of $[\mathbf{H}]^{-1}$ give the rms errors on the components of $\vec{T}$.

$$
\delta \bar{T}_{m s}^{\prime}=\sqrt{[\mathbf{H}]_{i t}^{-1}} .
$$

It is convenient to express the off-diagonal terms that are the correlated errors in unitless form:

$$
C_{u}=\frac{\left\langle\delta \vec{T}^{\prime} \delta \vec{T}^{j}\right\rangle}{\sqrt{\left(\delta \bar{T}^{\prime}\right)^{2}\left(\delta \vec{T}^{\prime}\right)^{2}}}=\frac{[\mathbf{H}]_{i j}^{-1}}{\sqrt{[\mathbf{H}]_{i i}^{-1}[\mathbf{H}]_{j i}^{-1}}} \quad i \neq j .
$$

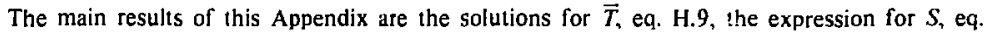
H.5, and the expressions for the errors on the components of $\vec{T}$, eq. H.15 and H.16.

The polar parameters of cosine anisotropy are computed from the reciangular components. We numericaily compute the errors on the polar parameters by jittering the input data with Gaussian distributed noise and then calculate the rms fluctuations, and cross-correlations in analogy with eq. H.15 and H.16.

\section{H.2 Comparison Between Two Independent Measurements of Cosine Anisotropy}

This section describes the algebraic details of a test that checks the consistency of two independent measurements of a vector quantity. The results are applied to the data in Section V.4. The idea is that the difference vector between the two measurentents should be consistent with a null vector, and we test this by constructing a variable that has a $\chi^{2}$ distribution if the null hypothesis is correct.

We work in a rectangular coordinate system (usuaily rectangular celestial coordinates) so the errors on the parameters are Gaussian. Assume two measurements $\vec{i}$ and $\vec{i}$ with error matrices $[\mathbf{V}]$ and $[\mathrm{T}]$ as defined in eq. H.14. (The reader won't be confused by the change in convention from the last section where it was convenient to exprcss the error matrix as an inverse of another matrix.) The difference vector we are interested in is the

$$
\vec{d}=\vec{\imath}-\vec{v}
$$

Computing the errors on the components of $\vec{d}$ generates an error matrix [D]. From the definition of the correlated errors we find:

$$
[D] \equiv\left\langle\delta d_{1} \delta d_{j}\right\rangle=\left\langle\delta\left(t_{1}-v_{j}\right) \delta\left(t_{j}-v_{j}\right\rangle\right\rangle
$$




$$
=\left\langle\delta t_{,} \delta t_{j}\right\rangle+\left\langle\delta v_{1} \delta v_{j}\right\rangle-\left\langle\delta t_{1} \delta v_{1}\right\rangle-\left\langle\delta v_{,} \delta t_{j}\right\rangle
$$

But the latter two terms have zero mean, because the errors of components from different vectors are, by hypothesis, uncorrelated. Thus the error matrix for the difference vector is just the sum of the error matrices for each measurement:

$$
[\mathbf{D}]=[\mathbf{V}]+[\mathbf{T}] \text {. }
$$

We now define a variable $S$ in terms of [D] and $\vec{d}$ and show that it is distributed as $x^{2}$ if the vector $\vec{d}$ is of zero length:

$$
\left\langle d_{1}\right\rangle=0 \quad ;=x_{i}, y_{1} z
$$

Lel $S$ be defined as the following scalar quantity:

$$
s \equiv \vec{d}^{\dagger}[\mathbf{B}] \vec{d} .
$$

Since [D] is a real symmetric mutrix, there is a rolation that will re-orient the c. ordinate system, diagonalizing [DI. In this rotated coordinate system the errors in the compor ants of $\vec{d}$ are uncorrelated. We then expand $S$ explicitly in terms of the componer:s in the diagonalized coor. dinates, whence

$$
S=\frac{d_{1}^{\prime 2}}{\sigma_{1}^{2}}+\frac{d_{j}^{\prime 2}}{\sigma_{1}^{2}}+\frac{d_{k}^{2}}{\sigma_{k}^{2}} .
$$

The primes refer to the components of $\vec{d}$ in the diagonalized coordinates system. If the mean values of the components of $\vec{d}$ are zero, then this is just the definition of a quantity with a $x^{2}$ of three degrees of freedom. 


\section{Acknowledgements}

It is the privilege of a student to receive gifts. It has been my particular good fortune to have had the experience of working with Richard Muller and Geurge Smoot on this project. Without Rich's initiative this project would not have come to be: he focused the group's energy on the problem of the microwave anisotropy. His imaginitive and original approach to research has been a major influence on my outlook. George Smoot's determined effort set the style for the execution of this work; he showed me how to focus on the major goals of the experiment and how to get the job done. The accomplishments presented in the pages of this thesis followed directly from Rich and George's ideas and efforts.

Andrew Buffington helped design the controlling and timing electronics. Terry Mast worked up the almospheric model from which the $54 \mathrm{GHz}$ frequency was chosen. I especially appreciate Andy and Terry for the personal interest they took in my education throughout the stages of this experiment. I have special thanks for $\mathbf{3}$. Anthony Tyson who, during a sabbatical year at Berkeley, contributed his experimental skill in helping solve the problems in the initial nights, and moreover provided for me an example of a gifted experimentalist.

John Gibson designed and built the numerous electronics packages crucial for the project's success. It is evidence of his skill that they all performed flawlessly throughout the flights. Hal Dougherly turned out precision machined metal quickly and with great skiil. Hal and John are unique in the effort and dedication they bring to the group's projects. Jon Aymong developed the efficient software that analysed the fight data. Robbie Smits designed the rotation system, and Richard Lane built the controlling and timing electronics. Chris Witebsky assembled the data on the galactic emission and provided the excellent computer drawings, Figures V.2 and F.1. Lynda Drexter contributed her skilis as a fast and accurate typist, and John Yamada provided needed support services.

I have been fortunate in be surrounded with a marvelous group of contemporaries, Jonathan Schonfeld, Gary Channan, Phil Lubin, Steve Pollaine, Scott Friedman and Joe Feliet. I look forward to a continued association with them all.

Luis Alvarez of the Lawrence Berkeley Laboratory provided wise and expert advice on all phases of the project. Hans Mark, former direcior of NASA-Ames, provided crucial support and our introduction to the U-2 aircraft. The pilots of the Earth Survey Airctaft facility at NASA-Ames, Chunky Webster, Jim Barnes, Ron Williains, and Bob Erikson, were, needless to say, indispensable. Their skills contributed immeasurably to the success of the experiment. The Lockheed Aircrart Company modified the special upper hatch for the U-2 that lurned the aircraft into a flying abservatory. W. J. Welch and Doug Thornton of the Space Sciences Laboratory of the University of Californis at Berkeley, and Branko Leskovar of the Lawrence Berkeley Laboratory contributed helpful advice and ideas. This experiment was made possible through 
the active support of Andrew Sessler, the Director of the Lawrence Berkeley Laboratory, Robert Birge, the head of the Physics, Computer Science and Mathematics Division at LBL, and Nancy Boggess of the National Aeronautics and Space Administration. This project was supported by NASA grant \#2125 and ERDA contract \#W-7405-ENG-048. Finally, I would like to thank the Physics Department of the University of California at Berkeley, the Space Sciences Laboratory, and the Lawrence Berkeley Laboratory for their support and hospitalty during my tenure. 


\section{References}

Alpher, R.A., Bethe, H. \& Gamow, G., Phys. Rev. 73, 803 (1948)

Alpher, R.A. \& Herman, R.C., Rev. Mod. Phys. 22, 153 (1950)

Batakis, N. \& Cohen. J.M., Phys. Rev. D12, 1544 (1975;

Barrow, J.D., Narure 267, 117 (1977)

Barrow, J.D, Nature 272, 211 (1978)

Barrow, J.D. \& Matzner, R.A., Mon. Not. R. astr. Soc. 181, 719 (1977)

Boughn, S.P.. Fram, D.M. \& Partridge, R.B., Ap. J. 165, 439 (1971)

Burke, W.L., Ap. J. 196, 329 (1975)

Collins, C.B. \& Hawking, S.W., Mon. Nor. R. astr. Soc. 162, 307 (1973a)

Collins, C.B. \& Hawking, S.W., Ap. J. 180, 317 (1973b)

Conklin, E.K., Nature 222, 971 (1969)

Corey, B.E., Ph. D. Thesis Princeton University, 1978

Corey, B.E. \& Wilkinson, D.T., Bull. Am. Astro. Soc, 8, 351 (1976)

de Vaucouleurs, G., Nature 182, 1478 (1958)

de Vaucouleurs, G., IAU Sympositm No. 44, ed. D.S. Evans (Reidel, New York, 1972, pg. 353)

de Vaucouleurs, G., Ap. J. 205, 13 (1976) 
de Vaucouleurs, G., IAU Sumposium No. 79 (Tallinn, Estonia, September 1977, to be published)

de Vaucouleurs, G. \& de Vaucouleurs, A., A. A. 28, 109 (1973)

de Vaucouleurs, G. \& Peters, W.L., Nature 220, 868 (1968)

de Vaucouleurs, G., Peters, W.L. \& Corwin, J., H.G., Ap. J. 211, 319 (1977)

Dicke, R.H., Peebles, P.J.E., Roll, P.G. \& Wilkınson, D.T., Ap. J. 142, 414 (1965)

Godë!, K., Rev. Mod. Phłs. 21, 447 (1949)

Godël, K., in Proceedings of the Imternational Congress of Mathematicians 1950, edited by L.M. Graves, E. Hille, P.A. Smith, and O. Zariski (Am. Math. Soc., Providence, R.I., 1952) Vol I, pg. 175

Gorenstein, M.V., Smoot, G.F. \& Muller, R.A., Bull. Am. Astro. Soc. 9, 431 (1977)

Gorenstein, M.V., Muller, R.A., Smoot, G.F. \& Tyson, J.A., Rev. Sci. Instrum. 49, 440 (1978)

Hagfors, T., Radio Sci. 5, 189 (1970)

Hawking, S., The Osservatory 89, 38, (1969a)

Hawking, S., Mon. Not. R. astr. Soc. 142, 129 (1969b)

Hawking, S.W. \& Ellis, G.F.R., The Large Scale Structure of Space-Time (Cambridge University Press, Cunjubridge, Eng., 1973)

Hawking, S.W. \& Penrose, R., Proc. R. Soc. London A 314, 529 (1969)

Henry, P.S., Narure 231, 516 (1971)

Hirabayashi, H., Publ. Astron. Soc. Japan 26, .63 (1974)

Kellermann, Ap. J. 140, 969 (1964) 
Kraus, J.D., Radio Astronomy (McGraw-Hill, New York, 1966)

Lang, K.R., Astrophysical Formulae (Springer-Verlag, New York, 1974)

Linsky, J.L., Ap. J. Supplement Series No. 216 25, 163 (1973)

Martin, B.R., Statistics for Physicists, (Academic Press, 1971)

Mayer, C.H., Surfaces and Interiors of Planets and Satellites, edited by A. Dollfus, pp. 180 (Academic, New York, 1970)

Meeks, M.L. \& Lilley, A.E., J. of Geophys. Res. 68, 1683 (1963)

Misner, C. W., Ap. J. 151, 431 (1968)

Misner, C.W., Phys, Rev. Lett. 22, 1071 (1S59)

Misner, C.W., Thorne, K.S., Wheeler, J.A., Gravitation (Freeman, San Fransisco, 1973)

Muehlner D. \& Weiss, R., Infrored and Submillimeter Astronomy 63, (Astrophysics and Space Sciences Library, Reidel, 1976)

Muller, R.A., Scientific American, (May, 1978, pg. 64)

North, J.D., The Measure of the Universe (Oxford University Press, Oxford, 1965)

Partridge, R.B., Am. Sci. 57, 37 (1969)

Partridge, R.B. \& Wilkinson, D.T., Phys. Rev. Lett. 18, 557 (1967)

Peebles P.J.E., Ap. J. 146, 524 (1966)

Peebles, P.J.E., Physical Cosmology (Princeton U. P., Princeton, N. J., 1971)

Peebles, P.J.E., Ap. J. 205, 318 (1976) 
Feebles, P.J.E. \& Wilkinson, D.T., Sciemific American, (June 1967)

Peebles, P.J.E. \& Wilkinson, D.T., Phys. Rev. 174, 2168 (1968)

Penzias, A. A. \& Wilson, R. W., Ap. J. 142, 419 (1965)

Penzias, A. A. \& Wilson R. W., Ap. J. 146, 666 (1966)

Rees, M. J., Phys. Rev. Lett. 28, 1669 (1972)

Rubin, V.C., Ford Jr., W.K., Thonnard, N., Roberts, M.S., Graham, J. A., Astro. J., 81, 687 (1976a)

Rubin, V.C., Thonnard, N., Ford Jr., W.K., Roberts, M.S., Astro. J. 81, 719 (1976b)

Sandage, A., Q. Jl. R. astr. Soc. 13, 282 (1972)

Sandage, A. \& Tammann, G.A., Ap. J. 196, 313 (1975)

Sandage, A. \& Tammann, G.A., Ap. J. 210, 7 (1976)

Schechter, P.L., Astron. J. 82, 569 (1977)

Schmidt, M., in Stars and Stellar Systems, Vol. IX Galactic Structure, (University of Chicago Press, 1965, pg. 513)

Schwartz, D.A., Ap. J. 162, 439 (1970)

Simmons, A.J. \& Kay, A.F., IEEE Conf. Publ. 21, 213 (1968)

Smoot, G.F., Proceedings of the Spring Meeting of the American Physical Society, Washington D.C., 1977a (unpublished)

Smoot, G.F., Proc. of the International School of Gen. Rel. Effects in Phys. and Astrophys.: Experiments and Theory (Max-Planck-Institut Für Physik und Astrophysik, Munich, 1977b) pp. 285 
Smool, G.F., Gorenstein, M.V. \& MulJer, R.A., Phys. Rev. Lett. 39, 898 (1977)

Solmitz, F.T., Ann. Rev. Nuc. Sci. 14, 375 (1964)

Stewart, J.M. \& Sciama, D.W., Nature 216, 748 (1967)

Taylor, R.E., Proc. IEEE 61, 469, (1973)

Thaddeus, P., Ann. Rev. Astron. Astrophys. 10, 305 (i972)

Tolman, R.C., Relativity, Thermodynamics and Cosmalogy (Oxford, 1934)

Verschuur, G.L. \& Kellerman, K.I., Galactic and Extragalactic Radio Astronomy (SpringerVerlag, New York, 1974)

Visvanathan, N. \& Sandage, A., Ap. J. 216, 214 (1977)

Wagoner, R.V., Fowler, W.A. \& Hoyle, F., Ap. J. 148, 3 (1967)

Webster, A.S., Mon. Not. R. astr. Soc. 166, 355 (1974)

Weinberg, S., Gravitation and Cosmology: Principles and Applicatinns of the General Theory of Relativity (John Wiley \& Soris, New York, 1972)

Weinberg, S., The First Three Minutes (Basic, New York, 1977)

Wilkinson, D.T. \& Partridge, R.B., Nature 215, 719 (1967)

Wilson, R.W. \& Penzias, A.A., Science 156, 1100 (1967)

Woody, D.P., Ph. D. Thesis (University of California, Lawrence Berkeley Laboratory, LBL Report \#4188, 1975)

Woody, D.P., Mather, J.C., Nishioka, N.S., \& Richards, P.L., Phys. Rey. Lett. 34, 1036 (1975)

Yahil, A., Tammann, G.A. \& Sandage, A., Ap. J. 217, 903 (1977) 
LEGAL NOTICE

This report was prepared as an account of work sponsored by the United States Government. Neither the United States nor the Department of Energy, nor any of their employees, nor any of their contractors, subcontractors, or their employees, makes any warranty, express or implied, or assumes any legal liability or responsibility for the accuracy, completeness or usefulness of any information, apparatus, product or process disclosed, or represents that its use would not infringe privately owned rights. 